

\section{UNIVERSITY OF \\ ILLINOIS LIBRARY \\ AT URBANA-CHAMPAICN \\ BIOLOGY}




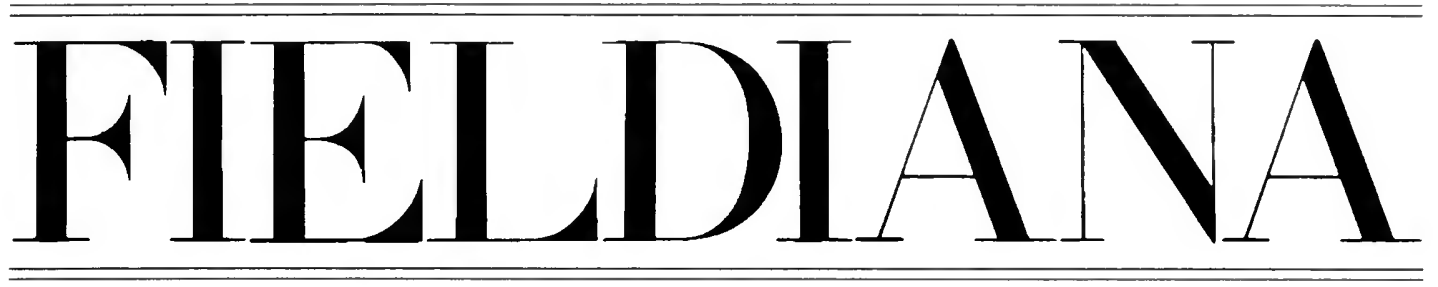

\section{Zoology}

NEW SERIES, NO. 108

\section{The Palatal Dentition in Squamate Reptiles: Morphology, Development, Attachment, and Replacement}

\section{Luke Mahler}

Department of Biology

Washington University in St. Louis

Campus Box 1229

One Brookings Drive

St. Louis, Missouri 63130

U.S.A.

Department of Zoology

Field Museum of Natural History

1400 South Lake Shore Drive

Chicago, Illinois 60605

U.S.A.

\author{
Maureen Kearney \\ Department of Zoology \\ Field Museum of Natural History \\ 1400 South Lake Shore Drive \\ Chicago, Mllinois 60605 \\ U.S.A.
}

Accepted December 29, 2005

Published July 10, 2006

Publication 1540 
(C) 2006 Field Museum of Natural History

ISSN 0015-0754

PRINTED IN THE UNITED STATES OF AMERICA 


\section{Contents}

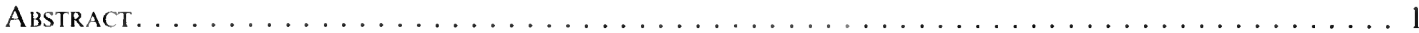

INTRODUCTION. . . . . . . . . . . . . . . . . . . . . . . 2

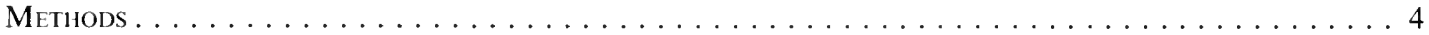

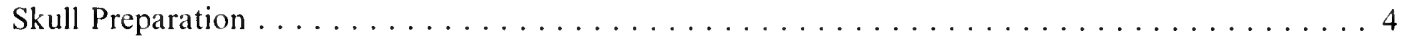

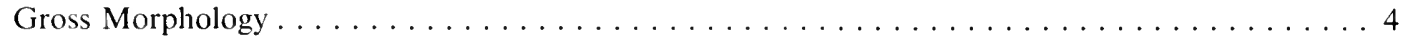

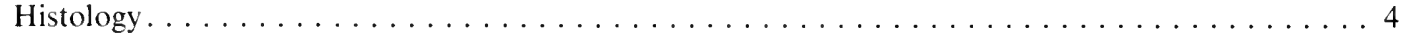

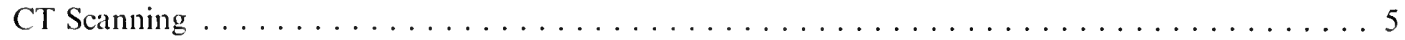

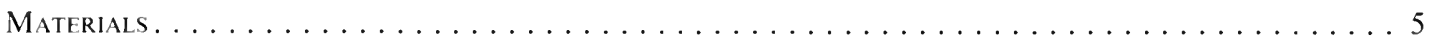

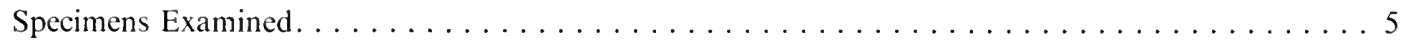

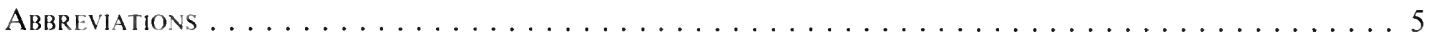

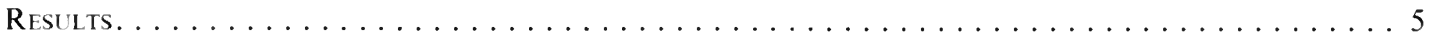

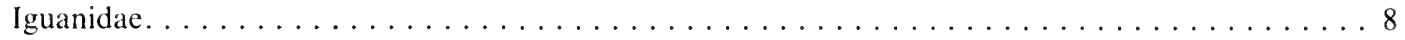

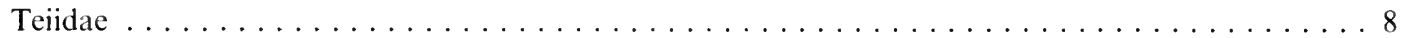

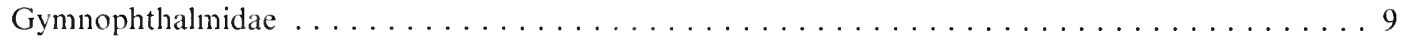

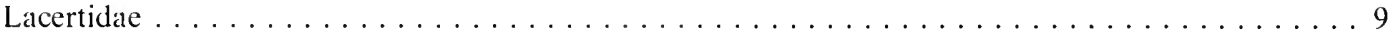

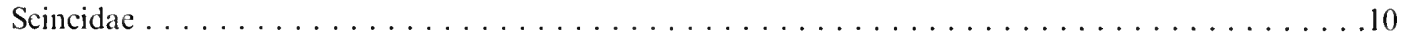

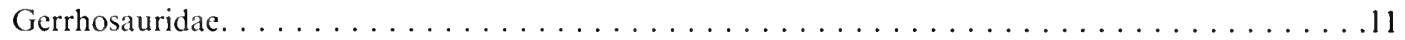

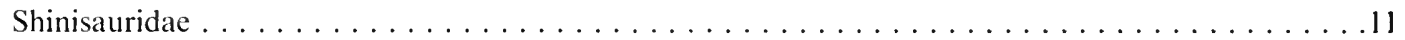

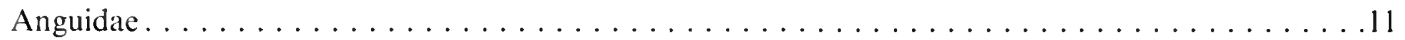

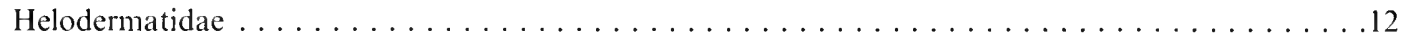

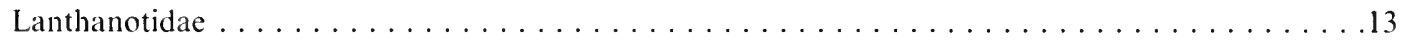

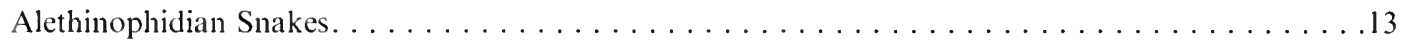

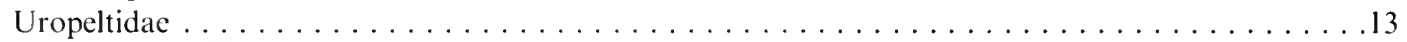

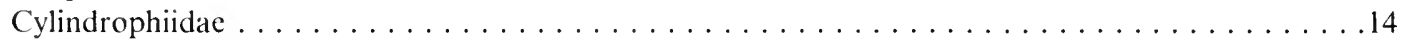

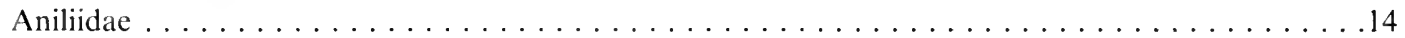

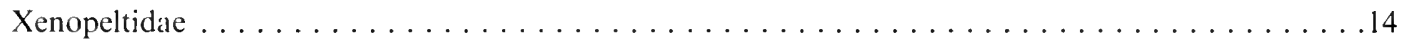

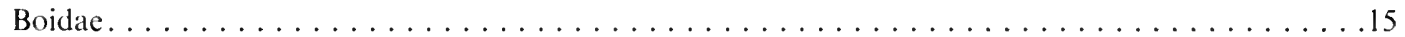

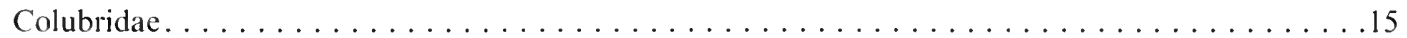

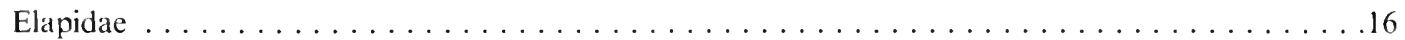

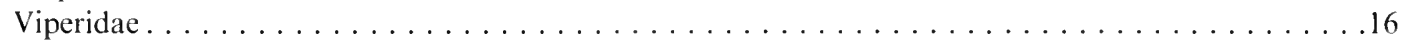

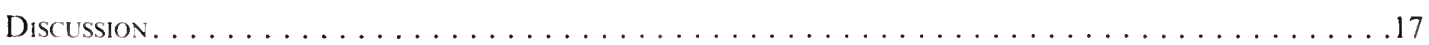

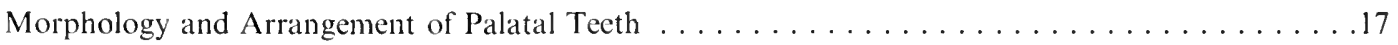

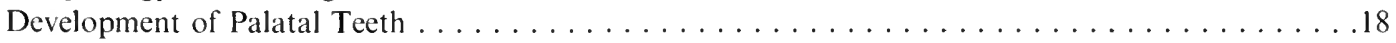

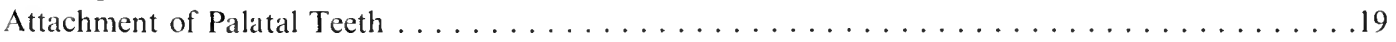

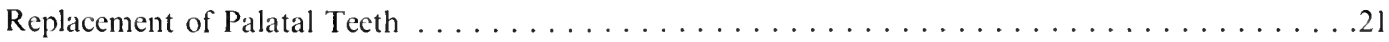

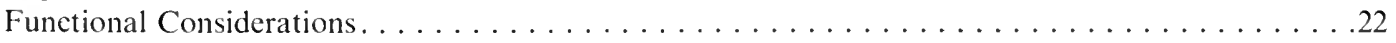

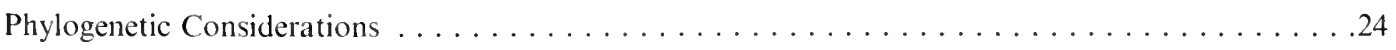

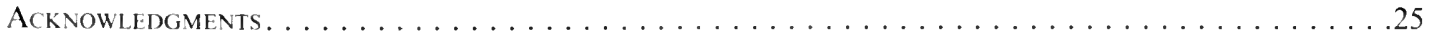

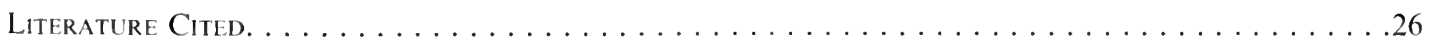

Appendix. List of Specimens Examined . . . . . . . . . . . . . . . . . . . . . . . . . . . 29 


\section{List of Illustrations}

1. Distribution, arrangement. and morphology of palatal teeth in selected iguanids $\ldots \ldots \ldots \ldots$

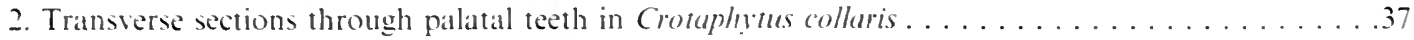

3. Distribution, arrangement. and morphology of palatal teeth in selected teiids . . . . . . . 38

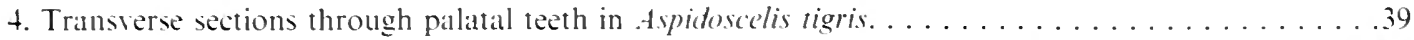

5. Distribution. arrangement, and morphology of palatal teeth in selected gymnophthalmids. . . . . . .40

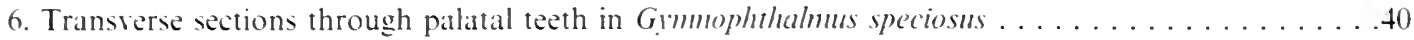

7. Distribution, arrangement. and morphology of palatal teeth in selected lacertids. . . . . . . . t

8. Transterse sections through palatal teeth in Lacerta lepida . . . . . . . . . . . . . . .

9. Distribution. arrangement. and morphology of palatal teeth in selected scincids . . . . . . . 42

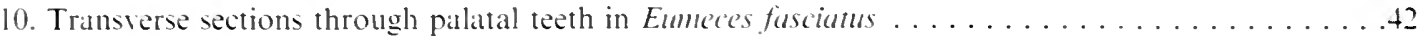

11. Distribution. arrangement. and morphology of palatal teeth in selected gerrhositurids........t3

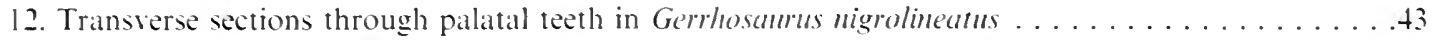

13. Distribution. arrangement. and morphology of palatal teeth in Shinisurus crocodilurus . . . . . . t4

14. Distribution. arrangement. and morphology of palatal teeth in Ophisurus apodus . . . . . . . 46

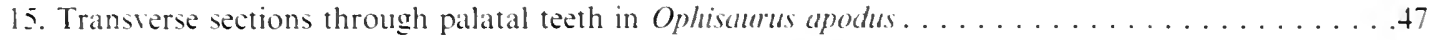

16. Distribution, arrangement. and morphology of palatal teeth in Heloderma suspectum . . . . . . . 48

17. Distribution. arrangement. and morphology of palatal teeth in Laminumotus horneensis . . . . . . .50

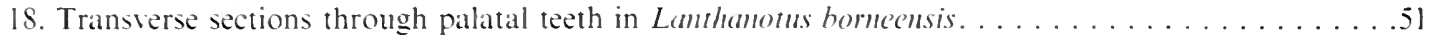

19. Distribution, arrangement. and morphology of palatal teeth in $C_{\text {glindrophis ruffus } \ldots \ldots \ldots \ldots .52}$

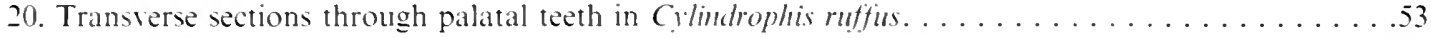

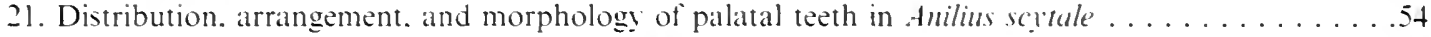

22. Transterse sections through palatal teeth in Anilius scytule $\ldots \ldots \ldots \ldots \ldots \ldots \ldots \ldots \ldots .55$

23. Distribution. arrangement. and morphology of palatal teeth in Fenopehtis unicolor . . . . . . 56

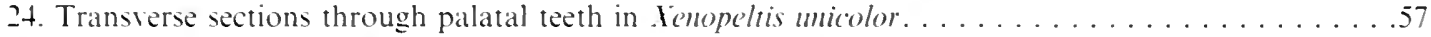

25. Distribution, arrangement. and morphology of palatal teeth in Boa constrictor..........58

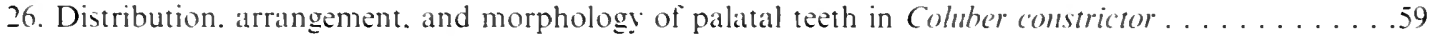

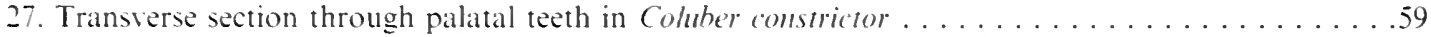

28. Distribution. arrangement. and morphology of palatal teeth in selected elapids $\ldots \ldots \ldots \ldots$

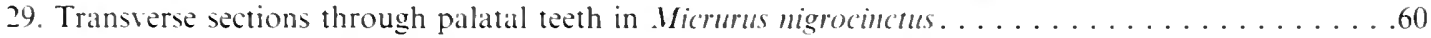

30. Distribution. arrangement, and morphology of palatal teeth in fgkistrodon contortrix . . . . .61

31. Transverse sections through palatal teeth in fghistrodon comortrix $\ldots \ldots \ldots \ldots \ldots \ldots \ldots \ldots$

\section{List of Tables}

1. Occurrence and distribution of palatal teeth across extant squamate reptile groups. . . . . . . 6 


\title{
The Palatal Dentition in Squamate Reptiles: Morphology, Development, Attachment, and Replacement
}

\author{
D. Luke Mahler Maureen Kearney
}

\begin{abstract}
The palatal dentition in squamate reptiles is poorly known compared to the marginal dentition. We surveyed species representing all squamate families for the occurrence of palatal teeth. For those exhibiting palatal teeth, we investigated palatal tooth arrangement, morphology, development, attachment, and replacement patterns using SEM, high-resolution $\mathrm{X}$-ray computed tomography imaging, and histology. We found substantial variability in the presence of palatal teeth and in the arrangement and number of palatal tooth rows at familial, generic, and specific levels among nonophidian lizards. However, snakes exhibit much more uniformity in both these respects. These patterns of variability have implications for trade-offs between phylogenetic, functional, and developmental constraints.
\end{abstract}

When numerous, palatal teeth in most nonophidian lizards are either arranged in fields or loosely organized rows near the back of the oral cavity. In contrast, palatal teeth in snakes and in the "lizards" Shimisauriss and Lanthanotus always occur in well-organized single rows; in snakes, these rows extend to the front of the oral cavity. Palatal teeth are usually morphologically similar to the marginal teeth, although in some cases they appear simpler. Replacement palatal teeth develop within a fold of the dental lamina that originates from the oral epithelium. In species with palatal teeth arranged in single rows, the dental lamina occurs along the labial edge of the tooth row. In others, various modifications of the dental lamina were observed that accommodate tooth replacement across multiple tooth rows or fields. Ankylosis of palatal teeth involves attachment either to the ventral surface of the toothbearing element or within a resorbed cavity or gutter within the element, except in some iguanids in which teeth attach to a raised ridge on the surface of the palatal bone. Tooth replacement patterns on the palate generally mirror those on the dentigerous marginal elements (i.e., labial replacement of palatal versus lingual replacement of marginal teeth), and traditionally recognized modes of tooth replacement for the marginal teeth are also observed for the palatal teeth. The strong correspondence in morphology and replacement patterns observed between marginal and palatal dentitions supports hypothesized developmental homology between them.

The homology of dental tissues and tooth attachment patterns in snakes and other lizards is currently controversial. We observed plicidentine in both the marginal and the palatal teeth of varanoid lizards, but not in the teeth of snakes as has recently been proposed. In addition, snakes and the extinct mosasaurs have been suggested to share a thecodont mode of tooth 
implantation. Relevant to this issue, we observed implantation of palatal teeth within resorbed cavities of varying depths in the attachment tissue or underlying bone of virtually all squamate groups. Also, an extensive buildup of attachment tissue that surrounds the teeth and prevents contact of tooth bases with each other occurs not just in snakes and mosasaurs, but also in Shinisaurus and Lanthanotus. Although palatal tooth ankylosis often occurs within a cavity, various attachment modes were observed within such cavities, generally corresponding to the attachment modes present in the marginal teeth. We conclude that tooth attachment geometry reflects, at least partially, constraints imposed by attachment to substrates of varying shapes. In other words, nearly all taxa observed exhibited some degree of "socketing" of the teeth on the palate regardless of actual attachment mode. It remains a matter for further study whether such a condition corresponds to the true thecodonty exhibited by archosaurs and mammals, which may differ fundamentally from squamate reptiles in their syndesmotic mode of tooth attachment.

Certain patterns of variation in the squamate palatal dentition may be informative as potential phylogenetic characters in future studies, including patterns of tooth arrangement on the palate, varying lengths of tooth rows, tooth sizes on different palatal elements, and tooth orientation.

Key Words: dentition; palatal teeth; lizards; snakes; tooth attachment; tooth development; tooth replacement.

\section{Introduction}

In addition to the dentigerous bones forming the margins of the jaws, some palatal bones also bear teeth in many species of squamate reptiles. Characteristics of the dentition in reptilesincluding gross morphology, implantation mode, and replacement patterns - have been studied in detail (e.g., Owen, 1840-1845; Tomes, 1874 , 1875; Edmund, 1960; Peyer, 1968) and have garnered renewed attention in recent years for their potential utility in inferring phylogenetic relationships among squamates (Lee, 1997a; Zaher \& Rieppel, 1999; Scanlon \& Lee, 2002; Caldwell et al., 2003). However, these investigations have focused almost exclusively on marginal teeth (but see Marx \& Rabb [1972] for advanced snakes). As a result, a full understanding of the squamate palatal dentition is lacking despite the fact that the palatal teeth may be informative in terms of patterns of tooth formation and development, attachment and replacement patterns, and form and function.

The cursory treatment that squamate palatal teeth have received may be due to their perceived relative simplicity and obscured function compared to the marginal dentition (e.g., Edmund, 1969). This is not necessarily the case in other tetrapod groups. For example, Rieppel (2001) showed that crushing teeth on the palate and on some marginal bones of the primitive reptile Placodus gigas may differ in attachment and replacement pattern from other marginal teeth according to varying function. Evidence does exist for a significant role for palatal teeth across many extinct and extant groups. Palatal teeth have a history dating as far back as the origin of teeth, and have occupied a wide range of unique and independent functions and morphologies (Romer, 1956; Smith \& Coates, 2000). Many fishes rely entirely on palatal teeth for dental functions (Scott \& Symons, 1964). The majority of early amphibian groups possessed palatal teeth, and in the labyrinthodonts, the vomers and palatines bear highly derived tusks (Romer, 1956). Other groups, such as the champsosaurs, lacked highly specialized palatal teeth but possessed a shagreen of smaller teeth adorning the entire palatal surface (Romer, 1956). Smith and Coates $(1998,2000)$ decouple tooth evolution and development from that of tooth-bearing elements, implying homology of pathways of tooth development regardless of where teeth occur. In light of this suggestion, it is of little surprise that palatal dentitions have been historically diverse.

Compared to the remarkable diversity of form and function in the palatal dentitions of fishes, amphibians, and some other tetrapods. the palatal dentition of squamate reptiles is 
relatively modest. However, it does exhibit morphological variability across groups and is therefore potentially informative (Marx \& Rabb, 1970, 1972). Early general works on the dentition of reptiles (e.g., Owen's Odontography, 1840 1845) depict palatal teeth for only a few squamate taxa. Edmund's (1969) review of reptilian dentition includes comments on the occurrence of palatal teeth in various squamate groups, but does not address arrangement or form. Likewise, Peyer (1968) mentions squamate palatal teeth only in subsidiary context to the marginal dentition, although he provides more detail for the palatal dentition of primitive reptiles. Romer (1956) summarized the occurrence of palatal teeth in reptilian groups, focusing primarily on family-level patterns of distribution.

Evolutionary aspects of squamate palatal teeth have been considered by some authors (Marx \& Rabb, 1970, 1972; de Queiroz, 1987; Estes et al., 1988; Lee, 1997a; Zaher \& Rieppel, 1999), and features of the palatal dentition have also been used as phylogenetic characters in some studies (Etheridge \& de Queiroz, 1988; Presch, 1988; Frost \& Etheridge, 1989; Caldwell, 1996; Caldwell \& Lee, 1997; Lee 1997b; Hallermann, 1998; Lee, 1998; Caldwell, 1999; Lee \& Caldwell, 2000; Scanlon \& Lee, 2000; Lee \& Scanlon, 2002). Marx and Rabb (1970, 1972) quantified variation in palatal tooth number in advanced snakes, and related trends in variation to ecological specialization and functional constraint.

The development of palatal teeth in squamates has received nominal treatment, with most researchers implicitly assuming developmental homology between palatal and marginal teeth. Indeed, tooth bud transplant experiments (Ten Cate \& Mills, 1972; Ten Cate, 1976) show that tooth development relates solely to the properties of the tooth bud and that specific tooth-bearing elements play little role in the developmental process. Other researchers have implied developmental homology not only between marginal and palatal teeth, but also between palatal teeth occurring on different palatal bones. Estes et al. (1988) found high levels of homoplasy for characters describing the presence or absence of teeth on individual palatal bones, and concluded that palatal tooth development is highly plastic within squamates. This conclusion, combined with their observation that pterygoid teeth are present in all those squamates that have palatine teeth, and that both palatine and pterygoid teeth are present in the few squamates that have vomerine teeth, led Estes et al. (1988) to suggest that the presence of teeth on each palatal bone is the result of a single developmental field. The absence of teeth on the anterior palatal elements in many species is thus thought to result from an anterior truncation in the expression of this field.

Few studies address the function of squamate palatal teeth; those that do deal mainly with higher snakes (e.g., Boltt \& Ewer, 1964; Frazzetta, 1966; Marx \& Rabb, 1970, 1972; Cundall \& Deufel, 1999). These biomechanical and comparative studies describe the role of the palatal dentition in the evolution of trademark snake feeding strategies, such as lateromedial jaw transport in ophidians with moderate skull kinesis, and medial jaw transport (i.e., the "pterygoid walk") in the highly kinetic skulls of colubroids (reviewed in Cundall \& Greene, 2000). Also, Marx and Rabb (1970, 1972) attribute variation in the number of palatal teeth to general cranial specializations for burrowing, capturing aquatic prey, or delivering venom. Beyond snakes, Montanucci (1968) described the palatal teeth of several iguanians in the context of their feeding modes, suggesting an important role in the oral manipulation of plant food items. The simpler palatal dentitions often found in insectivorous squamates have been suggested to aid in puncture crushing of hard prey items (Schwenk, 2000).

Replacement patterns and attachment modes have been studied in some detail for the marginal teeth of squamate reptiles (e.g., Edmund, 1960 , 1969). A classical distinction between varanidtype (replacement teeth developing distolingually, absence of resorption pits) and iguanidtype (replacement teeth developing mesiolingually within resorption pits) tooth replacement patterns has been recognized by many authors (McDowell \& Bogert, 1954; Edmund, 1969). An intermediate-type mode for some taxa has also been proposed (Rieppel, 1978). Distinct attachment modes (e.g., pleurodonty, acrodonty) have also been extensively discussed (Romer, 1956; Edmund, 1969), yet controversy continues regarding the validity of these definitions (Osborn, 1984). Estes et al. (1988) suggested that these traditionally defined attachment modes are artificial categories, but considered most squamates to exhibit a pleurodont attachment mode. Lee (1997a) proposed that both snakes and mosasaurs (but not other lizards) exhibit a thecodont mode of tooth implantation in 
both the marginal and the palatal elements. Zaher and Rieppel (1999) argued that the attachment mode is pleurodont in both these groups and, beyond that. is uniquely specialized in each. Caldwell et al. (2003) addressed this issue based on histology of attachment tissues. concluding that many squamate reptiles exhibit a thecodont mode of tooth attachment. These discussions have focused solely on the marginal dentitions. Replacement patterns and attachment modes for the palatal dentition in squamates are poorly known. and it is unclear whether previously described patterns (and debates about those patterns) apply equally to the palatal and marginal teeth.

Here we examine the morphology. development. attachment. and replacement patterns of palatal teeth across squamates. We seek to answer the following questions:

- Is the presence or absence of palatal teeth variable within currently recognized familial. generic. and specific groups?

- How are palatal teeth arranged in different squamates? Are there patterns of occurrence that may be informative with respect to developmental control of tooth expression. function, or phylogenetic significance?

- Does the morphology of palatal teeth closely mirror that of the marginal teeth?

- Do palatal and marginal teeth show the same mode of attachment?

- Are palatal teeth subject to the same replacement patterns as marginal teeth within species?

- Do patterns of the palatal dentition correspond closely with dietary habits and feeding behaviors?

- Can the palatal dentition shed any light on current issues related to homology and phylogeny in certain groups of squamate reptiles?

The study of dental morphology employs a terminology that varies over time. author. and study taxon. For simplicity and consistency. we adopt the terminology of Edmund (1969) as our primary source. Directional descriptors differ when applied to teeth versus tooth-bearing bones. The terms "medial." "lateral." "anterior." and "posterior." therefore. specify direction with respect to bones. while the terms "lingual." "labial." "mesial." and "distal" refer to corresponding directions on the teeth themselves. The homology and terminology of various mineral- ized tooth attachment tissues are the source of much disagreement (Osborn. 1984: Lee, 1997a: Zaher \& Rieppel. 1999: Gaengler. 2000: Rieppel \& Kearney. 2001: Caldwell et al.. 2003). We do not attempt to resolve this disagreement here and simply refer to "attachment tissues" as such.

\section{Methods}

\section{Skull Preparation}

We prepared numerous skulls from alcoholstored specimens in the collection of the Division of Amphibians and Reptiles of the Field Museum of Natural History (FMNH). Using a Leica MZ75 dissecting microscope. the skin of the head was peeled back from the underlying musculature. The hyolingual apparatus was freed from the cranium. and the latter was carefully separated from the body. Soft tissues were then removed from the cranium using finetipped forceps while leaving the dental lamina and developing replacement teeth intact. Skulls were then cleaned and dried.

\section{Gross Morphology}

Gross dental morphology was examined using different techniques according to availability, size. and preservation of specimens. We examined larger specimens using a Leica MZ75 dissecting microscope with a Spot Insight digital camera attachment (model 3.2.0). For smaller specimens. we used AMRAY 1810 and Zeiss Evo60 scanning electron microscopes for examination and image generation. These specimens were left uncoated and were viewed at low voltage $(2 \mathrm{kV})$. For rare or precious species that were not available for preparation. we used highresolution X-ray computed tomography (HRXCT) methods to obtain visualizations of the skull from alcohol specimens (see below).

\section{Histology}

We examined existing histological preparations in the FMNH slide collection for some species. For most species. however. new histological preparations were necessary. The heads of alcohol-stored specimens were first skinned and then removed from the bodies as described above. The heads were then decalcified. embed- 
ded in paraffin, and serially sectioned at $12 \mu \mathrm{m}$. Sections were stained with haematoxylin and eosin, mounted on slides, and then examined and photographed using a Leica DM LS2 compound microscope with a Spot Insight digital camera attachment (model 3.2.0).

\section{CT Scanning}

For some rare taxa, we used HRXCT studies of alcohol specimens scanned at the HRXCT Facility at the University of Texas at Austin. The resulting transverse data sets were digitally resliced along frontal and sagittal axes and rendered in three dimensions using either VoxBlast (Vaytek, Fairfield, IA) or VGStudio Max (Volume Graphics, Heidelberg, Germany). Further scanning details and additional HRXCT imagery are available from the authors.

\section{Materials}

\section{Specimens Examined}

We examined all squamate osteological specimens in the collection of the Division of Amphibians and Reptiles at FMNH. In addition, we examined specimens from the osteological collections at the Museum of Comparative Zoology (MCZ) at Harvard University; the National Museum of Natural History (NMNH), Smithsonian Institution; and the Natural History Museum and Biodiversity Research Center, University of Kansas (KU). To add taxonomic scope, we hand-prepared skulls from alcoholstored specimens at FMNH or CT-scanned them (described above). We examined hundreds of skeletal specimens representing over 900 species of snakes and other lizards. A complete list of specimens examined is given in the Appendix.

\section{Abbreviations}

The following abbreviations are used throughout the paper:
FMNH Field Museum of Natural History
KU Natural History Museum and Bio- diversity Research Center, University of Kansas

MCZ Museum of Comparative Zoology, Harvard University

TNHC Texas Memorial Museum, University of Texas

UF Florida State Museum, University of Florida

USNM National Museum of Natural History, Smithsonian Institution

YPM Peabody Museum of Natural History, Yale University

att attachment tissue

dl dental lamina

drt developing replacement tooth

dt developing tooth

lig attachment ligament

$\mathrm{mlg}$ mesiolingual groove

nt newer tooth

ot older tooth

pal palatine

plc plicidentine

pt pterygoid

rp resorption

tr tooth remnant

\section{Results}

All members of the following extant squamate groups have edentulous palates: Chamaeleonidae, Agamidae, Gekkonidae, Pygopodidae, Xantusiidae, Cordylidae, Anniellidae, Xenosauridae (but see character codings in Hallermann [1998] and Lee [1997b, 1998]), Varanidae, Dibamidae, Amphisbaenia, and Scolecophidia. Table 1 summarizes variability found for the presence or absence of palatal teeth in squamates, representing our observations augmented with data from the literature. When a species is variable for the presence of palatal teeth, we indicate the nature of this variability parenthetically in the descriptions that follow, for example, $(\mathrm{X} / \mathrm{Y})$. The former number indicates the number of specimens we found that exhibited palatal teeth; the latter indicates the total number of specimens examined. We roughly follow the family level taxonomies of Cundall et al. (1993) for snakes and Estes et al. (1988) for all other squamates, with some deviations for recent updates (e.g., Lang [1991] and Frost et al. [2001] suggest separate familial treatment of cordylids and gerrhosaurids). 
TABLE 1. Occurrence and distribution of palatal teeth across extant squamate reptiles $(n=$ number of specimens examined: $+=$ presence of teeth on element: $-=$ absence of teeth on element: $+1-=$ taxon variable for presence or absence of teeth on element).

\section{Pterygoid Palatine Vomer}

\section{"LIZARDS":}

Chamaeleonidale

Agamidac

Iguanidae

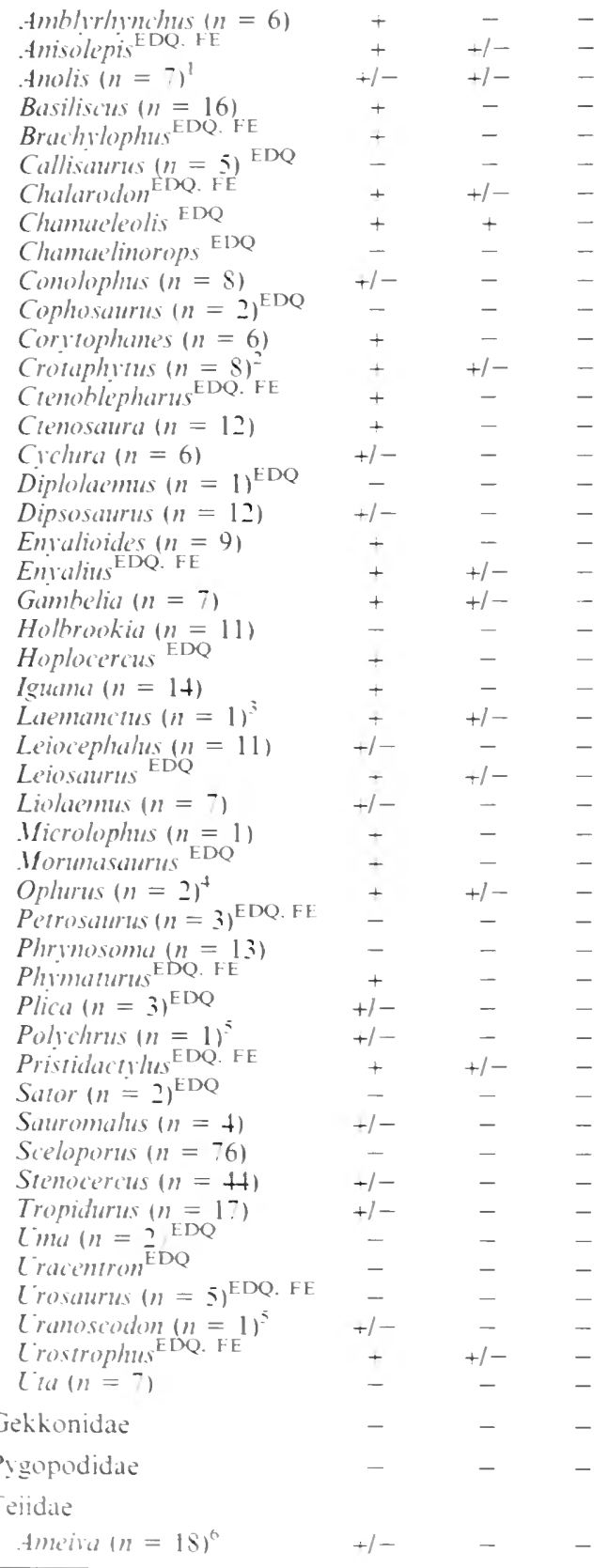

Table 1. Cominued.

Pterygoid Palatine Vomer

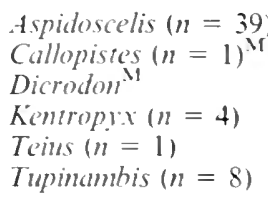

Gymnophthalmidae

$\begin{array}{llll}\text { Alopoglossus }(n=2) & + & - & - \\ \text { Bachio }(n=2) & + & - & - \\ \text { Colobosama }(n=1) & + & - & - \\ \text { Echinosama }(n=1) & - & - & - \\ \text { Gimnophinalmus }(n=1)^{\mathrm{M}} & + & - & - \\ \text { Veusticurus } & & & \\ \text { Pholidobohus }(n=8) & - & - & - \\ \text { Proctoporus }(n=4) & - & - & - \\ \text { Tretioscincus }(n=1) & + & - & -\end{array}$

Lacertidae

Acamhodactilus $(n=1)$

Adolphus

Algiroides

Gallotia ${ }^{\text {A }}$

Lacerta $(n=7)^{\text {A }}$

Meroles $(n=1)$

Podarcis $(n=5)^{-4}$

Psammodrommus

$\begin{array}{ccc}+ & - & - \\ + & - & - \\ + & - & - \\ +1- & - & - \\ + & - & - \\ - & - & -\end{array}$

Xantusiidae

\section{Scincidae}

Acontias ${ }^{\mathrm{G}}$ ?

Amphiglossus $(n=1$

Aprerigodon

Chalcides $(n=4)$

Corrucia $(n=3)$

Dasiza

Egernia $(n=2)$

Emoia $(n=10)$

Enmeria G3

Eumeces $(n=20)$

Fellinia ${ }^{\mathrm{at}}$

Gongllomorphins $\mathrm{G}^{2}$

Isopachls $(n=6)$

Janetuescincus $\mathrm{G} 2$

Lamprolepis ${ }^{\mathrm{G}}$ :

Lerisia $(n=1)$

Lrgosema $(n=5)^{\mathrm{G} 3}$

Mabula $(n=16)$

Macroscincus ${ }^{\mathrm{G} 3}$

Melamoseps ${ }^{\mathrm{G}}=$

Ophiomoris $(n=2$ )

Pamelaescincus ${ }^{\mathrm{G} 2}$

Proscelones ${ }^{\mathrm{G}=}$

Scelotes ${ }^{\mathrm{G}}$

Scincella $(n=6)$

Scolecoseps ${ }^{\mathrm{G}}$

Sepsina $(n=1)^{\mathrm{G} 2}$

Sphenomorplnus $(n=7)$

Tiliqua $(n=14)$

Tropidophorus $(n=10)$

Tiphlacontias $(n=2)^{\mathrm{G}}$

Tiphlosumes $(n=1)^{\mathrm{G}}$ 
Pterygoid Palatine Vomer

Cordylidae
Gerrhosauridae
Cordylosaurus
Gerrhosaurus $(n=5)^{\mathrm{L}}$
Tetradacty'us
Tracheloptychus
Zonosaurus $(n=1)^{\mathrm{L}}$

Shinisauridae

Shinisaurus $(n=3)$

Anniellidae

Xenosauridae

Anguidae

Abronia $(n=1)^{\mathrm{GD}}$
Anguis $^{\mathrm{R} 2}$
Barisia $(n=1)$
Celestus $(n=9)$
Diploglossus $(n=1)^{\mathrm{R} 2}$
Elgaria $(n=6)$
Gerrhonotus $(n=4)^{\mathrm{R} 2}$
Mesaspis $\mathrm{GD}$
Ophiodes $(n=1)^{\mathrm{R} 2}$
Ophisaurus apodus $(n=3)$
Ophisaurus attenuatus
$\quad(n=4)$

Ophisaurus harti $(n=1)$

Ophisaurus ventralis $(n=1)$

Helodermatidae

Heloderina $(n=12)$

Varanidae

Lanthanotidae

Lanthanotus $(n=2)$

Dibamidae

AMPHISBAENIA

SNAKES:

Scolecophidia

Uropeltidae

Melanophidium $^{\mathrm{R} 1}$
Platyplectrurus $^{7}$

Plectrurus $^{\mathrm{R} 1}$

Rhinophis ${ }^{\mathrm{R} 1}$

Uropeltis $(n=1)^{\mathrm{R} I}$

Cylindrophiidae

Aniliidae

Xenopeltidae

Boidae

Calabaria $(n=3)$

Charina $^{\mathrm{KL}}$

All other observed boids

Colubridae

$\begin{array}{lccc}\text { Aparallactus }(n=2)^{\mathrm{UK}} & +\mathrm{-} & + & - \\ \text { Apostolepis } & - & + & -\end{array}$

Pterygoid Palatine Vomer

$\begin{array}{lccc}\text { Atractaspis }(n=9)^{\mathrm{UK}, \mathrm{MR}} & - & + & - \\ \text { Chilorhinophis }(n=2)^{\mathrm{MR}} & +/- & + & - \\ \text { Dasypeltis }(n=5)^{\mathrm{MR}} & - & + & - \\ \text { Elachistodon } \mathrm{MR} & - & + & - \\ \text { Lytorhynchus }(n=2)^{\mathrm{MR}} & +/- & + & - \\ \text { All other observed } & + & + & - \\ \quad \text { colubrids } & & & \end{array}$

Elapidae

Emydocephalus $(n=1)^{\mathrm{MR}}+{ }_{-} \quad-\quad-$

$\begin{array}{llll}\text { Calliophis }^{\mathrm{MR}} & - & + & - \\ \text { All other observed elapids } & + & + & -\end{array}$

Viperidae

Calloselasma $(n=1)^{\mathrm{K}}$

Crotalus $(n=95)$

Echis $(n=8)^{\mathrm{MR}}$

Ophryacus $(n=1)$

Protobothrops $(n=3)^{\mathrm{MR}}$

All other observed viperids

A Data obtained from Arnold (1973).

${ }^{B}$ Data obtained from Bell et al. (2003).

${ }^{\text {EDQ }}$ Data obtained from Etheridge and de Queiroz (1988).

${ }^{F E}$ Data obtained from Frost and Etheridge (1989).

G1 Data obtained from Greer (1970a).

G2 Data obtained from Greer (1970b).

G3 Data obtained from Greer (1977).

GD Data obtained from Good (1987).

K Data obtained from Kardong (1990).

${ }^{\mathrm{KL}}$ Data obtained from Kluge (1993b).

${ }^{\mathrm{L}}$ Data obtained from Lang (1991).

${ }^{M}$ Data obtained from MacLean (1974).

MR Data obtained from Marx and Rabb (1970, 1972).

R1 Data obtained from Rieppel (1977).

${ }^{R} 2$ Data obtained from Rieppel (1980).

UK Data obtained from Underwood and Kochva (1993).

${ }^{1}$ We observed pterygoid teeth in five out of seven specimens of Anolis, corroborating Etheridge and de Queiroz (1988), who indicate variability in this genus. Frost and Etheridge (1989) report the presence of palatine teeth in Anolis, and Etheridge and de Quciroz report absence for the same character. In our survey, we find the character to be polymorphic at the genus level.

${ }^{2}$ Etheridge and de Queiroz (1988) scored Crotaphytus as possessing palatine teeth uniformly. We observed this trait to be highly variable.

${ }^{3}$ We observed palatine teeth in Laemanctus, but Etheridge and de Queiroz (1988) and Frost and Etheridge (1989) reported them to be absent in this genus.

${ }^{4}$ We observed only pterygoid teeth in two specimens of this genus, but Etheridge and de Queiroz (1988) report the palatines to be variable as well.

${ }^{5}$ We observed pterygoid teeth in a single specimen. Etheridge and de Queiroz (1988) observed pterygoid tecth to be variable in a larger sample.

${ }^{6}$ Presch (1974) reports the presence of pterygoid teeth in Ameiva ameiva and A. bifrontata. Based on different results in our survey, the genus Ameiva and the species $A$. ameiva are variable for pterygoid tceth.

${ }^{7}$ Cundall and Greene (2000) report a simple palatal dentition in Platyplectrurus but do not indicate which bones in the palate possess teeth. 


\section{Iguanidae}

Pterygoid teeth are very common in iguanids. whereas palatine teeth are less common and vomerine teeth are completely absent (Table 1). At the generic level. 12/36 taxa with palatal dentition are polymorphic for pterygoid teeth. We found variability at the specific level for the presence of pterygoid teeth in Anolis cristatellus (1/2). Conolophus subcristatus (3/8). Cyclura comura (5/6), Dipsosaurus dorsalis (2/11). Leiocephulus carinatus (1/4). Stenocercus chrisoprgus (1/2). Stenocercus empetrus (2/3), and Stenocercus varius (1/4). Palatine teeth are found uniformly in 1/12 iguanid genera that express them and variably in $11 / 12$. Presence of palatine teeth varies intraspecifically in Crotaphrtus collaris ( 1 / 8) and in Gambelia wislizenii (3/4).

Iguanid palatal teeth are typically arranged in loosely organized rows (Fig. 1). In many specimens of Iguana, Basiliscus, Crotaplytus, Ctenosaura. and Cyclura, one row of pterygoid teeth is flanked by a second more medial row. which may be complete (Fig. 1C) or incomplete (Fig. 1D) (see also Montanucci. 1968: de Queiroz, 1987). Orientation and shape of the tooth row vary. In Iguana. the straight tooth row is oriented diagonally relative to the long axis of the skull. and its anterior extent corresponds roughly to the posterior extent of the marginal tooth row. In other taxa, such as Brachllophlus, Ctenosaura, Ciclura, and Sanromalus, the posteriormost section of the tooth row curves laterally to depart from the medial edge of the pterygoid (de Queiroz. 1987) (Fig. 1A. D). In some Ctenosatra, the laterally curving tooth row curves back toward the midline posteriorly, forming a medially open arc (Fig. 1B). Except for those taxa in which the posteriormost section of the tooth row curves laterally. tooth rows are usually located along the extreme medial edge of the pterygoid body.

Iguanid palatal teeth are generally conical and range from short and blunt (Basiliscus basiliscus, Plica plica) to elongate, pointed. and mildly curved (Ctenosaura similis). Although Edmund (1969. p. 154) described iguanian palatal teeth as "always small and never very numerous," the palatal teeth of some iguanids are numerous ( $>70$ per pterygoid in some Igu(ma igu(ana) and may exhibit a complex morphology in some species. For example. the palatal teeth of Crotaplyitus colluris are beveled. and those of Ctenosaura imilis are flattened at the tips and multicuspate
(Fig. 1E). similar to the morphology seen in the marginal teeth (Fig. lF). This morphology is most evident in the immature. developing replacement teeth, whereas the mature palatal teeth tend to exhibit a slightly simpler shape.

The palatal teeth of iguanids usually attach obliquely to the pterygoid or palatine. In Crotaplivtus collaris, histological sections show the presence of a shallow channel in the ventral lamellar surface of the pterygoid bone. presumably created through resorption (Fig. 2). The teeth are ankylosed within this channel. affixed with a substantial amount of attachment tissue. In other taxa. such as Iguana and Ctenosaura. attachment tissues play a bigger role in determining the geometry of the attachment site. with a large buildup of attachment tissue occurring on the pterygoid. that creates a pronounced ridge to which side of the tooth attaches. In contrast to the pleurodonty seen in the marginal dentition for all iguanians, the geometry of palatal tooth attachment varies. In some species. the palatal teeth within the resorbed cavity attach lingually to the medial wall of that cavity in a reclined position. In others, the side of the palatal tooth attaches to a ridge composed of attachment tissue. resulting in a more upright orientation. In all iguanids. the palatal teeth are replaced in the same manner as the marginal teeth (i.e.. the "iguanid replacement mode $"$ of Edmund, 1960). Tooth germs develop in a dental lamina that extends the length of each tooth row along the bases of the functional teeth. In those taxa with a single pterygoid tooth row (e.g.. Basiliscus). the replacement teeth develop labially (the mirror image of replacement of the marginal teeth). In those with a double pterygoid tooth row (e.g., Ctenosaura. Iguana), the replacement teeth develop along the lingual side of the medial row and along the labial side of the lateral row. From these positions. the replacement teeth migrate into resorption cavities in the bases of the functional teeth at an early stage (Figs. 1D, E: 2C, D).

\section{Teiidae}

Our survey of teiids revealed pterygoid teeth to be present (but neither numerous nor well developed) in Callopistes, Aspidoscelis. and Teins (Table 1). MacLean (1974) additionally reports pterygoid teeth in Dicrodon. We found the presence of pterygoid teeth to be variable in Ameiva (1/18) and Kentrop!x (3/4) and absent in 
all eight observed specimens of Tupinambis. We observed $A$. ameiva (1/4) and $K$. calcarata (3/4) to be intraspecifically variable for the presence of pterygoid teeth (Presch [1974] also reports the variable presence of pterygoid teeth in $K$. calcarata). No teiids were found to possess palatine or vomerine teeth.

In teiids, pterygoid teeth typically form an extremely short row along the medial margin of the pterygoid (Fig. 3A). In most species examined, the pterygoid teeth are attached to the ventral surface of the pterygoid and point ventrally; however, in a few species, the teeth on each pterygoid point toward the midline of the skull because they are affixed to the inner edge, rather than the ventral surface, of the pterygoid. Unlike the condition in iguanids, the anterior extent of the pterygoid tooth row in teiids is well posterior to the posterior extent of the marginal tooth row.

Pterygoid teeth in teiids are typically small and conical (Fig. 3B) and are generally morphologically simpler than the often beveled or cusped marginal teeth. However, a few individuals of Aspidoscelis were found to exhibit a small cusp on the pterygoid teeth (Fig. 3D), similar to that seen in the marginal teeth (Fig. 3E).

The pterygoid teeth in teiids attach within a shallow gutter resorbed in the ventral surface of the pterygoid (Fig. 3B, C). Attachment geometry varies. Usually, the teeth are attached along their basal and lingual surfaces with a minimum of attachment tissue (Fig. 4C, D), similar to the pleurodont attachment mode seen with the marginal teeth. Attachment may sometimes be more symmetric, however (Fig. 3C). Replacement teeth develop inside resorption pits that lie mesiolabial or labial to the functional pterygoid teeth. Unlike in iguanids, immature replacement teeth are sometimes observed in the absence of the corresponding functional tooth, suggesting possible early loss of the functional tooth during the process of replacement (e.g., Kentropyx calcarata, Fig. 3C; Aspidoscelis tigris punctilineatus, Fig. 4A, B).

\section{Gymnophthalmidae}

Bell et al. (2003) recently described the absence of palatal teeth in a large survey of Neusticurus ecpleopus, a species they considered representative of the family Gymnophthalmidae. In a larger work on teiids and gymnophthalmids, MacLean (1974) described pterygoid teeth only in Gym- nophthalmus speciosus, which also suggests that palatal teeth are uncommon in this family (Table 1). In the single dry skull available to us for observation for Gymnophthalmus speciosus, two to three very small teeth are present on each pterygoid. Two specimens of Bachia lack palatal teeth. Our observations of cleared-and-stained material and CT data for other taxa indicate that Alopoglossus angulatus, Colobosaura modesta, and Tretioscincus bifasciatus possess one to two teeth on each pterygoid, and that Echinosaura, Pholiclobolus, and Proctoporus lack palatal teeth. Additional specimens were unavailable for assessing variability in this family comprising 36 genera (Pellegrino et al. 2001).

In Gymmophthalmus speciosus and Colobosaura modesta, two or three small teeth form a short transverse row on the central body of the triradiate pterygoid (Fig. 5). Unlike in iguanids or teiids, the pterygoid teeth in these gymnophthalmids are not positioned along the medial margin of the ptergyoid; instead they occur at the base of the transverse process of the ptergyoid. These teeth are stout, conical, and slightly compressed, similar in form to the marginal teeth (Fig. 5C).

The pterygoid teeth of Gymnophthalmus speciosus are ankylosed within a wide depression in the ventral surface of the pterygoid (Figs. 5B; 6), and the teeth attach to the wall of this cavity via a small amount of attachment tissue (Fig. 6). Although replacement mode is not evident from histological sections, resorption cavities containing immature teeth may be seen developing mesiolingual to functional teeth in a prepared skull (Fig. 5B, C), suggesting either an intermediate-type (Rieppel, 1978) or an iguanid-type (Edmund, 1960) mode of replacement.

\section{Lacertidae}

As noted by Arnold (1973), palatal teeth are common in lacertids and occur solely on the pterygoids (Table 1). Arnold (1973) indicates that Gallotia possesses pterygoid teeth uniformly and that Algyroides, Lacerta, Podarcis, and Psammodromus are variable for this trait (the species reported to possess pterygoid teeth in these genera are Algyroides moreoticus, $A$. nigropunctatus, Lacerta agilis, $L$. lepida, $L$. princeps, $L$. brandtii, L. dugesii, L. jayakari, $L$. laevis, L. schreiberi, L. strigata, $L$. trilineata, $L$. viridis, Podarcis milensis, P. peloponnesiaca, P. taurica, and Psammodromus algirus). Our survey, 
though taxonomically restricted, revealed uniform presence of pterygoid teeth in all examined specimens of Lacerta ( $L$. lepida and L. viridis) and a single specimen of Meroles ( $M$. anchietae). It also indicated variable presence of pterygoid teeth in Podarcis. Within Podarcis, we observed pterygoid teeth in single specimens of $P$. lilfordi and $P$. taurica and found pterygoid teeth to be variable in $P$. sicula (1/3). In addition. Arnold (1973) reported the presence of pterygoid teeth to vary intraspecifically in Algyroides moreoticus and $A$. nigropunctatus.

Lacerta exhibits an unusual palatal tooth arrangement. In Lacerta lepida, for example, an uneven row of teeth runs anteroposteriorly near the middle of the pterygoid. Medial and posteromedial to this row, smaller teeth are scattered in subparallel rows, extending all the way to the medial edge of the pterygoid (Fig. 7B). These rows are less prominent than the primary lateral row; the teeth are fewer, smaller, and appear to be heavily embedded in a large buildup of attachment tissue. The most posteromedial teeth appear nearly completely degraded (either through partial resorption or wear). The lateral row, on the other hand, is more continuous and consists of larger teeth that are generally fully intact.

The pterygoid teeth in Lacerta are stout at their base and become constricted below the tip, terminating in a blunt knob with a chiseled edge (Fig. 7C). This morphology approximates the form of the marginal teeth. Both marginal and palatal teeth in Lacerta exhibit a mild curvature (labial curvative of palatal teeth, lingual curvature of marginal teeth).

The teeth are affixed within a gutter in the ventral surface of the pterygoid (Figs. 7C;8A), ankylosed with small amounts of attachment tissue (Fig. 8B). Both basal and lingual surfaces of the tooth attach to the pterygoid, creating a pleurodont appearance (Fig. 7C).

Developing replacement teeth, embedded in the dental lamina, are observed labial to the functional teeth in histological sections (Fig. 8A), and migrate into resorption pits in the mesiolabial surface of the functional tooth base (Fig. 7C). The presence of additional degraded rows of pterygoid teeth medial to the primary lateral row in L. lepida suggests that older teeth may migrate medially across the pterygoid rather than being lost during the replacement process. Such a migration would involve a reworking of underlying bone and attachment tissues, as described by Ricqlès and
Bolt (1983) for the primitive reptile Captorhinus aguti.

\section{Scincidae}

Presence of pterygoid teeth (no scincid possesses palatine or vomerine teeth) is variable among scincids (Table 1) and has been used as a key character to inform the phylogenetic relationships within this group (Greer, 1970a). Among scincids, all available specimens of Corucia, Eumeces, Ophiomorus, and Sepsina uniformly possess pterygoid teeth. In addition, Greer (1977) notes the uniform presence of ptergyoid teeth in Dasia and Eumecia. We found variability in the presence of pterygoid teeth in Mabuya and Tropidophorus. Greer (1977) reports variability in the presence of pterygoid teeth for Lygosoma based on examination of 19 species, reporting that 5 species possess them and 14 uniformly lack them. Tropidophorus brookei (2/4) was the only scincid examined in our survey that showed intraspecific variation in the expression of pterygoid teeth, although Greer (1977) notes a similar condition in Lygosoma punctata.

Scincid palatal teeth are usually loosely arranged in a short to moderate single row of longitudinal orientation on the pterygoid (Fig. 9A), although this row is transversely oriented in Sepsina (Greer, 1970b) and Lygosoma (Greer, 1977). Some specimens of Eumeces fasciatus exhibit additional teeth out of line with this primary row (Fig. 9B). The tooth row typically does not traverse the medial margin of the pterygoid but is located a short distance away from this edge (Fig. 9A).

Palatal teeth in most scincids exhibit broad bases and conical tooth crowns (Fig. 9B), morphologically similar to the fairly simple marginal teeth seen in most species. In taxa where the marginal teeth exhibit more morphological complexity, the palatal teeth roughly approximate this condition. For example, Corucia zebrata, an herbivorous scincid with spatulate marginal teeth (Fig. 9D), exhibits a similar flattening of the pterygoid tooth tips (Fig. 9C). although the resemblance is not exact.

Histological sections of Eumeces fasciatus show pterygoid teeth implanted within a deeply resorbed cavity in the pterygoid (Fig. 10A; see also Fig. 9B). Attachment occurs through a substantive deposition of attachment tissue at the base and side of the tooth. Tooth replacement occurs as in the iguanid mode: new teeth develop 
within a dental lamina that is positioned along the labial side of the functional teeth (Fig. 10B) and migrate to occupy basal resorption pits within the bases of the functional teeth (Fig. 9B).

\section{Gerrhosauridae}

Although we were unable to perform extensive sampling within Gerrhosauridae (1 Gerrhosaurlıs flavigularis, 1 G. nigrolineatus, 3 G. validus, 1 Zonosaurus ornatus), Lang (1991) reports the presence of palatal teeth on the ptergyoids in all gerrhosaurid genera (Cordylosaurus, Gerrhosaurus, Tetraclactylus, Tracheloptychus, and Zonosaurus) except the monotypic Angolosaurus (data unknown). Our observations indicate the presence of pterygoid teeth in all sampled taxa.

The pterygoid teeth are arranged either in a single straight row that is oriented diagonally relative to the long axis of the skull (Fig. 11A) or sometimes in a single curving row. Curving rows turn laterally and then return toward the midline to form a slight arc that is open medially (Fig. 11C). Tooth orientation may vary along the row, with several teeth pointing in different directions (Fig. 11C); this seeming disorganization within a tooth row is mirrored closely in the opposite row. In Gerrhosaurus, the pterygoid teeth are short and slightly curved at the tip. The tooth bases are broad, and the tips of the crowns are flattened to form wedges (Fig. 11B). Both of these conditions are similar to the conditions seen in the marginal teeth (Fig. 11E). In the case of the marginal dentition, the bases are broadened and the tips flattened mesiolingually. However, the orientation of the pterygoid teeth differs from that of the marginal teeth, with the flattened tips and the broadened bases occurring in a diagonal plane. The flattened tips of the ptergyoid teeth also bear striations in some species (Fig. 11D) that mirror those seen in the marginal teeth (Fig. 11E). One individual of $G$. validus (FMNH 22293) exhibited rudimentary cusps on the pterygoid teeth, though they were far less differentiated than those of the marginal teeth (Fig. 11D, E).

The teeth of Gerrhosaurus are ankylosed within an excavation in the ventral surface of the pterygoid (Fig. 12). They are fastened at the base and sides via moderate to large amounts of attachment tissue. The tooth attachment site bears evidence of frequent and imprecise resorption and redeposition of attachment tissue. Some sections show new functional teeth affixed to partially eroded teeth and to masses of old attachment tissue.

New teeth develop within basal resorption pits that receive tooth buds from the dental lamina. Histology indicates that this replacement may occur lingually (Fig. 12A) as well as labially (Fig. 12B), although only labially replacing teeth were observed on skeletal material, and this could be anomalous.

\section{Shinisauridae}

Palatal teeth are found only on the pterygoid in Shinisaurus crocodilurus (Conrad, 2004). The teeth are arranged in a well-organized, longitudinal row within a cavity that courses along the medial edge of the pterygoid (Fig. 13). The teeth are widely spaced throughout this row (Fig. 13B, C) in contrast to the crowded palatal tooth rows seen in most nonophidian lizards. The pterygoid teeth of Shinisaurus are conical, pointed, slightly recurved, and fairly tall, similar to the morphology of the marginal teeth.

Each pterygoid tooth has an expanded base that is affixed perpendicularly to the pterygoid via a buildup of attachment tissue (Fig. 13B). The walls of the pterygoid cavity are higher medially than laterally (Fig. 13C), but the sides of the teeth nonetheless do not attach to this wall. They are instead ankylosed solely at their bases with attachment tissues completely surrounding the base of each tooth (Fig. 13B, C), precluding direct contact of the tooth bases with each other or with the walls of the cavity. Histological preparations of Shinisaurus were unavailable.

The replacement mode of the pterygoid teeth in Shinisaurus is somewhat obscure. None of the specimens we observed exhibited resorption cavities in the pterygoid teeth; however, these are visible in the marginal teeth and indicate an intermediate-type mode of tooth replacement. In addition, we observed some instances of immature teeth occupying several tooth positions along the ptergyoid tooth row.

\section{Anguidae}

The Anguidae contains species that possess teeth on the pterygoids, palatines, and vomers (Table 1). Pterygoid teeth were observed in all specimens of Elgaria, Ophisaurus, and the single available specimen of Barisia (Good [1987] describes this genus as uniformly possessing pterygoid teeth). Also, pterygoid teeth were 
found variably in the genus Gerrhonotus. and Rieppel (1980) has described variability in the pterygoid teeth of Anguis. We found variable presence of palatine teeth in Ophisaurus and intraspecific variability in $O$. attematus (3/4). Vomerine teeth were observed only in $O$. apodus (2/3). In every specimen exhibiting palatine teeth. pterygoid teeth are also present: likewise. specimens with romerine teeth always possess both palatine and pterygoid teeth.

The palatal teeth are either arranged in a single row (e.g.. Ophisaurus attenututus and O. harti) or in multiple uneven rows (subparallel rows of Edmund. 1969) on each palatal element (e.g.. Elgaria, $O$. ventralis. and $O$. apochus) (Fig. 14). We observed a single row of teeth on each pterygoid in Gerrhonomus. but Good (1987) illustrates a specimen of $G$. liocephalus that possesses multiple rows. In some specimens of $O$. upodus. numerous palatal teeth appear to form a long but disjunct secondary tooth row extending from the middle of the vomer anteriorly to the posterior region of the pterygoid body: in others. the teeth are poorly developed or absent on the romer. Even in those species with well-developed teeth on all three elements. however. a continuous (uninterrupted) row such as that seen in higher snakes is not present. Typically. the vomer bears a single uneven row. the palatine may bear an incomplete second row. and the ptery goid may bear multiple uneven rows.

Anguid palatal teeth are short. blunt cones with broad bases (Fig. 14C). They closely resemble the marginal teeth in shape but are comparatively diminutive. Size and shape of the teeth are often inconsistent along the palatal tooth row: On the pterygoid of Ophisaurus upodus, for example. larger teeth in the lateral position are bordered medially by a somewhat random scattering of smaller teeth that point in different directions (Fig. 14D). Likewise. some anterior teeth on the palatine of a specimen of $O$. apodus appear as large. stout cones. while those more posterior appear somewhat smaller and distorted in shape (Fig. 14C).

Palatal teeth are attached within fairly deep cavities in the palatal elements of anguids (Fig. 15). The role of attachment tissues varies: at some attachment sites. old tooth remnants and attachment tissues have undergone incomplete resorption and seemingly comprise the foundation for new teeth (Fig. 15D). Edmund (1969) stated that tooth replacement in anguids proceeds without tooth resorption. that is. with replacement teeth dereloping distolingual to the functional teeth but with no resorption pits observed. However. Cooper (1966) and Rieppel (1978) describe tooth replacement in anguids as insolving resorption of the tooth base around the alveolar foramen to house the growing replacement tooth (Rieppel"s "intermediate mode" of tooth replacement). These studies were restricted to the marginal dentition. For the palatal dentition. replacement teeth develop within an infolding of dental lamina that originates from oral epithelium along the ventrolateral surface of the palatal bone and extends across the tooth rows (Fig. 15B-D). Developing teeth were found to cause incomplete resorption of old teeth (Fig. 15D). similar to the process described by Cooper (1966) and Rieppel (1978) for the marginal dentition. Once the functional tooth has been shed. the replacement tooth migrates dorsally from the dental lamina to achieve ankylosis.

\section{Helodermatidae}

Teeth are uniformly present on the pterygoids of Heloderma horridum and variably present in H. suspectum (contra McDowell and Bogert [1954]. who report absence in $H$. suspectum). Teeth are also present on the palatines of $H$. horridum but not $H$. suspectum. In $H$. suspectum. teeth are typically found in a short longitudinal row centered on the body of the pterygoid. just posterior to the palatine-pterygoid suture (Fig. 16A. B). In H. horridum. this row continues anteriorly onto the palatine. where one to a few teeth are present. Tooth orientation varies markedly along the row. with teeth pointing in several different directions (Fig. 16B). The palatal teeth of helodermatids are conical and distinctly curved. with stout bases (Fig. 16B). As with the marginal teeth (Fig. 16D), the pterygoid teeth exhibit strong dentine infoldings at the base of the crown (Fig. 16C): however, unlike the marginal teeth. they lack renom grooves. The pteryoid teeth in Heloderma attach directly to the flat rentral pterygoid surface. Although individual teeth create a shallow cavity in the pterygoid bone at the site of attachment. the tooth row in Heloderma does not sit within a continuous depression or gutter (Fig. 16B. C) as it does in teiids and Shinisaurus, for example.

Although histological preparations were not available for Heloderma. some observations regarding replacement pattern were possible from skeletal specimens and CT scans. Palatal teeth 
develop mesial or mesiolabial to their corresponding functional teeth; this is in contrast to the distolingual position of the replacement teeth in the marginal bones. Replacement palatal teeth in Heloderma do not develop within resorption cavities, but rather migrate into position once an older functional tooth has been shed (Fig. 16B, second tooth from right).

\section{Lanthanotidae}

Our observations of Lanthanotus borneensis confirm the presence of palatal teeth on the pterygoid and palatine bones (McDowell \& Bogert, 1954). The palatal teeth are arranged in an evenly spaced, mildly curved row along the medial edge of the pterygoid and extend anteriorly onto the palatine for a short distance (Fig. 17A, B). This row is continuous from the posterior portion of the palatine to the posterior extent of the pterygoid body, interrupted only by a short diastema at the suture of these elements. The shape of the pterygoid-palatine tooth row as a whole is a shallow arc that opens medially; the tooth row follows the curve of the medial aspect of the pterygoid and palatine bones. The palatal tooth row does not overlap the marginal tooth row but occurs more posteriorly on the palatal surface.

CT data for Lanthanotus indicate that the palatal teeth in this species are small, conical, and slightly recurved. Palatal teeth were largely missing in the skeletal specimens we observed, but some tooth bases were present for observation (Fig. 17B, C). The base of each tooth is cylindrical, and a large alveolar foramen pierces the attachment tissue and the base of the tooth mesiolingually, where the tooth meets the pterygoid (Fig. 17C). Dentine infoldings were not observed externally at the tooth bases, although these would be difficult to detect given the quality of the teeth present on these specimens. Histological sections indicate the presence of plicidentine at the bases of the palatal teeth in Lanthanotus (Fig. 18B, C).

Palatal teeth in Lanthanotus are ankylosed within a longitudinal depression in the ventral surface of the ptergyoid. Within this depression, copious amounts of attachment tissue anchor the teeth and fill the remaining spaces around the teeth (Figs. 17C; 18C). This differs from the attachment of the marginal teeth, which exhibit a typical varanoid type of specialized attachment (Kearney \& Rieppel, in press). When teeth are shed, the attachment tissue exhibits a superficially "socketed" appearance, with interdental ridges formed of attachment tissue occurring between tooth attachment sites (Fig. 17D).

Zaher and Rieppel (1999) report labial replacement of the palatal teeth in Lanthanotus. Through histology, we confirm labial replacement in the pterygoid teeth of Lanthanotus (Fig. 18B, C), but also observed lingual replacement in the palatine teeth of the same specimen (Fig. 18A).

\section{Alethinophidian Snakes}

Among alethinophidian snakes (no scolecophidians have palatal teeth), the morphology of palatal teeth generally mirrors that seen in the marginal teeth. The arrangement and replacement patterns are far more conservative than those seen in lizards, being much the same throughout the entire group, and we therefore discuss these as a whole here. Typically, teeth are arranged in a single, straight row that extends posteriorly from the anterior portion of the palatine, across the palatine-pterygoid suture, and sometimes along the quadrate ramus of the pterygoid (Table 1). While nearly all alethinophidians exhibit continuous palatal tooth rows, the number of teeth found on the palatine and pterygoid elements of advanced snakes (colubroids) is quite variable (discussed in detail in Marx and Rabb, 1972). Teeth are generally attached to the palatal bones perpendicularly via a large buildup of attachment tissue and are always replaced labially, mirroring the lingually replaced teeth of the marginal tooth-bearing bones (Lee, 1997a). As with the marginal dentition, replacement palatal teeth always develop in a recumbent position and rotate into an upright position when fully developed, migrating into position once the functional tooth is shed. Very few snakes deviate significantly from these patterns; thus, while palatal tooth morphology and attachment will be described for all alethinophidian snake groups, arrangement and replacement will be described only when exceptional.

\section{Uropeltidae}

Skeletal material for most uropeltid snakes was unavailable. However, CT imagery of Uropeltis melanogaster indicates the absence of palatal teeth. Rieppel (1977) describes three small teeth in each palatine in Melanophidium 
punctatum but reports teeth to be absent in $M$. urnaudense as well as in Cropeltis brevis, $U$. ocellatus, Rhinophis, and Plectrurus. Cundall and Greene (2000) also report a simple palatal dentition in Platyplectrurus, citing Smith (1943). Complete absence of palatal teeth is extremely rare in alethinophidian snakes but occurs with unusual frequency in uropeltids.

\section{Cỵlindrophiidae}

The palatal teeth of cylindrophiids are very similar morphologically to their marginal counterparts. They are stout, recurved. and conical. with heavily built bases (Fig. 19). Tooth size changes from anterior to posterior in the palate: the anteriormost teeth are moderate in size, giving way to smaller teeth more posteriorly (Fig. 19A). This is not the case with the marginal teeth. which are of uniform size.

The palatal teeth are ankylosed with an extensive buildup of attachment tissue lining a deep excavation running the length of the ventral surface of the palatal elements. The walls of this excavation are uneven in height. with the lingual wall being higher than the labial (Figs. 19A: 20B). The palatal teeth attach to the walls of this excavation by the base and both sides (Fig. 20A). The bases of the palatine teeth. but not the pterygoid teeth. incline slightly medially (Figs. 19A: 20).

\section{Aniliidae}

The palatal teeth of Anilius are very similar in shape to the marginal teeth but are comparatively smaller (Fig. 21). The palatine teeth are larger. less numerous, and more widely spaced from each other than are those on the pterygoid. These changes in size and spacing are not gradual. occurring abruptly at the junction of the two elements (Fig. 21 A). The palatal teeth are fairly short. strongly recurved, and have a well-developed carina on lingual and labial edges (Fig. 21C). On some palatal teeth. weak striations are apparent at the base (Figs. 21 C: 22): these are more pronounced in the marginal teeth and seem to reflect impressions of overlying bone of attachment (Kearney \& Rieppel. in press).

The palatal teeth of Anilius are ankylosed within a gutter nearly as wide as the narrow palatal elements themselves. This gutter is lined with attachment tissue, which serves as a foundation into which the palatal teeth attach
(Figs. 21C: 22). The tooth bases are separated from each other by extensively developed attachment tissue. Shed teeth reveal the extent to which the teeth are implanted within the attachment tissue (Fig. 21B). Attachment tissues cover the very base of the tooth externally and also invade the tooth cavity to cover the internal surface of the tooth base (Figs. 21C; 22B).

\section{Xenopeltidae}

Xenopeltids have a unique dentition (Figs. 23: 24). The shape of the palatal teeth mirrors the spatulate morphology seen in the marginal teeththe teeth are anteroposteriorly compressed, providing flat mesial surfaces (Figs. 23B; 24A). Our observations indicate that the palatal teeth in xenopeltids are larger than the marginal teeth. a unique condition among squamates. In some specimens. the palatal teeth appear to be at least twice as large as those on the marginal bones. This condition may bear further scrutiny within a functional context. The palatal teeth are not uniform in size but gradually decrease in size posteriorly (Fig. 23A).

Tooth attachment in Xenopeltis employs a unique ligamentous structure that allows the teeth to fold posteriorly under pressure during feeding. This condition has been described explicitly for the marginal dentition (Savitzky, 1981: Cundall \& Greene. 2000), and our results show that the same type of attachment also occurs with the palatal teeth (Fig. 24C). The palatal bones are deeply excavated at the sites of tooth attachment (Fig. 24). The walls of the resultant cavity are tall and of roughly even height. Ligaments extend from the tooth base to the insides of these walls but not to the floor of the cavity, anchoring the tooth to the palatal bone in a manner that allows folding.

Replacement teeth lie in a recumbent position within the dental lamina occurring labial to the bases of the functional teeth, and extending the length of the tooth row (Figs. 23C; 24B). Savitzky (1981) reported that all functional tooth positions in Xenopeltis are occupied simultaneously by teeth of the same size and suggested a unique. fully synchronous replacement scheme for this taxon. However, examination of our CT data (Fig. 23A) and some dried skulls (Fig. 23C) contradicts this. In both marginal and palatal dentitions. we observed several empty tooth positions along the tooth rows as well as replacement teeth in various stages of development and of various sizes. 


\section{Boidae}

We observed palatal teeth on both the pterygoids and palatines of all boids examined, except for the erycine Calabaria reinhardtii, which uniformly lacks palatal dentition, and Charina bottae, which occasionally lacks palatine teeth (Kluge, 1993b). The palatal teeth of boids are morphologically similar to the marginal teeth; they are long, recurved, sharp cones similar in size to those occurring on the marginal bones (Fig. 25). In most boids, the more anterior palatal and maxillary teeth exhibit "reverse curvature," where the tooth is S-shaped, facilitating penetration during prey snaring (Cundall \& Deufel, 1999; Deufel \& Cundall, 1999). Tooth size may vary within the palatal tooth row. As reported by Kluge (1993a), in many pythonines, the anteriormost teeth of the palatine are significantly larger than teeth on the remainder of the palatine and on the pterygoid. We observed this difference in size to be most pronounced in Chondropython viridis and Morelia amethistina and found the transition in tooth size to be more gradual in other boids. The posterior reduction in tooth size is concordant between the palatal and marginal tooth rows. In addition, the pterygoid teeth tend to point posteromedially, whereas the palatine teeth point posteriorly (Fig. 25A). The line of demarcation between posteriorly oriented teeth and posteromedially oriented teeth on the palate again corresponds to a similar transition in orientation for the marginal teeth. The bases of the palatal teeth are slightly ovoid and attached within a deep palatal groove lined with attachment tissue (Fig. 25B, C). The tooth bases are not in contact, separated by interdental ridges composed of attachment tissue. No histological preparations were available for boids.

\section{Colubridae}

Colubrids typically possess teeth on the palatine and pterygoid, but the egg-eating Dasypeltis and Elachistodon lack pterygoid teeth (Gans, 1952; Marx \& Rabb, 1970, 1972), as do some atractaspids (e.g., Aparallactus werneri, Atractaspis bibroni, A. dahomeyensis, A. irregularis, A. microlepidota, and Xenocalamus bicolor), Apostolepis ambiniger (Underwood \& Kochva, 1993), and Lytorhynchus paradoxus (Marx \& Rabb, 1972). Underwood and Kochva (1993) also note a lack of pterygoid teeth in Chilorhi- nophis, but we observed them to be present in $C$. carpenteri. No colubrids were observed to lack palatine teeth, although observations were inconclusive for some Atractaspis specimens. In contrast to other alethinophidian snakes (Figs. 19A; 21 A; 23A; 25A), the palatal tooth rows in colubrids are typically greatly elongated, often twice as long as the marginal tooth rows (see Marx and Rabb [1972] for discussion of exceptions). In Coluber constrictor, for example, the palatal tooth row extends posteriorly almost the entire length of the quadrate ramus of the ptergyoid (Fig. 26A). In the anterior portion of the palatal tooth row, the teeth point posteriorly; more posteriorly along the row, they point posteromedially. This transition is similar to the condition we observed in boids.

Palatal teeth in colubrid snakes are generally elongate, conical, and sharply recurved (Fig. 26). Some, such as those of Coluber constrictor, show a pronounced carina on the lingual and labial edges leading to the tip of the crown (Fig. 26B), a condition also seen in the marginal teeth. Vaeth et al. (1985) describe accessory longitudinal fluting mainly on the posterior surface of both the marginal and the palatal teeth of many piscivorous colubrids (variably present in the genera Afronatrix, Amphiesma, Cereberis, Dipsas, Erpeton, Homalopsis, Enhydris, Heurnia, Helicops, Macropisthodon, Natrix, Nerodia, Pareas, Sibon, Sibynomorphts, Sinonatrix, Tetranorhinus, and Thamnophis). In specimens of these taxa observed in our survey, the degree of fluting on the marginal and palatal teeth was very similar. Differences between the marginal and palatal dentitions exist, however, in the heterodontous colubrids (taxa that exhibit variation in size, shape, and continuity in the marginal tooth row) and in the monospecific genera Pythonodipsas and Bitia. In heterodontous colubrids, the palatal tooth row consists of teeth of uniform shape, continuous arrangement, and consistency of size, even when the maxillary and dentary teeth exhibit multiple tooth shapes, diastemas along the tooth row, and pronounced size heterogeneity (e.g., Heterodon, Xenodon, and Lycodon). Although palatal teeth were often seen to decrease in size posteriorly in these taxa, this transition was observed to be gradual rather than abrupt (contra the condition seen in many boids and elapids). As exceptions to this pattern, the enigmatic colubrids Bitia hydroides and Pythonodipsas carinata exhibit pronounced heterogeneity in tooth size and spacing within the palatal 
tooth rows. In Bitia, the third palatine tooth is markedly larger than others in the tooth row. The viper-like Prthonodipsas possesses a large, ungrooved fang on the anterior palatine, separated from the remaining palatine teeth by a short diastema (Marx \& Rabb. 1970; Marx et al., 1982). This morphology is relatively unique among snakes, although the pythons Chondropython viridis and Morelia amethistina also possess distinctly enlarged anterior palatine teeth. In most colubrids we examined, the palatal teeth are somewhat smaller than the marginal teeth despite an overall similarity in form and arrangement (Fig. 26A).

Palatal tooth attachment in Coluber constrictor (and also in some elapids and viperids - see below) differs from that seen in more primitive snakes. Rather than implanting within a gutter, the teeth attach directly to the surface of the palatal bones--this is likely a result of the highly modified orientation of these elements. In many higher snakes, the palatal elements are deflected such that they are no longer oriented in the mediolateral plane but lie instead in the dorsoventral plane; thus, the palatal teeth attach along a flange that projects from the medial edge of the palatal bones (Fig. 27). The teeth attach via a mass of attachment tissue deposited on the surface of this flange and ankylose directly perpendicular to the surface (Figs. 26B; 27).

\section{Elapidae}

Nearly all elapids possess teeth on both the pterygoid and the palatine bones, including three specimens of Homoroselaps lacteus (contra Underwood \& Kochva, 1993). Palatine teeth are absent in the hydrophiid Emydocephahus, a group specialized to feed entirely on fish eggs (Voris, 1966: Marx \& Rabb. 1970. 1972). and Calliophis bivirgatus is reported to lack teeth on the pterygoid bones (Marx \& Rabb. 1972). As in colubrids, the palatal tooth row is much longer than the marginal tooth row. In some species, this is largely due to the extreme shortening and specialization of the marginal tooth row rather than to a posterior elongation of the palatal tooth row per se (e.g., Micrurus fulvius. Fig. 28A). In many other elapids, however. pterygoid teeth do extend posteriorly onto the quadrate ramus of the ptergyoid, as observed in most colubrids.

Generally. elapid teeth are elongate. recurved cones (Fig. 28). Differences in tooth size within palatal tooth rows are common. The pterygoid teeth may be shorter and stockier than the elongate palatine teeth (e.g., Micrurus fulvius. Fig. 28A). Many species exhibit modest carinae on the lingual and labial edges (e.g., $M$. nigrocinctus, Fig. 28B, C), and some have flat mesial surfaces (e.g., Aspidomorplus muelleri). The majority of elapids surveyed exhibit a very shallow longitudinal groove (most likely a developmental correspondence to the venom tube in the anterior maxillary teeth) along the mesiolingual side of the palatal teeth (similar grooves are found on the mesiolabial side of the dentary and posterior maxillary teeth) (Figs. 28C: 29). These grooves (described by Van Denburgh \& Thompson, 1908) are sometimes very faint and difficult to detect but are nonetheless widely distributed among elapids. They are generally more pronounced on the anterior palatine teeth and become less well developed on the posterior pterygoid teeth. The grooves develop early in the ontogeny of the replacement teeth (Fig. 29) and are found on the side of the tooth opposite the dental lamina in both palatal and marginal teeth.

The attachment of palatal teeth in Micrurus nigrocincus occurs within a resorbed cavity in the fairly narrow palatal bones (Fig. 29). The palatal teeth are attached within this cavity primarily at the sides of the tooth base (Fig. 29B). Attachment tissue extends far up the sides of the tooth. and, in sections, the distinction between attachment tissue and tooth is difficult to discem. Instead, the junction of attachment tissue and dentine is blurred, and the two tissue types appear somewhat interwoven (Fig. 29A). This phenomenon is also evident in the palatal teeth of Naja nigricollis and $N$. nivea.

\section{Viperidae}

We found palatal teeth to be present on both the palatines and the pterygoids of most viperids, although the number of teeth on the palatine is few compared to many colubrids (Marx \& Rabb. 1970. 1972). Several species appear to have independently lost palatine teeth (e.g., Crotalus basiliscus, Echis coloratus [variable-palatine teeth were present in our single observed specimen but were reported as absent in Marx \& Rabb. 1970. 1972]. Calloselasma rhodostoma [variable according to Kardong. 1990]. Ophriacus undulatus, Protohothrops flavoriridis [Marx \& Rabb, 1970, 1972], and Protohothrops mucrosquamatus). Viperid palatal teeth are elongate. smoothly recurving cones that point toward the 
midline (Fig. 30A). Unlike in elapids, in which the venom groove of the marginal teeth is mirrored in the palatal teeth, viperid palatal teeth do not exhibit any of the morphoiogical features related to the venom delivery system that are seen in the marginal teeth. The number of marginal teeth in viperids is typically highly reduced; the palatal teeth constitute the primary tooth row in these species. Palatal teeth do not differ substantially in size along this row.

Tooth attachment in Agkistrodon contortrix is similar to that in Coluber. The palatine and pterygoid bones in Agkistrodon are unusually narrow, and the teeth attach directly to the ventral edge of the bone rather than being set within a cavity (Fig. 31). Although the palatal bone may sometimes exhibit a ventral concavity, the palatal teeth do not sit within it. Rather, the tooth base abuts and fuses to the walls of this cavity via a substantial deposition of attachment tissue (Fig. 31B).

\section{Discussion}

\section{Morphology and Arrangement of Palatal Teeth}

The presence or absence of palatal teeth in nonophidian squamates varies extensively from family to species level; snakes, however, are more uniform in these patterns (Table 1). In nonophidian squamates, variability occurs within the families Iguanidae, Teiidae, Gymnophthalmidae, Lacertidae, Scincidae, Anguidae, and Helodermatidae; within the genera Algyroides, Ameiva, Anguis, Anisolepis, Anolis, Chalarodon, Conoloplus, Crotaphytus, Cyclura, Dipsosaurus, Enyalius, Gambelia, Gerrhonotus, Heloderma, Kentropyx, Laemanctus, Leiocephalus, Leiosaurus, Liolacmus, Lygosoma, Mabuya, Mesaspis, Ophisaurus, Oplurus, Plica, Podarcis, Polychrus, Pristidactylus, Sauromalus, Stenocercus, Tropidophorus, Tropidurus, Uroscanodon, and Urostrophus; and within the species Ameiva ameiva, Anolis cristatellus, Conolophus subcristatus, Crotaphytus collaris, Cychra cornuta, Dipsosaurus dorsalis, Gambelia wislizenii, Heloderma suspectum, Kentropyx calcaratus, Leiocephalus carinatus, Lygosoma punctata, Ophisaurus apodus, $O$. attenuatus, Podarcis sicula, Stenocercus chrysopygus, Stenocercus empetrus, Stenocercus varius, and Tropidophorus brookei. Beyond presencel absence, variability was also found in the number of rows of teeth on the palate for nonophidian taxa. For example, individuals of Iguana, Basiliscus, Crotaphytus, Ctenosaura, Cyclura, Lacerta, Gerrhonotus, and Ophisaurus differ in whether teeth are arranged in single or multiple rows. Among snakes, variability in palatal tooth presence (variability on palatines, pterygoids, or both) occurs within the families Uropeltidae, Boidae, Colubridae, Elapidae, and Viperidae; within the genera Aparallactus, Atractaspis, Calliophis, Calloselasma, Charina, Chilorhinophis, Crotalus, Echis, Lytorhynchus, and Protobothrops; and within the species Calloselasma rhodostoma, Charina bottae, and Echis coloratus. While some uropeltid species and the boid Calabaria lack palatal teeth altogether, nearly all colubroids possess at least some teeth on either the palatines or the pterygoids.

Higher taxa exhibiting the uniform absence of palatal teeth include Chamaeleonidae, Agamidae, Gekkonidae, Pygopodidae, Xantusiidae, Cordylidae, Aniellidae, Xenosauridae, Varanidae, Dibamidae, Amphisbaenia, and Scolecophidia. Those exhibiting the uniform presence of palatal teeth (teeth on one or more palatal elements) include Gerrhosauridae and the alethinophidian families Aniliidae, Cylindrophiidae, Xenopeltidae, Colubridae, Elapidae, and Viperidae. Potential explanations for the uniform absence and uniform presence of palatal teeth in such taxa are discussed below under "Functional Considerations."

Among those species that exhibit palatal teeth, the number, extent, and arrangement of teeth across the palate varies. Generally, higher snakes exhibit a complete secondary tooth row on the palate that extends from the anterior portion of the oral cavity for a length that is roughly equivalent to the marginal tooth row in basal alethinophidians, and sometimes much longer than the marginal tooth row in colubroids. This row is always single. Palatal tooth rows in nonophidian squamates may be single, double, or multiple. In most "lizards" with palatal teeth, expression is limited to discrete regions of the palatal surface, and these are usually located posteriorly on the palate. Ophisaurus is somewhat of an exception to this pattern, expressing teeth in more regions of the palate. However, these teeth occur in discrete patches unlike the uninterrupted, single tooth row typically seen in snakes. The only nonophidian squamates exhi- 
biting a "snake-like," single, well-organized tooth row are Shinisaurus and Lanthanotus.

In most nonophidian lizards, palatal teeth occur only on the pterygoids (occasionally also on the palatines). In Ophisaurus uniquely, palatal teeth may occur on ptergyoids, palatines, and vomers. In snakes, teeth occur on both the ptergyoid and the palatine in almost all species. As noted by Estes et al. (1988), vomerine teeth occur only in those individuals that exhibit palatine teeth, and palatine teeth occur only in those individuals that exhibit pterygoid teeth.

In snakes, both marginal and palatal tooth rows are linear, well organized, and longitudinally oriented, and individual tooth orientation is nearly always posteriorly recurved. The only exception is seen in boids, colubrids, and viperids, where some palatal teeth may be oriented posteromedially: when this condition occurs, it is consistent between the marginal and palatal dentitions. In contrast, the palatal tooth rows of lizards may differ in orientation from the marginal tooth rows, and are not constrained in linear rows. Examples of transverse orientation, diagonal orientation, curving tooth rows, and linear tooth rows are seen. Also, in contrast to snakes. orientation of individual palatal teeth in lizards ranges from quite variable (e.g., Heloderma) to highly consistent (e.g., Shinisaurus). In both cases, these do not necessarily mirror what is seen in the marginal dentition. In the case of Shinisaurus, for example, the palatal teeth are recurved posteriorly, whereas the marginal teeth are not.

In almost all squamates, palatal teeth are smaller than marginal teeth. In all nonophidian lizards, this size disparity is large and, in some cases, extreme (e.g., Iguana). In most snakes, however, the palatal teeth are only slightly smaller than the marginal teeth. In one species with highly specialized dentition (Xenopeltis unicolor), the palatal teeth exceed the marginal teeth in size. In addition, differences in tooth size on different palatal elements are evident in snakes. Two distinct patterns can be seen. In some species, there is an abrupt change in tooth size between tooth groups occurring on different palatal elements. but the teeth on any given element are roughly the same size (e.g., elapids and boids; see also Kluge, 1993a). In other species, a gradual decrease in tooth size occurs along the palatal tooth row from anterior to posterior (e.g., colubrids and xenopeltids).

in general, palatal teeth in squamates are either very similar in form, or simpler than the marginal teeth. There are no cases where the palatal teeth are morphologically more complex than the marginal teeth. In many species. detailed morphological correspondence is seen between the dentitions: the palatal teeth of varanoids exhibit plicidentine just as the marginal teeth do; in some Corucia and Ctenosaura, the pattern of cusps seen on the marginal teeth is also present on the palatal teeth: the spatulate tooth crowns of Xenopeltis and the fluting of the teeth in Cerberus are found in both dentitions. In snakes, morphological correspondence between palatal and marginal dentitions is nearly uniform, with the exception of those species in which the marginal dentition exhibits extreme specializations (i.e., for envenomenation). For example. the blade-like posteriormost maxillary tooth in Heterodon nasicus has no palatal analog. Interestingly, although the highly specialized hypodermic marginal tooth form of elapids is not seen in the palatal teeth, an early corresponding stage of development is evident in the mesiolingual groove (e.g., Fig. 28C). These observations support the general idea of developmental homology at some level between marginal and palatal dentitions.

\section{Development of Palatal Teeth}

Tooth development in squamate reptiles occurs within the dental lamina, an infolding of oral epithelium that possesses the potential to produce teeth. On the marginal dentigerous bones, the dental lamina extends along the lingual base of the tooth row. Tooth germs develop on the labial side of this fold and migrate apically during development to eventually replace older teeth (Edmund, 1969). With respect to the development of palatal teeth, a dental lamina occurs labially in most species that exhibit well-organized single tooth rows, with modifications of this arrangement observed in those species exhibiting multiple rows (see below under "Replacement of Palatal Teeth").

Some researchers have proposed the existence of developmental modules corresponding to different functional regions in the dentition. According to Stock (2001), modularity of tooth expression may explain how some taxa lose entire regions of a dentition despite the unmodified persistence of tooth groups in other regions. A question of central relevance to the topic of modularity in tooth development is whether the presence of palatal teeth can be 
"switched off" for periods of evolutionary time and then reexpressed in a descendant organism. The condition in some groups such as anguids, in which only Ophisaurus apodus possesses vomerine teeth, could be explained by modularity, where tooth expression is switched on after a period of absence, as has been suggested for some teleost fishes (Stock, 2001).

Researchers have yet to explore patterns of palatal tooth expression in the early development of squamates. Greven and Clemen (1980) report that the giant salamandrid Andrias japonicus develops tooth rows and dental laminae on the palatine bones early in ontogeny, but these structures are then quickly resorbed (adults lack palatine teeth). If such processes occur in squamates, they might aid in understanding the variation and distribution of palatal teeth across groups.

Despite the level of variability observed in the palatal dentition of squamates, the expression of teeth along the palate also indicates some level of constraint. Palatal teeth are most consistently present in the posterior region of the palate (the pterygoids); when suppression occurs, it apparently follows a directional bias (vomers, then palatines, then pterygoids) (see Estes et al., 1988). Most taxa that bear teeth on more than one palatal element (e.g., iguanids, varanoids, anguids, and some viperids) follow this pattern. However, colubroids demonstrate variability in the posterior rather than anterior extent of the palatal tooth row, and a few taxa lack ptergyoid teeth while retaining palatine teeth (e.g., Melanophidium, Atractaspis, Dasypeltis).

Constraint could also be a factor in those squamate groups that uniformly lack palatal teeth (e.g., Agamidae, Gekkonidae, Varanidae), given the variability observed in other family groups. Also, higher snakes (Alethinophidia) and gerrhosaurids uniformly possess palatal teeth, save a very few exceptions (e.g., Calabaria). While the feeding mode of nearly all higher snakes imposes a strong functional constraint for the retention of palatal teeth, the role of developmental constraint is less certain. In instances where functional constraint is purportedly absent (e.g., Emydocephalus) and where palatal teeth may be a functional hindrance (e.g., Dasypeltis, various viperids), the palatal dentition is lost or reduced. In addition, a majority of colubroids with reduced or no palatal teeth exhibit extensive cranial modifications associated with a fossorial existence, and some venomous colubroids may exhibit low palatine tooth counts because of contraints associated with venom delivery (Marx \& Rabb, 1970, 1972). It thus seems that functional considerations may drive the patterns observed in higher snakes. In gerrhosaurids, however, the uniform presence of palatal teeth is not tied to a particular feeding mode, and tooth shape and arrangement are also highly variable within this group. It seems more likely that this group exhibits uniform presence of palatal teeth because of either developmental or phylogenetic constraint.

\section{Attachment of Palatal Teeth}

Mechanisms of tooth attachment, long recognized to differ among vertebrate groups (Tomes, 1874; Romer, 1956; Edmund, 1960, 1969) have been a recurrent source of controversy (Smith, 1958; Osborn, 1984; Gaengler, 2000). Squamate reptiles are no exception, and recent studies have come to very different conclusions regarding modes of tooth attachment across different squamate groups and potential homologies between them (Lee, 1997a; Zaher \& Rieppel, 1999; Caldwell et al., 2003).

Traditionally, three basic modes of tooth attachment (pleurodonty, acrodonty, and thecodonty) are recognized (Edmund, 1969), although the validity of these discrete categories has been questioned (Estes et al., 1988), and numerous authors recognize the existence of subcategories of these modes for some taxa (Osborn, 1984; Zaher \& Rieppel, 1999; Gaengler, 2000). Thecodonty is a mode of attachment long considered to occur only in archosaurs and mammals, entailing the attachment of teeth within a discrete bony alveolus (socket) via a periodontal ligament (i.e., a syndesmotic attachment). Replacement teeth develop within alveoli in thecodont animals; the dental lamina therefore is not continuous along the tooth row but instead is divided among sockets. In contrast, pleurodonty and acrodonty, both normally considered to occur in lepidosaurs, traditionally describe a synostotic type of attachment. Most squamate reptiles exhibit a pleurodont attachment mode wherein the tooth is ankylosed to the lingual surface of the pleura of the jaw via the deposition of mineralized attachment tissue (usually called bone of attachment; but see Osborn, 1984; Gaengler, 2000; Caldwell et al., 2003). Tooth replacement is continuous throughout life in these species, and the dental lamina extends 
without interruption along the base of the marginal tooth row. A few taxa (e.g.. trogonophid amphisbaenians, agamids, and chamaeleonids) exhibit an acrodont attachment mode where the teeth are attached apically to the jaw within a shallow alveolar groove whose walls are composed of labial and lingual flanges of the tooth-bearing element. The teeth are ankylosed to the margins of this groove on both sides, and the bases of the teeth are typically in contact and fused to each other. Acrodont teeth are not replaced in adults, and resorption pits are absent. Histological sections of Chamaeleo and Agamodon indicate the absence of a dental lamina in adults of these taxa (pers. obs.), although Röse (1893) reports the dental lamina to be present but inactive in adult agamids.

Recently, several authors have suggested a thecodont attachment mode in snakes and in the extinct mosasaurs (Lee, 1997a) or in most squamates (Caldwell et al., 2003). This is based on the observation that teeth in some taxa are ankylosed within a cavity in the bony tooth base (but see Zaher \& Rieppel. 1999) and on histological similarities in attachment tissues (Caldwell et al., 2003). The primary questions here are the nature (homology) of "sockets" and of the attachment tissues. For example, is the bony alveolus seen in mammals and archosaurs homologous to the "socket" seen in snakes and mosasaurs. or is the latter a resorbed cavity within the attachment tissue that creates the superficial impression of a socket once the tooth is shed? Additionally, is such "socketing" seen only in snakes and mosasaurs?

Our results indicate that most squamate taxa generally exhibit the same attachment mode in the palatal teeth as they do in the marginal teeth, but these correspondences are tempered somewhat by differences in the attachment substrates. In taxa exhibiting labial pleurodonty of the marginal teeth. the palatal teeth are often seen to attach with a "pleurodont" geometry as well. The details of this pleurodonty, however, may differ due to attachment to the flat palatal surface. In many cases, teeth are implanted in a slightly reclined position such that attachment to the flat pterygoid surface occurs via the base and side of the tooth (Figs. 1E; 3B; 9B, C). In others. such as Gymnophthalmus, teeth ankylose within a cavity in the ventral pterygoid surface, attaching to the bottom and posterior wall of this cavity much as the marginal teeth in this taxon affix to the pleura of the maxilla or dentary
(Fig. 5B, C). In Iguana and Ctenosaura, palatal teeth attach primarily by their sides to a buildup of mineralized tissues on the palatal surface (Fig. 1B, C). The "pleurodont" attachment mode in this case is facilitated by the accretion of these tissues on the palatal substrate to form a vertical surface for attachment.

Despite these examples, some squamates with pleurodont teeth along the margins demonstrate nonpleurodont palatal tooth attachment. In anguids such as Oplisaurus (Fig. 14B-D), many specimens exhibit symmetric attachment of tooth bases to the palatal bones rather than an inclined implantation incorporating the side of the tooth. Attachment of the palatal teeth in Shinisaurus crocodilurus also differs from the attachment observed in the marginal teeth. In this species, the palatal teeth ankylose within a longitudinal gutter on the pterygoid (Fig. 13C). Although the lingual wall of this gutter is taller than the labial wall, the teeth nonetheless attach solely by the base via large amounts of attachment tissue, and the side of the tooth does not play a role in attachment.

Histology of the palatal dentition in nearly all observed nonophidian squamates reveals another important distinction from the marginal teeth. On palatal surfaces, tooth attachment nearly always involves implantation within a resorbed cavity or groove in the ventral surface of the palatal element. Even in Heloderma, in which the palatal teeth appear to attach very superficially, a shallow resorbed cavity within the palatal bone is revealed by open tooth positions in some specimens. In this sense, nearly all taxa observed exhibit some level of "socketing" of the palatal teeth due to the constraints of attachment to a flat surface, regardless of the attachment mode.

The role of attachment tissues may also differ between the margin and the palate, perhaps again reflecting differences in the shape of the underlying bone. Lanthanotus borneensis, for example, possesses a copious amount of attachment tissue ankylosing the palatal teeth (Fig. 17C), but not the marginal teeth. The extent of this attachment tissue covering is such that the tooth bases are completely separated from each other: a pterygoid with the teeth stripped from it shows a "socketed" pattern (Fig. 17D) reminiscent of that seen in some snakes and mosasaurs.

Variability in tooth attachment geometry is seen on the palatal elements of many squamate species. For example, among iguanids, depend- 
ing on the shape of the ventral surface of the palatal element, teeth may attach within an excavated cavity in the element or to the side of a ridge created by attachment tissue. Attachment geometry therefore may represent a complex combination of phylogeny, constraints of tooth development, and constraints imposed by attachment to substrates of varying shapes. One implication of these results is that "thecodonty" cannot be inferred solely from the presence of implantation within a resorbed cavity. The implantation of teeth within cavities is seen to vary according to qualities of the underlying bone and may even vary across the dental elements of a single organism (e.g., Lanthanotus). Further, snakes and mosasaurs are not unique among squamates in exhibiting tooth attachment within resorbed cavities.

Still, the attachment of teeth within deep cavities filled by attachment tissues is indeed an interesting characteristic of snakes and mosasaurs (Lee, 1997a; Caldwell et al., 2003), and this condition is now shown to extend to Lanthanotus and Shinisaurus as well. The composition of tissues involved in ankylosis of teeth to underlying bone may better indicate attachment homologies (Gaengler, 2000; Caldwell et al., 2003). Potential homologies of the attachment tissues in snakes and mosasaurs have been proposed (Caldwell et al., 2003). Such tissues in other squamate taxa have not yet been examined in comparable detail, and these similarities will doubtless bear further scrutiny.

\section{Replacement of Palatal Teeth}

Our results indicate that traditionally recognized modes of tooth replacement in squamates for the marginal dentition are mirrored in the palatal dentition. However, the position of the dental lamina may differ between the palatal and marginal dentitions, resulting primarily from differences in the arrangement and distribution of teeth on different elements. Also, in some taxa, tooth replacement is imprecise on the palatal elements, and incomplete resorption may contribute to accumulation of palatal teeth in loosely organized rows.

Edmund (1960, 1969) described two modes of replacement to account for the variability found in squamates. Iguanid-type replacement entails the development of replacement teeth in an upright position within a lingual resorption cavity in the base of the functional tooth and loss of the functional tooth through such resorption. Varanid-type replacement entails distolingual development of replacement teeth in an upright position and loss of older teeth through erosion of attachment tissues rather than the formation of a resorption pit. Higher snakes (alethinophidians) exhibit a modification of the varanid-type replacement, but are unique in the recumbent orientation of the developing replacement teeth (Zaher \& Rieppel, 1999). Rieppel (1978) introduced an additional mode of tooth replacement, the intermediate mode, to describe replacement patterns in some anguinomorph lizards. With this mode, replacement occurs distolingually, but involves the development of a resorption pit around or above the alveolar foramen, which is implicated in the shedding of the functional tooth. Intermediate replacement thus differs from the iguanid mode in the distolingual rather than lingual origin of the replacement tooth (although this varies), and differs from the varanid mode in the development of resorption cavities during the replacement process.

Generally in squamates, replacement of the palatal teeth closely approximates the type of replacement mode observed in the marginal teeth, and the location of the replacement teeth relative to the functional teeth is exactly mirrored (Lee, 1997a). There are some exceptions to this mirroring phenomenon, such as Lanthanotus (in which we observed both lingual replacement on the small number of palatine teeth and labial replacement throughout the longer pterygoid tooth row); Gerrlosaurus (in which we observed one instance of lingual replacement in the otherwise labially replacing pterygoid tooth row); and Iguana (in which lingual and labial replacement occurs in different rows).

Despite the wide variety of arrangements we observed in the palatal dentition of iguanids, developing replacement teeth always occupy basal resorption cavities, just as with the marginal teeth. Likewise, the palatal teeth of Heloderma exhibit the varanid mode of replacement observed in the marginal teeth. Also, the palatal teeth of alethinophidian snakes develop labially in a recumbent position, mirroring the lingual recumbent replacement teeth of the maxillae. This consistency of replacement mode corroborates other sources of evidence for a homology relationship between the dentitions of the marginal and palatal elements.

The marginal dentition in squamates occurs without exception in a single row. The dental 
lamina uniformly exists as a strip of infolded epithelial tissue that extends along the lingual base of this row. In some squamates, the palatal dentition is also arranged in a single row (e.g., alethinophidian snakes, Shinisaurus, Lonthanotus, and many teiids). In such cases, replacement teeth develop within a dental lamina located labial to this tooth row. In the case of Iguana, in which teeth are organized into two parallel rows on each pterygoid, a dental lamina is present on each side of the pterygoid tooth rows.

In taxa with more than two closely spaced palatal tooth rows, we observed two different replacement mechanisms. In Ophisaurus apodus, the pterygoid typically exhibits multiple tooth rows. Histological sections of the pterygoid reveal a single infolding of dental lamina extending across all tooth rows from which replacement teeth develop (Fig. 15B, C). The multiple pterygoid tooth rows in $O$. apodus are concurrently deciduous; replacement is seen to occur across multiple adjacent rows (Fig. 15B). In Lacerta lepida, older teeth remain affixed to the pterygoid posteromedially, and newer teeth become ankylosed to the ptergyoid anterolaterally, to contribute to an overall patch-like distribution of teeth in various stages of wear (Fig. 7B). As replacement is observed only along the anterolateral margin of these tooth patches (Fig. 7C), the presence of the more posteromedial tooth rows must be explained via a mechanism other than the simultaneous replacement described above for Ophisaurus. In a study of the Permian reptile Captorhinus aguti, Ricqlès and Bolt (1983) describe a possible mechanism for the replacement of multiple adjacent marginal tooth rows: upon attachment of a new, medial row of teeth, the older tooth rows migrate laterally across the dental element via a reworking of the underlying bone and attachment tissues. Through such processes of growth and resorption, multiple rows of teeth from a single point of origin "travel" across the surface of the tooth-bearing element. The oldest, most lateral teeth are eventually shed via an unknown mechanism. This model for the development and replacement of the marginal teeth in Captorhinus could describe the development and replacement of the palatal teeth in Lacerta. The only other explanation would be that the dental lamina retreats anterolaterally over time, leaving incompletely resorbed teeth in more posteromedial rows.

\section{Functional Considerations}

The well-developed palatal dentition in higher snakes has received considerable attention within a functional context (Boltt \& Ewer, 1964; Frazzetta, 1966; Cundall \& Gans, 1979; Cundall \& Deufel, 1999; Deufel \& Cundall, 1999), commonly explained in terms of the unique feeding mechanisms involved in prey striking and in the swallowing of large prey (e.g., "preysnaring" or the "ptergyoid walk"). In contrast, the palatal dentition in nonophidian squamates, although arising frequently in phylogenetic contexts, is rarely discussed in terms of function. Indeed, it is implicit in the work of many researchers that palatal teeth in many non-snake squamates are vestigial remnants of an ancestral condition. This view seems especially tempting in taxa such as Aspidoscelis and Heloderma, in which the palatal teeth are very few in number compared to the marginal teeth and extremely small relative to the size of the mouth. Moreover, high variability in presence, arrangement, and morphology of palatal teeth within many taxa (e.g., Cyclura and Tropidophorus) suggests an absence of functional constraint on these traits.

Nonetheless, some researchers have postulated specific functions for the palatal dentitions in some "lizards." In a comparative study of diet and dentition in several iguanids, Montanucci (1968) proposed two functional explanations for the different shapes and arrangements of the palatal teeth. First, taxa with a modest number and a simple arrangement of palatal teeth were proposed to use them to supplement the marginal dentition in subduing and processing live prey. Such taxa tend to be insectivorous or carnivorous and generally kill their prey by piercing and crushing with teeth. This "puncture-crushing" falls short of mammalian mastication (which involves transverse movement of the mandible), but helps soften prey items for swallowing and digestion (see also Schwenk, 2000). Indeed, in numerous primarily insectivorous taxa (e.g., many scincids and teiids), we found a generally small number of palatal teeth disrupting the otherwise flat palatal surface in the rear of the mouth.

Second, some taxa with numerous palatal teeth arranged in longer rows were proposed to use these teeth to enhance prey grip. Montanucci (1968) notes that all those iguanid species exhibiting long rows of palatal teeth are herbiv- 
orous and possess a specialized marginal dentition that serves to shear plant matter. $\mathrm{He}$ proposes that the simpler palatal teeth compensate by providing the gripping function that is not possible with the shearing marginal teeth. The doubling of the tooth row (especially evident in Iguana and Ctenosaura) serves to increase the area and the purchase of this gripping surface (Montanucci, 1968). Throckmorton (1976) similarly suggests that the arrangement of small, sharp teeth on the pterygoid of I. iguana stabilizes food matter during feeding.

This functional dichotomy is consistent with ontogenetic changes observed in the pterygoid tooth number in iguanids (Montanucci, 1968; de Queiroz, 1987). In iguanids that exhibit palatal teeth, the number of pterygoid teeth is strongly correlated with skull size (Montanucci, 1968). Herbivorous iguanids may also undergo an ontogenetic shift in diet. Juveniles of Ctenosaura and some Iguana are reported to feed largely on live prey (e.g., insects) and transition to herbivory as they reach a larger body size (Montanucci, 1968). The transition from relatively few pterygoid teeth to a long row may thus correspond to an increasing dependence on plant matter in the diet.

In higher snakes, most taxa exhibit a functionally conserved feeding mode that actively uses the palatal tooth rows. In boids, the palatal and maxillary dentitions operate in unison to snare and secure prey during a strike, the recurved and reverse-curved teeth working like a rachet as the jaws move over the prey item (Cundall \& Deufel, 1999; Deufel \& Cundall, 1999). Also, as detailed by Boltt and Ewer (1964) and Frazzetta (1966), higher snakes use modes of medial jaw transport (the "pterygoid walk") and lateromedial jaw transport that involve the specialized use of both palatal and marginal tooth rows to draw the head and jaws over large prey items during ingestion. In elapids and viperids, the palatal tooth rows must perform this function alone, as the maxillary dentitions in these snakes are highly specialized for envenomation (Cundall \& Greene, 2000). These clear roles of the palatal dentition in snake feeding help explain the relative consistency in tooth arrangement and morphology across alethinophidian groups. Moreover, when the palatal dentition in higher snakes deviates from this typical arrangement (which is rare), it is usually in taxa with highly specialized diets or cranial modifications. In the egg-eating snake Dasypeltis, for example, teeth are absent on the pterygoids and reduced on the palatines (Gans, 1952). In the sea snake Enydocephalus, an exclusive diet of small, soft fish eggs may be related to the absence of palatine teeth (Voris, 1966). Likewise, in viperids and atractaspids, reduction of the palatal dentition may be tied to functional trade-offs involving venom delivery and fossorial existence, respectively (Marx \& Rabb, 1970). In vipers with few or no palatine teeth, the palatine bone is small in size and forms a mobile joint with the pterygoid, allowing greater kinesis during a strike. In the fossorial colubrid Atractaspis, the loss of pterygoid teeth may be associated with the shortening of the cranium for increased burrowing capability.

In addition to these examples from higher snakes, it is likely that the lack of palatal teeth in basal snakes (scolecophidians) is due to extreme specializations in feeding mode. Scolecophidian snakes are gape-limited and are restricted in diet to prey that can pass through the diminutive buccal cavity (Cundall \& Greene, 2000). Kley (2001) reports that leptotyplophids ingest prey through raking movements of the mandibles and that typhlopids perform this function via maxillary raking (the feeding mechanism of anomalepidids is unknown). Both of these highly specialized feeding mechanisms use the marginal dentition to accomplish intraoral transport. In addition, these taxa feed mainly on insect larvae and pupae, obviating any putative role for palatal teeth.

The patterns observed in the palatal dentitions of nonophidian squamates do not appear to be as closely tied to functional constraints as they are in snakes. While the correlations between lizard diet and palatal teeth described above are indeed plausible for some groups, these patterns are not sustained across groups. For example, while certain specializations of the palatal dentition (i.e., long, doubled rows of small teeth) may aid in an herbivorous diet, this trend seems to be restricted to iguanids. Largely herbivorous lizard taxa from other families often have simple palatal teeth or none at all. A recent survey of levels of herbivory across nonophidian squamates by Cooper and Vitt (2002) reveals high levels of plant consumption in numerous species with few or no palatal teeth. Examples of such taxa whose diet consists of more than $50 \%$ plant matter include the agamid Uromastyx acgyptius, the iguanid Uma inornata, the lacertid Podarcis liffordi, the teiid Aspidoscelis murimus, the scincid Tiliqua rugosus, and the cordylid Platysantus guttatus. Many of these taxa feed largely on flowers and fruits rather than leaves (Cooper \& Vitt, 2002); Uromastyx, 
however. is highly folivorous yet exhibits no palatal dentition. Moreover, we observed a wide range of palatal tooth morphologies and arrangements in iguanines. most of which feed nearly entirely on plant material. For example. palatal teeth are rarely found in Dipsosaurus and Conolophus (de Queiroz. 1987: pers. obs.). but Cooper and Vitt (2002) describe species of these genera as $97.3 \%$ and $99 \%$ herbivorous. respectively. Although the presence of highly specialized palatal tooth rows in Iguama may indeed contribute to an herbivorous feeding mode. the absence of palatal teeth in the herbivorous species mentioned above challenges a simple functional correlation. Another similar challenge to such explanations is our observation of high variability. in palatal tooth presence across squamate taxa that are largely insectivorous.

Functional correlations between diet and patterns of palatal dentition may be somewhat weak in lizards in part because the diets of most lizards are fairly broad (Schwenk, 2000: Cooper \& Vitt. 2002). Highly specialized feeders are uncommon among lizards: most can be regarded as opportunistic generalists (Hotton. 1955: Greene. 1982: Schwenk, 2000). A similar argument has been proposed by Greene (1982) to explain the absence of other feeding-related phenotypic specializations in lizards. In higher snakes. on the other hand. nearly all types of feeding specifically involve use of the palatal teeth for intraoral transport. The absence of palatal teeth in snakes can in most instances be attributed to functional correlations stemming from dietary or life history specialization (e.g.. Scolecophidia. Emydocephalus. Dasypeltis).

In summary. palatal teeth are present in squamate taxa that exhibit a wide range of feeding habits. Except for higher snakes. which are committed to a highly specialized feeding strategy, no particular feeding mode is associated with the uniform absence or presence of palatal teeth. Arrangement and morphology of palatal teeth do offer some correlations with dietary habits (e.g.. Iguanu iguma). but more general patterns of correlation are tempered by variability in lizard diet and by evidence of phylogenetic constraint on the development of palatal teeth in some lizard families.

\section{Phylogenetic Considerations}

The presence or absence of palatal teeth and characteristics of palatal teeth have implications for phylogenetic studies of squamate reptiles. One basic question regarding the use of palatal tooth characters in phylogenetic studies is polarity-are squamate palatal teeth primitive or derived? Conventional wisdom holds that palatal teeth were fairly ubiquitous in early tetrapods and that multiple independent losses of palatal teeth have occurred during the evolution of this clade (e.g.. Evans. 2003). However. for some squamate groups (e.g.. gymnophthalmids). palatal teeth appear to be rare and occur in distantly related taxa within the clade (Pellegrino et al.. 2001), potentially implying multiple origins. Likewise. the presence of vomerine teeth in Ophisaurus apodus indicates a probable reacquisition (see also Estes et al.. 1988). It has also been suggested that the palatal teeth in snakes might be neomorphic. that is. not homologous to the generally simpler teeth of nonophidian squamates (Cundall \& Greene. 2000). Clearly, the ability to re-evolve teeth will affect interpretations of the polarity and homology of palatal teeth across groups.

Another phylogenetic issue concerns the putative independent occurrence of teeth on different palatal elements. Some researchers have coded the presence or absence of teeth on each palatal element as independent characters in phylogenetic studies. However. Estes et al. (1988) have questioned the independence of teeth distributed on different palatal bones. and our survey supports their interpretation. This is consistent with the idea of a continuous developmental field generating tooth development. According to this model. tooth development would then be repressed from anterior to posterior in those taxa that lack a full palatal dentition.

Within higher snakes. most basal taxa appear to exhibit a fairly uniform distribution of teeth on the palatal elements, but colubroids exhibit variability in the posterior extent of the palatal dentition (Fig. 26) rather than the anterior extent, as is seen in lizards. Thus, variability in palatal tooth distribution does appear to be related to directional constraints in tooth expression. but the direction differs between nonophidian and ophidian groups.

Several features of the palatal dentition may be important to the specific phylogenetic issue of snake origins within Squamata. First, one general distinction between the palatal dentitions of ophidians and most nonophidian squamates is the uniformity of the tooth arrangement in the 
former. Even in taxa with a highly developed palatal dentition, such as Iguana, the palatal teeth are arranged in a less orderly fashion than the marginal teeth (Fig. IC). In contrast, the palatal dentition of higher snakes is virtually identical in organization to the marginal dentition. This degree of organization has an obvious functional basis in the palate's role during ingestion of large prey items by alethinophidian snakes (Boltt \& Ewer, 1964; Frazzetta, 1966; Cundall \& Gans, 1979); however, phylogenetic correlations have also been suggested. The linear, highly organized palatal dentition of Lanthanotus borneensis, in addition to its recurved teeth, led McDowell and Bogert (1954) to infer either a functional or an evolutionary relationship between Lanthanotus and snakes. In both groups, the marginal teeth are pointed and recurved, possess a small medullary foramen, vertical striations at the base (we find this only rarely in snakes), and replace alternately. Furthermore, they note that Lanthanotus is the only extant "lizard" with a snake-like arrangement of palatal teeth (although the extinct Saniwa ensidens and mosasaurs are also similar in this regard). We observed that this arrangement, at least on the pterygoid bones, is also shared to a degree by Shinisaurus crocodilurus.

Estes et al. (1970) noted that both Lanthanotus and the fossil snake Dinilysia possess palatal dentitions similar to those of extant snakes but also emphasized key differences. Compared to most snakes (including relatively basal taxa such as $C y$ lindrophis), the palatal teeth in these taxa are comparatively smaller than the marginal teeth, are arranged in a more curvilinear row, and do not extend to the anterior portion of the palatines.

Cundall and Greene (2000) suggested that the absence of palatal teeth is plesiomorphic for snakes based on the lack of palatal teeth in scolecophidians. In addition, they note morphological dissimilarity between lizard and snake palatal teeth, and disparity between marginal and palatal teeth in nonophidian lizards as opposed to the more uniform condition seen in snakes. In the absence of any scleroglossan lizard showing detailed similarity to snakes in these respects, they raise the possibility that palatal teeth in snakes may be neomorphic.

Although there is some dissimilarity between the palatal and marginal teeth in some nonophidian lizards, we also observed numerous examples of detailed morphological similarity in palatal and marginal teeth, indicating a level of homology between these structures (e.g., Figs. 3D, E; 9C, D; 11D, E; 16C, D). In addition, both Lanthanotus and Shinisaurus possess moderately long, well-organized rows of recurved palatal teeth that bear some resemblance to the palatal tooth rows seen in snakes. As in higher snakes, palatal teeth in both Lanthanotus and Shinisaurus are attached within deep, longitudinal grooves and rely on substantive deposition of attachment tissue to achieve ankylosis. These teeth are smaller than their marginal counterparts, but the fossil snake Dinilysia exhibits a similar size disparity (Estes et al., 1970). Lanthanotus is also similar to snakes in having teeth separated by interdental ridges (at least on the palatal bones) and in the possession of a large alveolar foramen. While we do not propose either Lanthanotus or Shinisaurus as the sister group to snakes, we believe these similarities should be considered when evaluating the hypothesis of a neomorphic origin for the palatal teeth of snakes.

As discussed above, our study of the squamate palatal dentition is also relevant to the proposed homologous condition of thecodonty in support of a snake-mosasaur clade (Lee, 1997a) or pertaining to squamates more generally (Caldwell et al., 2003). Specifically, our results indicate the widespread occurrence of tooth implantation within resorbed bony cavities, and this is not a condition unique to snakes and mosasaurs. Whether such modes of attachment are broadly interpreted as thecodonty will depend on future detailed histological studies of attachment tissues and implantation in many more taxa.

Finally, this survey has revealed some patterns of variability that could be considered as potential characters in future phylogenetic studies of squamates. These include the occurrence of palatal teeth in single rows versus clusters versus multiple rows, varying posterior extent of the palatal tooth row in snakes, varying palatal tooth size in snakes (relative to the marginal teeth and within the palatal tooth row itself), and orientation of the palatal teeth in snakes.

\section{Acknowledgments}

We thank Jose Rosado for loan of skeletal specimens; Emma Dahl, Angela Marion, and Beth Bastiaans for laboratory assistance; Betty 
Strack for assistance with SEM; Jessie Maisano for CT image processing; Jim Schulte and Omar Torres-Carvajal for checks on remote specimens; Kurt Schwenk for Lanthanotus histology; Alan Resetar and Jamie Ladonski for help with specimen access, selection and facilities; and Olivier Rieppel and Eric Hilton for discussions about squamate dentition. David Cundall, Harry Greene, and Janet Voight provided helpful criticisms that improved the manuscript. This research was supported by NSF grants DEB0235628 and EF-0334961 to MK.

\section{Literature Cited}

Arnold, E. N. 1973. Relationships of the Palaearctic lizards assigned to the genera Lacerta, Algyroides and Psammodromms (Reptilia: Lacertidae). Bulletin of the British Museum of Natural History, 25(8): 289-366.

Bell, C. J., S. E. Evans, and J. A. Maisano. 2003. The skull of the gymnophthalmid lizard Neusticurus ecpleopus (Reptilia: Squamata). Zoological Journal of the Linnean Society, 139(2): 283-304.

Boltt, R. E., and R. F. Ewer. 1964. The functional anatomy of the head of the puff adder, Bitis arietons (Merr.). Journal of Morphology, 114: 83-106.

Caldwell, M. W. 1996. Ontogeny and phylogeny of the mesopodial skeleton in mosasauroid reptiles. Zoological Journal of the Linnean Society, 116: 407-436.

1999. Squamate phylogeny and the relationships of snakes and mosasaluroids. Zoological Journal of the Linnean Society, 125: 115-147.

Caldwell, M. W., L. A. Budney, and D. O. LamourEUX. 2003. Histology of tooth attachment tissues in the Late Cretaceous mosasaurid Platecurpus. Journal of Vertebrate Paleontology, 23(3): 622-630.

Caldwell, M. W., and M. S. Y. Lee. 1997. A snake with legs from the marine Cretaceous of the Middle East. Nature, 386: 705-709.

Conrad, J. L. 2004. Skull, mandible, and hyoid of Sliniscams crocodilums Ahl (Squamata, Anguimorpha). Zoological Journal of the Linnean Society, 141: 399434.

CoOper, J. S. 1966. Tooth replacement in the Slow worm (Anguis frugilis). Journal of Zoology, London, 150: $235-248$.

Cooper, W. E., and L. J. Vitt. 2002. Distribution, extent, and evolution of plant consumption by lizards. Journal of Zoology, London, 257: 487517.

Cundall, D., and A. Deufel. 1999. Striking patterns in booid snakes. Copeia, 1999(4): 868-883.

Cindoli, D., and C. Gans. 1979. Feeding in water snikes: an electromyographic study. Journal of Experimental Zoology, 209: 189-208.
Cundall, D., And H. W. Greene. 2000. Feeding in snakes, pp. 293-333. In Schwenk, K., ed., Feeding: Form, Function, and Evolution in Tetrapod Vertebrates. Academic Press, San Diego, California.

Cundall, D., V. Wallacu, and D. A. Rossman. 1993. The systematic relationships of the snake genus Anomochilus. Zoological Journal of the Linnean Society, 109: 275-299.

DE Querroz, K. 1987. Phylogentic systematics of iguanine lizards. University of California Publications in Zoology, 118: 1-203.

Deufel, A., and D. Cundall. 1999. Do booids stab prey? Copeia, 1999(4): 1102-1107.

, 2003. Feeding in Atractaspis (Serpentes: Atractaspididae): A study in conflicting functional constraints. Zoology, 106(1): 43-61.

Edmund, A. G. 1960. Tooth replacement phenomena in the lower vertcbrates. Contributions of the Life Sciences Division of the Royal Ontario Museum, 52: 1-190.

1969. Dentition, pp. 117-200. In Gans, C., A. d'A. Bellairs and T. S. Parsons, Biology of the Reptiles Vol. 1. Academic Press, New York.

Estes, R., K. de Queiroz., And J. A. Gauthier. 1988. Phylogenetic relationships within Squamata, pp. 119-281. In Estes, R., and G. Pregill, eds., Phylogenetic Relationships of the Lizard Families. Stanford University Press, Stanford, California.

Estes, R., T. H. Frazzlitta, and E. E. Williams. 1970. Studies on the fossil snake Dinilysia patagonica Woodward: Part 1. Cranial morphology. Bulletin of the Museum of Comparative Zoology, 140(2): 25-73.

Etheridge, R., And K. DE Queiroz. 1988. A phylogeny of lguanidae, pp. 283-367. In Estes, R. and G. Pregill, eds., Phylogenetic Relationships of the Lizard Families. Stanford University Press, Stanford, California.

Evans, S. E. 2003. At the feet of the dinosaurs: the origin, evolution and early diversification of squamate reptiles (Lepidosauria: Diapsida). Biological Reviews, Cambridge, 78: 513-551.

Frazzetta, T. H. 1966. Studies on the morphology and function of the skull in the Boidae (Serpentes) Part II. Morphology and function of the jaw apparatus in Python sehae and Python moluris. Journal of Morphology, 118: 217-296.

Frost, D. R., and R. Etheridge. 1989. A phylogenetic analysis and taxonomy of iguanian lizards (Iguania: Squamata). Miscellaneous Publications, University of Kansas Museum of Natural History, 81: 1-65.

Frost, D. R., D. Janies, P. Le F. N. Mouton, and T. Titus. 2001. A molecular perspective on the phylogeny of the girdled lizards (Cordylidae, Squamata). American Museum Novitates, 3310: $1-10$.

Gaengler, P. 2000. Evolution of tooth attachment in lower vertebrates to tetrapods, pp. 173-185. In Teaford, M. F., M. M. Smith, and M. W. J. Ferguson, eds., Development, Function, and Evolution of Teeth. Cambridge University Press, Cambridge. 
Gans, C. 1952. The functional morphology of the eggeating adaptations in the snake genus Dasypeltis. Zoologica, 37(4): 209-244.

GooD, D. A. 1987. A phylogenetic analysis of cranial osteology in the gerrhonotine lizards. Journal of Herpetology, 21(4): 285-297.

Greene, H. W. 1982. Dietary and phenotypic diversity in lizards: Why are some organisms specialized?, pp. 107-128. In Mossakowski, D., and G. Roth, eds., Environmental Adaptation and Evolution. Gustav Fischer, Stuttgart.

Greer, A. E. 1970a. A subfamilial classification of scincid lizards. Bulletin of the Museum of Comparative Zoology, 139(3): 151-184.

$1970 \mathrm{~b}$. The systematics and evolution of the subsaharan Africa, Seychelles, and Mauritius scincine scincid lizards. Bulletin of the Museum of Comparative Zoology, 140(1): 1-24.

1977. The systematics and evolutionary relationships of the scincid lizard genus Lygosoma. Journal of Natural History, 11: 515-540.

Greven, H., And G. Clemen. 1980. Morphological studies on the mouth cavity of urodeles VI. The teeth of the upper jaw and the palate in Andrias davidianus (Blanchard) and $A$. japonicus (Temminck) (Cryptobranchidae: Amphibia). Amphibia-Reptilia, 1: $49-59$.

Hallermann, J. 1998. The ethmoidal region of Dibamus taylori (Squamata: Dibamidae), with a phylogenetic hypothesis on dibamid relationships within Squamata. Zoological Journal of the Linnean Society, 122: $385-426$.

Hotton, N. III. 1955. A survey of adaptive relationships of dentition to diet in the North American lguanidae. The American Midland Naturalist, 53(1): 88-114.

KARdonG, K. V. 1990. General skull, bone, and muscle variation in Agkistrodon and related genera, pp. 573-581. In Gloyd, H. K., and R. Conant, eds., Snakes of the Agkistrodon Complex. Society for the Study of Amphibians and Reptiles, Ithaca, New York.

KeARNey, M., AND O. Rieppel. In press. An investigation into the occurrence of plicidentine in the teeth of squamate reptiles. Copeia.

Kley, N. J. 2001. Prey transport mechanisms in blindsnakes and the evolution of unilateral feeding systems in snakes. American Zoologist, 41: 13211337.

Kluge, A. G. 1993a. Aspidites and the phylogeny of pythonine snakes. Records of the Australian Museum Supplement, 19: 1-77.

1993b. Calabaria and the phylogeny of erycine snakes. Zoological Journal of the Linnean Society, 107: 293-351.

LANG, M. 1991. Generic relationships within Cordyliformes (Reptilia: Squamata). Bulletin van het Koninklijk Belgisch Instituut voor Natuurwetenschappen, 61: 121-188.

LEE, M. S. Y. 1997a. On snake-like dentition in mosasaurian lizards. Journal of Natural History, 31: 303-314. 1997b. The phylogeny of varanoid lizards and the affinities of snakes. Philosophical Transactions of the Royal Society of London Series B, 352(1349): 53-91.

1998. Convergent evolution and character correlation in burrowing reptiles: Towards a resolution of squamate relationships. Biological Journal of the Linnean Society, 65(4): 369-453.

LeE, M. S. Y., and M. W. Caldwell. 2000. Adriosaurus and the affinities of mosasaurs, dolichosaurs, and snakes. Journal of Paleontology, 74(5): 915-937.

LeE, M. S. Y., AND J. D. Scanlon. 2002. Snake phylogeny based on osteology, soft anatomy and ecology. Biological Reviews, 77(3): 333-401.

Maclean, W. P. 1974. Feeding and locomotor mechanisms of teiid lizards; functional morphology and evolution. Papeis Avulsos de Zoologia, 27(15): $179-213$.

MARX, H., AND G. B. RABB. 1970. Character analysis: An empirical approach applied to advanced snakes. Journal of Zoology, London, 161: 525-548.

1972. Phyletic analysis of fifty characters of advanced snakes. Fieldiana (Zoology), 63(1153): $1-321$.

Marx, H., G. B. RABB, And S. J. ARnold. 1982. Pythonodipsas and Spalerosophis, colubrid snake genera convergent to the vipers. Copeia, 1982(3): $553-561$.

MCDowell, S., And C. Bogert. 1954. The systematic position of Lanthanotus and the affinities of the anguinomorphan lizards. Bulletin of the American Museum of Natural History, 105(1): 1-142.

Montanucc1, R. R. 1968. Comparative dentition in four iguanid lizards. Herpetologica, 24: 305-315.

Osborn, J. W. 1984. From reptile to mammal: Evolutionary considerations of the dentition with emphasis on tooth attachment. Symposium of the Zoological Society of London, 52: 549-574.

OWEN, R. 1840 1845. Odontography. Hippolyte Bailliere, London.

Pellegrino, K. C. M., M. T. Rodrigues, Y. YoneNAGA-YASSUdA., AND J. W. Sites. 2001. A molecular perspective on the evolution of microteiid lizards (Squamata, Gymnophthalmidae), and a new classification for the family. Biological Journal of the Linnean Society, 74: 315-338.

Peyer, B. 1968. Comparative Odontography. University of Chicago Press, Chicago, Illinois.

Prescli, W. 1974. A survey of the dentition of the macroteiid lizards (Teiidae: Lacertilia). Herpetologica, 30: 344-349.

1988. Phylogenetic relationships of the Scincomorpha, pp. 471 -492. In Estes, R., and G. Pregill, eds., Phylogenetic Relationships of the Lizard Families. Stanford University Press, Stanford, California.

RiCQLĖs, A. D., AND J. R. Bolt. 1983. Jaw growth and tooth replacement in Captorhinus aguti (Reptilia: Captorhinomorpha): A morphological and histological analysis. Journal of Vertebrate Paleontology, 3(1): 7-24. 
Rieppel. O. 1977. Studies on the skull of the Henophidia (Reptilia: Serpentes). Journal of Zoology. London. 181: 145-173.

197s. Tooth replacement in anguinomorph lizards. Zoomorphologie, 91(1): 77-90.

19s0. The phylogeny of anguinomorph lizards. Denkschriftenkonmission der Schweizerischen Naturforschenden Gesellschaft, 94: 1-\$6.

2001. Tooth implantation and replacement in Sauropterygia. Palaeontologische Zeitschrift. 75(2): $207-217$

Rieppel. O.. AND M. KEARIEY. 2001. The origin of snakes: Limits of a scientific debate. Biologist. $48(3)$ : $110-114$

ROMER. A. S. 1956. Osteology of the Reptiles. Lniversity of Chicago Press. Chicago. Illinois.

Rōse. C. 1893. Leber die Zahnentwicklung von Chamueleon. Anatomischer Anzeiger. 8: $566-677$.

SAltzky, A. H. 19\$1. Hinged teeth in snakes: An adaptation for swallowing hard-bodied prey. Science. 212: $346-349$.

SCANLON. J. D.. AXD M. S. Y. LEE. 2000. The Pleistocene serpent 1 onambi and the early evolution of snakes. Nature. $403:+16+20$.

2002 . Varanoid-like dentition in primitive snakes (Madtsoiidae). Journal of Herpetology. 36(1): $100-106$.

SCHWE $\backslash$. K. I000. Feeding in lepidosaurs. pp. 175291. In Schwenk. K.. ed.. Feeding: Form. Function. and Erolution in Tetrapod Vertebrates. Academic Press. San Diego. California.

SCOTT. J. H.. AND X. B. B. Sivoss. 1964. Introduction to Dental Anatomy. E. \& S. Livingstone Ltd. Edinburgh and London.

Sumth. H. M. 1958. Evolutionary lines in tooth attachment and replacement in reptiles: Their possible significance in mammalian dentition. Transactions of the Kansas Academy of Science. 61(2): $216-225$.

Smith. M. A. 1943. The Fauna of British India. Ceylon and Burma. Including the Whole of the IndoChinese Subregion: Reptilia and Amphibia. Vol. III. Taylor and Francis. London.

Surth. M. M.. IND M. I. Contes. 1998. Evolutionary origins of the vertebrate dentition: Phylogenetic patterns and developmental evolution. European Journal of Oral Sciences. 106(Supplement 1): $452-500$
2000. Evolutionary origins of teeth and jaws: Developmental models and phỵlogenetic patterns. pp. 133-151. In Teaford. M. F.. M. M. Smith.. and M. W. J. Ferguson. eds.. Development. Function. and Evolution of Teeth. Cambridge Lniversity Press. Cambridge.

Stock. D. W. 2001. The genetic basis of modularity in the development and evolution of the vertebrate dentition. Philosophical Transactions of the Roval Society of London. Series B. 356(1414): 16:31653.

TEX CATE. A. R. 1976. Derelopment of the periodontal membrane and collagen turnover. pp. 281-289. In Pode. D. F. G.. and M. V. Stack. eds., The Eruption and Occlusion of Teeth. Butterworths. London.

Tex CAte. A. R.. ANd H. R. Mills. 1972. The development of the periodontium: The origin of alveclar bone. Anatomical Record. 173(1): 6977.

Throckiortos. G. S. 1976. Oral food processing in two herbivorous lizards, Iguana iguma (Iguanidae) and Lromastix aeglptius (Agamidae). Journal of Morphology: 148: $36: 390$.

TouEs. C. S. 1874. On the development of the teeth of the newt. frog. slowworm, and green lizard. Philosophical Transactions of the Royal Society of London. 165: 285-296.

1875 . On the structure and development of the teeth of Ophidia. Philosophical Transactions of the Roval Society of London. 165: 297-302.

LYDERWOOd. G.. A\D E. KoCHu. 1993. On the affinities of the burrowing asps Atractaspis (Serpentes: Atractaspididae). Zoological Joumal of the Linnean Society. 107: 3-64.

VAETh, R. H.. D. A. Rossmal. AND W. ShOOP. 1985. Observations of tooth surface morphology in snakes. Joumal of Herpetology. 19(1): 20-26.

VAI Dexblrgh. J.. A\D J. C. Thompsox. 1908. Description of a new species of sea snake from the Philippine Islands. with a note on the palatine teeth in the Proteroglypha. Proceedings of the California Academy of Sciences (Fourth Series). 3: +1 - 18 .

VORIS. H. K. 1966. Fish eggs as the apparent sole food item for a genus of sea snake. Emidoceplualus (Krefft). Ecology. 47(1): 152-154.

Ziher, H.. AND O. Rieppel. 1999. Tooth implantation and replacement in squamates. with special reference to mosasaur lizards and snakes. American Museum Vovitates, 3271: 1-19. 


\section{Appendix. List of Specimens Examined}

"Lizards": Abronia deppii FMNH 38523. Acanthodactylus pardalis FMNH 63073. Acanthosaura crucigera FMNH 222259; A. lepidlogaster FMNH 229477. Acontias meleagris orientalis FMNH 187063. Aeluroscalabotes felimas FMNH 188235. Agama agama FMNH 22190, 22191, 22189. Amblyrhynchus christatus FMNH 15072, 15073, 22042, 22094, 22100, 22213, 22374. Alopoglossus angulatus KU 112190, 122144. Ameiva ameiva FMNH 22294, NMNH 257529, 292416, 292425; A. chrysoldema NMNH 225056, 259531; A. chrysolaena chrysolaema FMNH 51622; A. corax NMNH 236837; A. desechensis NMNH 221738; $A$. dorsalis FMNH 22326; A. festiva NMNH 319265; $A$. griswoldi NMNH 218349; $A$. lineolata NMNH 259533; A. fuscala NMNH 158908: $A$. pleei NMNH 236375; $A$, pluviamotata NMNH 236524; $A$. quadrilineata NMNH 313852; $A$. tacniura NMNH 225058. Amphiholurus barbatus FMNH 211265, 22451, 51647, 51648, 229937: A. muricatus FMNH 97700; $A$. sp. FMNH 232739. Ampliglossus splendidus FMNH 72806. Anniella pulchra nigra FMNH 213666. Anolis carolinensis FMNH 229897, 229898; A. cristatellus FMNH 130108, 130111; A. equestris FMNH 31312, 229922; $A$. sp. FMNH 98636. Aspidoscelis deppei FMNH 98486 98492; $A$. exsanguis FMNH 223698; A. gularis FMNH 9849398497; A. motaguae FMNH 207870; . ocellifer FMNH 44150, 44151; A. perplexus FMNH 98504; $A$. sexlineatus FMNH 98505 98507, 222222; A. tigris gracilis FMNH 98498-98503, 115480, 161622; $A$. sp. FMNH 98470 98472, 98474-98482. Bachia heteropa FMNH 49880; $B$. trisanale FMNH 206114. Barisia imbricata NMNH 32166. Basiliscus basiliscus FMNH 16489, 22290; B. plumifrons FMNH 228376, 231609, 257162; B. vitlatus FMNH 4500. 31277, 98362, 98363, 207871, 211919, 228396: B. sp. FMNH 98360, 98939, 211858, 217638. Brachylophus fasciatus FMNH 210158. Bradypodion fischeri FMNH 229598, 229961. Bronchocela cristatella FMNH 52391. 52397, 63747. Callisaums draconoides inusitamus FMNH 98364 98367; C. draconoides ventralis FMNH 1936. $C$. flavipunctatus FMNH 8452: C. maculatus FMNH 223689. Calotes enma FMNH 196208: C. versicolor FMNH 229471-229474, 196115, 229475, 229476; C. sp. FMNH 236133. Celestus harbouri KU 225857; C. costatus FMNH 13254, NMNH 259470; $C$. crusculus NMNH 244580; $C$. curtissi KU 226038; C. darlingtoni KU 226519; C. hewardi KU 226529; C. stermus NMNH 259471, 259472. Chalcides ocellatus NMNH 313452; C. ocellatus ocellatus FMNH 154619, 164674, 167941, 22385, 31294. Chamaeleo gracilis FMNH 22192, 25407, 31369, 31370; C. jacksonii FMNH 22040, 206753, 229611, 229968, 257482, 257483; C. melleri FMNH 98769, 98770, 98878; $C$. oweni FMNH 25408; $C$. sp. FMNH 22008, 22391, 257102. Chlamydosaurus kingii FMNH 51709. Coleonyx brevis FMNH 209432: C. mitratus FMNH 5053; C. variegatus FMNH 98353, 98354, 209433, 209434, 216543, 216544. Colobosaura modesta USNM 341978. Conolophus subcristatus FMNH 15071, 22009, 22203, 22206, 22208, 22406, 37317, 98859.
Cophosaurus texanus FMNH 98383, 98384. Cordylus gigunteus FMNH 31283, 211837, 257130; C. trepidosternum FMNH 251836; C. sp. FMNH 204662, 213252. Corucia zebrata FMNH 257163. 258800, NMNH 306212. Corytophanes cristatus FMNH 206165, 211939, 229589, 229601, NMNH 319262, 319226, 559596; C. pericarinatus KU 93456, 190773. Cosymbotus platyurus FMNH 209452, 209453. Crotaphytus collaris FMNH 8543, 8950, 22236. 22301-22303, 98368, 98369, 210169. Ctenosaura acanthura FMNH 31298; C. similis FMNH 6175, 31323, 196144, 211849; C. sp. FMNH 22103, 98371, 98373, 198379 , 211835, 213330; Ctenosaurallguana sp. FMNH 98370. Cychira cornuta FMNH 14801, 22383, 216626, 218645. 250424; C. cormuta stejnegeri FMNH 213069. Cyrtodactyhis cavernicolis FMNH 131508; C. malayamus FMNH 188211; C. pulchellus FMNH 209435; C. scaber FMNH 236232. Diplodactylus clderi FMNH 213418. Diploglossus millepunctatus FMNH 19348. Diploluenus bibronii FMNH 7947. Dipsosatus dorsalis FMNH 98374 98376 , 206188, 249738, 249783, 249785, 249786, 257011; D. dorsalis sonoricnsis FMNH 98377, 98378; D. sp. FMNH 229599. Draco bimaculatus FMNH 52212; D. cormutus FMNH 150616: D. haematopogon FMNH 150628; $D$. lineatus FMNH 142246; D. maculatus FMNH 180834; $D$. melanopogon FMNH 184776, 184868; D. obscurus FMNH 150698; D. quinquefasciatus FMNH 159679, 213405; D. volans FMNH 52204, 77665, 143024. Echinosaura horrida FMNH 177475. Egernia cuminghami FMNH 31041, 75329; E. stokesii FMNH 51707. Elgaria coerulea NMNH 8626, 11584; E. kingii NMNH 292554; E. multicarinata NMNH 13783, 313412; E. sp. FMNH 213397. Emoia atracostatum KU 20605, NMNH 534092: E. caenuleocaula NMNH 323705; E. cyamura NMNH249754; E. jakati NMNH 512285: E. kuekenthali notomoluccense FMNH 134594; E. nigromarginata NMNH 334059; E. trossula NMNH 249744, 249745; E. sp. FMNH 236132. Enjalioides laticeps FMNH 31354: E. palpebralis FMNH 40008. Eumeces algeriensis FMNH 229652; E. brevirostris FMNH 111614; E. brevirostris inchbitus FMNH 114201; E. copei FMNH 98509, 98510; E. fasciatus FMNH 9851]98513. 118853: YPM 12689: E. laticeps FMNH 98514. 218437; E. latiscutatus FMNH 55511: E. obsoletus FMNH 98515-98521, 196127: E. ochoterenae FMNH 114493. Furcifer pardalis FMNH 250433: $F$. verrucosus FMNH 72789. 76096. G. sp. FMNH 211251. Gehyra mutilata FMNH 209436, 209437. Gokko gecko FMNH 14448. 31008, 31013, 209438, 213417, 216495: G. sp. FMNH 216516. Gerrhonotus liocephalus FMNH 22452, NMNH 25085; G. monticolus KU 125410; G. sp. FMNH 22105. Gerrhosaurus flavigularis (personal collection of Kevin de Queiroz 134); G. nigrolineatus 15373, 15375; G. validus FMNH 22293, 215858, 228400. Gonocephalus grandis FMNH 188196; G. liogaster FMNH 151542. 188172. 63709, 210099. Gymnophthalmus speciosus FMNH 165771, 176990. Helodema horridum FMNH 22038, 31366, 98776, 250611; H. suspectum FMNH 22232, 
98468,98469, 98774,98775, 218077, 229925, TNHC 62767; H. sp. FMNH 22102. Hemida'ty/us brookii FMNH 209442, 209443; H. frenutus FMNH 98356, 209444 209447; H. garnotii FMNH 206754: H. leschenaultii FMNH 98355, 196101. Henithecontr.x suticinctus FMNH 209441. Heteronotia binoei FMNH 195572, 195573. Holbrookia maculata FMNH 98380, 98381; $H$. maculata? FMNH 98385; H. maculata elegans FMNH 98386 98390; H. sp. FMNH 98379, 98382, 98391. Igluana iguan $\mathrm{FMNH}$ 2694, 22041, 22085, 22291, 22492, 51646. $51679,51680,128431,196847,207655,211878,211937$. 222373. Isopachys roulei FMNH 196171-196172, $196197-$ 196200. Japalura swinhomis FMNH 207644, 195575. 207672. Kentropix calcarata FMNH 31352, 42523, NMNH 292411. 292412. Lacerta lepida FMNH 22098, 22267. 83665, 229612 NMNH 279861; L. viridis YPM 12858, KU 47164. NMNH 258747, 284452. Laenunctus longipes FMNH 213398. Lanthanotus borneensis FMNH 134711, 148589, 151714, MCZ 8305. Leiocephalus carinatus armouri FMNH 22754. Leiolepis belliana FMNH 229469. 229470. Lepidophyma flavomaculatum FMNH 22299; L. gaigae FMNH 98560. Lerista elegans FMNH 11319. Lialis burtonis FMNH 22109. Liolaemus chiliensis FMNH 24023. Ligosoma bonringii FMNH 35409, 35411, 196173, NMNH 72277; L. fernandi FMNH 12763. Mahuya cumingi NMNH 498999; M. elegats. NMNH 336438; M. gravenhorsti NMNH 336440; M. mabouia KU 113519; M. multicarinata NMNH 509420; M. multifaseiata FMNH 120304, 171520, 229938-229940; M. rulis FMNH 120270, 150823: M. seychellensis NMNH 297506: M. sp. FMNH 22193, 98525, 98526. Meroles anchietae FMNH 82558. Moloch horridus FMNH 233214. O. sp. FMNH 9270. Ophionorus brevipes FMNH 141550; $O$. persicus FMNH 141557. Ophisaterus apodus FMNH 22088, 22359, 161121, 216745, YPM 12870; O. attentuatus FMNH 98466, 98467, 98911, 207671; O. harti FMNH 24298; O. ventralis FMNH 31006. Pachydactylus bibronit FMNH 209448-209451. Petrosalurus mearnsi FMNH 216151; P. thatassinus FMNH 216154, 229972. Pholidobolus montium KU 141610-141617. Phrynosoma asio FMNH 31315; $P$. cormutum FMNH 31311. 98392. 98393; P. coronatum blainvilli FMNH 22394, 98954; $P$. hermandesi FMNH 98394; $P$. mcallii FMNH 216162; $P$. platyrhinos FMNH 31289; P. platyrhinos platyrlinos FMNH 216163; P. solure FMNH 22415, 98395, 98396. Phyllockutylus homolepilurus FMNH 98357, 98358; $P$. lanei FMNH 98359: P. platurus FMNH 252870. Physignathus cocincinus FMNH 255017, 98914; P. lesuenti FMNH 22093. 22246, 22245. Plica plica FMNH 31355; $P$. umbra KU 135267, NMNH 204266. Podarcis lilford FMNH 22295; P. sicula FMNH 800212: P. sicula cazzat FMNH 66902: $P$. sicula cetti FMNH 21645; $P$. Laurica FMNH 213390. Pogona vitticeps FMNH 257083. Polychrus femoralis FMNH 81405. Proctoportus bolivianus FMNH 204231: P. melectgris FMNH 28049; P. pachlum FMNH 134388: P. striatus FMNH 177078. Ptychozoon lionotum FMNH 217383. Ptyodactylus hasselyuisti FMNH 210095. Sutor angustus FMNH 216166; S. grandaevus FMNH 216152. Sauromalus ater or obesus FMNH
31015; S obesus FMNH 22248, 229860; S. obesus townsendi FMNH 98397. Sceloporus acanthinus FMNH 20156; S. acneus FMNH 98398. 98399. 98401; S. asper FMNH 32041; S. clarkii FMNH 98402-98414; S. grammicus microlepidotus FMNH 98418, 98425-98431; S. horridus alhiventris FMNH 98422; S. lunaci FMNH 64687, 68623, 68627; S. lundelli FMNH 49225, 49226; S. magistel FMNH; S. magister magister FMNH 216159: S. malichiticus FMNH 31039, 210648-210650; S. melanorhinus FMNH 33348, 98424; S. merriami merriani FMNH 216153; S. nelsoni FMNH 98433, 98434; S. ochoterente FMNH 102118; S. olivaceus FMNH 216160; S. orcutit orcutti FMNH 216158; S. poinsettii mucrolepis FMNH 216157; S. prrhocephalus FMNH 98435; S. seculuris FMNH 98436, 216135; S. sceloportus FMNH 98415; $S$. serrifer cyanogenys FMNH 98416, 98417; S. siniferus FMNH 98437, 98438, 106501, 116292: S. spinosus FMNH 98439, 98440; S. spinosus spinostes FMNH 216156; $S$. torquatus torquatus. FMNH 216165; S. unchulatus FMNH 98442. 98444; S. undulatus hy'acinthintus FMNH 98443; S. undulatus tristichus FMNH 98441; S. utiformis FMNH 98445-98451; S. variabilis variabilis FMNH 98452. Scincella forbesora FMNH 98522; S. lateralis KU 13932 , 16437, NMNH 332758, 451674; S. melanosticta FMNH 180970. Sepsina angolensis FMNH 142793. Shinisaurus crocodilurus FMNH 215541, UF 62497, 62536. Sphenomorphus cyolacmus FMNH 120244, 239877; S. hallieri FMNH 243813; S. multisquamatus FMNH 138537 , 239895: S. nigrolabris FMNH 14255; S. subanus FMNH 239825. Stenocercus aculeatus KU 121093; S. apurimacus KU 134278, 134284; S. arentuitus FMNH 40589; $S$. boettgeri KU 134014, NMNH 299613; S. chysopygus KU 133895, 133906; S. crassiculudatus KU 133859, 163602; S. empetrus KU 134401, 134403, 134404; S. festae KU 134595, 134603; S. formosus 134110; S. guentheri KU 147319, 147326, NMNH 222584; S. lumeralis KU 134001. 134004; $S$. iriclescens KU 142695, NMNH 200912, 222585; S. ochoal KU 133878, 133884; S. omatus KU 121128 , 134128; S. pectinatus KU 187794, 187798; S. praeornatus KU 134229; S. rhodomelas KU 152184, 152186, NMNH 222586, 222587: S. scapularis FMNH 40612; S. trachycephalus NMNH 313935-313940; S. vartus 121135, 134563. 142704, NMNH 201321. Teius teyou FMNH 170853. Thecadactylus rapicaudus FMNH 13006, 22212, 209454 209456. Tiliqua nigrolutea FMNH 22498, 23149; T. scincoides FMNH 22091, 22092, 22779, 51702, 51710, 73343, 229975: T. rugosus FMNH 22361. 22470. 22490, 31353, 195570. Trapelues mutahilis FMNH 620. 58293 , $58691,58692,62589,63037-63041,63958,66131,66132$, 66136, 67207-67209, 67213, 67222, 72588, 72590-72594. Tretiosaurus bifasciatus FMNH 165837. Tropidophorus herdmorei FMNH 106976, 196201; T. brookei FMNH 16584, 129526, 145910, 167971; T. grayi FMNH 152399; T. micropus FMNH 151530: T. miscminius FMNH 68926; T. perplexus FMNH 7950. Tropidarus atacamensis $\mathrm{KU}$ 161986; T. bogerti NMNH 300598; T. etheridgei KU 186102; T. hoodensis FMNH 22099; T. hygomi NMNH 209644; T. itanhere NMNH 148776; T. melantoplearus KU 136370; T. montamus NMNH 218210: T. occipitulis 
NMNH 222582; $T$. peruvianus FMNH 34191, KU 134695: T. spimulosus KU 97856; T. theresoides KU 162012; $T$. thoracicus KU 163721; T. tigris KU 163753; T. torquatus NMNH 208276, 208278. Tupinambis teguixin FMNH 18, 22393, 31279, 98759, 161555, 217382, 218521; $T$. sp. FMNH 31027. Typhlacontias gracilis NMNH 159338. T. ngamiensis FMNH 142787. Typlilosanrus lineatus FMNH 142756. Uma notata notala FMNH 26183, 26228. Uromastyx acanthinura FMNH 229935, 229959; $U$. aegyptia FMNH 31030, 31031, 63961, 22247, 22214; $U$. hardwickii FMNH 98934. U. sp. FMNH 250684. Urosalurus bicarinatus FMNH 98455: $U$. ornatus FMNH 98456. Uroscanodon supereiliosa NMNH 290895. Urosanus ornatus lateralis FMNH 98458-98460. Uta stansburituna FMNH 98461; U. stanshuriana taylori FMNH 98462-98465; $U$. sp. FMNH 98453, 98454. Varames acanthurus FMNH 218083: V. albigularis FMNH 17143; V. dumerilii FMNH 223194, 228151: V. exanthematicus FMNH 51683, 212985, 228398, 229530; V. gouldii FMNH 31340, 250434: V. grisens FMNH 31308; V. komodoensis FMNH 22199, 22200; $V$. nelulosus FMNH 22495; $V$. niloticus FMNH 12300, 17144-17146, 22084; $V$. olivaceus FMNH 223181: $V$, ornatles FMNH 45087, 58935; $V$. prasinus FMNH 229907, 229966, 250848; V. rudicollis FMNH 98943, 98946, 98949, 131538; V. salvator FMNH 22204, 31358, 98944, 121145, 211938, 229928, 236130; V. timorensis FMNH 250436; V. sp. FMNH 195576, 218834 , 235516. Xantusita vigilis FMNH 22329; $X$. sp. FMNH 22101. Xenosanrus grandis FMNH 211833. Zonosanrus ornatus YPM 12671.

Snakes: Acalyptophis peronii FMNH 201920, 215543. Acanthophis antarcticus FMNH 20769, 213076. Aclulinus meiguensis FMNH 18777; A. spinalis FMNH 24896. Acrantophis dumerili FMNH 228340, 238160. Acrochordus arafurae FMNH 250808: A. gramulatus FMNH 213148$213151,213182,221397,221398,231720,231730,232777$, $232780,232787,232789,232793-232795,232797-232800$, 233200, 233202, 234129, 234131, 234135, 234138, 234139, $234142,234233,234234,234235,242163,242177,242178$, 242186, 242187, 242477-242490, 244291-244296, 11081 , 51711, 51712, 98780; A. sp. FMNH 98957. Adenortinos barbouri FMNH 142636. Afronatrix anoscopus FMNH 58135; A. anoscopus FMNH 58138. Agkistrodon bilineatus FMNH 98906-98909, 154775, 204658, 229689; A. bilineatus taylori FMNH 250435; A. contortrix FMNH 22268. 22365, 23408, 62059, 166644, 167413; A. contortrix phaeogaster FMNH 98623-98631: A. piscivorus FMNH 21636, 22312, 22325, 98897, 98898, 229910. Alltetulla mycterizans FMNH 98554, 98555: A. nasuta FMNH 51713, 98877, 229592; A. prasina FMNH 1605, 15067, 148953, 188517, 252115; A. sp. FMNH 250104. Aipysurus eydouxii FMNH 236522, 245557-245638, 251450, 251452 251469, 251471-251484, unnumbered specimen from series 251450-251484. Alsophis sanctaecrucis FMNH 235. Amblyodipsas unicolor FMNH 74822. Amphiesma craspedogaster FMNH 24788; A. stolatum FMNH 6722. 169407. Anilius scytale FMNH 11175, 35683, 35687. 35688, USNM 204078. Aparallactus hunulatus FMNH 62227; A. werneri FMNH 81061. Arizona elegans elegans
FMNH 6201. Aspidelaps lubricus FMNH 77630; $A$. lubricus hubricus FMNH 204897. Aspidomorphus muelleri FMNH 13889. Aspidura trachyprocta FMNH 98767. 121479, 131369. Atheris chlorechis FMNH 44413; $A$. hispida FMNH 164740; A. nitsehei FMNH 8984, 8987; A. squamigera FMNH 22423, 22424, 98928, 98929. 154890. Atractaspis bibronii FMNH 81140; A. corpulenta FMNH 58069; A. dahome'yensis FMNH 74786; $A$. irregularis FMNH 58409, 62204, 142994; A. microlepidota FMNH1 51682, 58397, 62192. Atractus elaps FMNH 23485; A. erythromelas FMNH 3993; A. latifrons FMNH 11190; A. ventrinaculatus FMNH 3995. Atropoides nummifer FMNH 22454, 27125, 31042. Azemiops feae FMNH 218628. Bitia hydroides FMNH 229792, 229794. Bitis arietuns FMNH 11006, 22258, 22277, 22387, 31316. 98919, 154895, 167057, 196152; B. atropos FMNH 143000; B. caltellis FMNH 17198, 17200, 165150, 187154: B. gabonica FMNH 22254, 51634, 51635, 51698, 166640, 167433; B. heraldica FMNH 166959; B. netsicornis FMNH 3996, 19457, 31003, 98875, 98876, 154776 , 229895, 229896; B. peringueyi FMNH 82544, 82545; B. sp. FMNH 167437. Boa constrictor FMNH 22407, 22427. 22438, 22439, 22458, 31182, 211860, 211926, 216950;B. constrictor constrictor FMNH 11163, 22362, 22372, 22435. 22444, 22453; B. constrictor inperator FMNH 22256. 22323, 22353, 22363, 31188, 166520. Bogertophis suboc'ularis FMNH 75860. Boiga blandingii FMNH 19449 , 121974; B. ceylonensis FMNH 123475; B. cyanea FMNH 180046; B. cynodon FMNH 131814, 145840, 158653. 168006; B. dentrophila FMNH 11128, 31282, 31305, 31347, 145847, 210098, 211908, 211941; B. drapiezii FMNH 131805, 145684, 178613; B. forsteni FMNH 165052: B. irregularis FMNH 98931, 121869, 142119; B. jaspidia FMNH 129437, 148822; B. kracpelini FMNH 127971; B. multonaculata FMNH 6674; $B$. nigriceps FMNH $128150 ; B$. pulverulenta FMNH 44417; $B$. trigonata FMNH 83087, 83089; B. sp. FMNH 212401. Bothriechis marchi FMNH 31291, 31292, 31304; B. schlegelii FMNH 2524, 51688. Bothriopsis pulchra FMNH 165593: B. punctata FMNH 55888. Bothrochilus boat FMNH 13882, 21729. Bothrophthalmus lineatus FMNH 44406. Bothrops alternatus FMNH 51663; B. ammodytoides FMNH 10831; B. asper FMNH 3480, 20641, 23796, 31167, 51689, 197882; B. atrox FMNH 51658; B. burnetti FMNH 9788; B. brazili FMNH 165563; B. cotiara FMNH 51662; B. itapetiningate FMNH 10815; B. jararaca FMNH 69951; B. jararucussu FMNH 51659, 51660; B. microplithalmus FMNH 63740; B. moojeni FMNH 171278; B. neturiedi FMNH 35743, 51661; B. sp. FMNH 9742. Boulengerina annulata FMNH 214756. Bungarus' caeruleus FMNH 165115; B. candidus FMNH 180054: B. ceylonicus FMNH 178377; B. fasciatus FMNH 11542: B. flaviceps FMNH 145854; B. multicinctus FMNH 167970, 213121213127, 213137-213141; B. sp. FMNH 98953. Cacophis harrietae FMNH 97006. Calabaria reinhardtii FMNH 19478, 31372, 191123. Calemeria gervaisii FMNH 15025; C. lencogaster FMNH 71598; C. linnalei FMNH 100870; C. pavimentata FMNH 11528; C. schlegelii FMNH 69977; C. septentrionalis FMNH 7139. Calloselasma rhodostoma 
FMNH 11522. Cancloia aspera FMNH 13915, 21731; $C$. bibroni anstralis FMNH 22997; $C$. carinata FMNH 217065, 249734, 249736, 250097; C. sp. FMNH 250845. Cantoria violace FMNH 250115. Carphophis amoenus FMNH 98527, 98528, 196133, 196140; Carphophis vermis FMNH 8766, 22478, 22479, 98529-98532, 98534. Cansus defilippii FMNH 81133, 81134; C. resimus FMNH 62182. 62183: C. thombeatus FMNH 2268, 51693, 58066, 164744. Cemophora coccinca FMNH 427. Corastes cerastes FMNH 142986, 142990, 142991, 142993-143996. 153114; C. vipera FMNH 22379, 79181, 82300, 154893, 154894, 195969. Cerberus rynchops FMNH 219845 219848, 219850, 219851, 242148, 250103, 250109, 251509-251516. Cerrophidion burbouri FMNH 38503; $C$. godmani FMNH 20264. Charina bottae FMNH 1218, 22348, 31300. Chilomeniscus straminews FMNH 1125. 130286. Chilothinophis corpenteri FMNH 81022, 81032. Chironius carinatus FMNH 21997, 51690, 201009; $C$. exoletus FMNH 61662; C. fuscus FMNH 21998, 98758. Chrysopelea ornata FMNH 11566, 23426, 180063. 252867-252869; C. paradisi FMNH 67300; C. pelias FMNH 98749, 98750; C. sp. FMNH 229593. Clelia clelia FMNH 4448. Clonophis kirtlandii FMNH 16126. Coluber constrictor FMNH 98536, 135284, 191781, 196109, 196187, 196188, 216633; C. constrictor flaviventris FMNH 3275, 22251, 22261, 22347, 23390, 98537, 211857; $C$. florulentus FMNH 153054; C. gemonensis FMNH 21451; C. hippocrepis FMNH 15747: C. jugalaris FMNH 19623. 26383; C. ravergieri FMNH 19617; C. rhodorhachis FMNH 31649; C. rogersi FMNH 19588, 69262; $C$. mubriceps FMNH 22811; $C$. spinolis FMNH 67129; $C$. ventromaculatus FMNH 19506, 26357; C. viridiflavus FMNH 51694: C. sp. FMNH 229927. Coniophanes fissidens fissidens FMNH 22911. Comophis lineonts FMNH 10999; C. lineaths? FMNH 98542, 98543: C. sp. FMNH 98540. Conopsis lineata lineata FMNH 987; C. nasus FMNH 39053; Conopsis? FMNH 98539, 98541; C. sp. FMNH 98538. Corallus caninus FMNH 223192, 223193, 229856; C. cooki FMNH 212337; C. hortulamus enhyelis FMNH 229903-229905. Coronella austriaca FMNH 51623; C. anstriaca anstriaca FMNH 22810. Crotahts adamantens FMNH 22205, 22381, 31050, 31051, 51640, 98757, 218079; C. atrox FMNH 8484, 15236, 22243. 22244, 22331, 31010, 98632, 98892-98896, 98918, 167407. $167410,167411,167417-167421,167425-167427,167429$. $167434,167668,238179-238193,251262 ;$ C. basilicus FMNH 31299; C. cerastes FMNH 1243, 26122, 98904, 167431, 167432; C. durissus terificus FMNH 1731, 20160. 51664; C. horridus FMNH 3502, 22271, 22335, 98633 98635, 98901-98903, 98927, 98932, 98933, 223670: C lepichs FMNH 22317; C. lepidus klauberi FMNH 900; $C$. lepichs lepidhus FMNH 23787; C. mitchelli pyrrhus FMNH 1159; C. molossus FMNH 167435; C. molossus molossus FMNH 4770; $C$. rwher FMNH 5997, 8050, 31290; $C$. scutulatus FMNH 223668, 231611; C. viridis FMNH 22272, 22282, 22283, 22316, 98888, 98890, 98891, 167416, 167428: C. viridis helleri FMNH 5993; C. viridis oreganus FMNH 207914. Crotaphopeltis hotamboeia FMNH 4036. Cyclophiops major FMNH 18746, 23443.
127952, 127953, 127955, 127966-127968. Daboia russelii FMNH 22456, 31007, 31363, 154896, 166638, 167121, 167405, 167436. Cylindrophis maculatus FMNH 142395: C. ruffius FMNH 13100, 60958, 69980, 69981, 131778, 179033. Dasypeltis fasciata FMNH 19455; D. scabra FMNH 17677, 51695, 62212, 142635. Deinagkistrodon acutus FMNH 25177. Dendrelaphis pictus FMNH 41100. Dendroaspis angusticeps FMNH 17653, 51699. 74069. 251189; D. jamesoni FMNH 75076; D. viridis FMNH 31325, 31346; D. sp. FMNH 98921. Dendrophidion hrumneus FMNH 232577, 232578, 232580-232582. Diadophis punctutus FMNH 3513, 11821, 98546, 98547, 196142. 196153; D. punctatus amyi FMNH 98548-98552; D. punctatus edwardsii FMNH 207629, FMNH 207630. Dinodon rufozonatum FMNH 11429, 18733; D. rufozonatum rufozonatum FMNH 7091. Dipsaloboa unicolor FMNH 44415. Dipsas latifrontalis FMNH 23532. Dispholidus typus FMNH 17679. 74263. 251190. Dronicodryas bernieri FMNH 75596. Dromophis lineatus FMNH 12876. Drymarchon corais couperi FMNH 22228, 22305. 22367; D. corais erebenmus FMNH 98553; D. melanurus FMNH 31706. Drymolius margaritifens FMNH 1310. Dryophiops rubescens FMNH 183765. Drysdalia coronoides FMNH 29116. Echis carinatus FMNH 65914, $65918,73543,121567,154889,154891,154892$; E. coloratus FMNH 143999. Eirenis rothii FMNH 21910. Elaphe carinata FMNH 21971, 24901; E. dione FMNH 7119, 7121; E. flavinufa FMNH 1452; E. guttata FMNH 8623, 22484, 22489, 257100; E. mandarina FMNH 18695; $E$. obsoleta FMNH 22179, 22343, 98556, 196093, 257061; E. obsoleta obsoleta FMNH 22196, 22371, FMNH $98557-$ 98559; E. obsoleta quadrivittata FMNH 212336, 223699; E. porphyracea FMNH 7102, 11794; E. quatuorlineata santomates FMNH 249735; E. radiata FMNH 15824; $E$. infoclorsota FMNH 22341, 212395-212397, 212851; E. sclurenckii FMNH 7066, 216547; E. taeniura yummonensis FMNH 16804; E. vulpina FMNH 22250, 211940,251143 , 251519, 256996, 257009, 257481. Elapsoidea semiammilata FMNH 78220. Emydocephalus ijimae FMNH 120880. Enhydrina schistosi FMNH 199036, 199137, 199555, 199601, 201769, 203065, 203066, 203074, 203076 , 203082, 203091, 203123, 206707, 234226, 306697. Enhydris bocourti FMNH 11549; E. chinensis FMNH 167439 , 207645; E. dorice FMNH 129420; E. enhydris FMNH 252598-252608, 252686-252688; E. plumbea FMNH 98768. 120575-120579, 251282, 251283, 251572-251588. Ephalophis greyae FMNH 212365. Epicrates angulifer FMNH 250425; E. cenchria FMNH 22292, 22443, 22486; E. cenchria mourus FMNH 22848; E. striatus FMNH 13272, 130984; E. sp. FMNH 223197. Eristicophis macmahomi FMNH 140280, 165151. Erpeton tentaculatum FMNH 210072. Erythrolamprus aesculapii FMNH 2621, 10800. Ery jaculhs FMNH 19624; E. jolmii FMNH 23534. 31319. Eumectes murimus FMNH 8546. 22776. 39465, 45700, 212710, 232745: E. murimus gigas FMNH 31665; E. notaeus FMNH 229918, 9084, 229857-229859. 229919, 229921. Farancia abacura FMNH 8570, 22320. 22364, 257099; F. abacura abacura FMNH 31327; F. (ritrogramma FMNH 5731. Ficimia publia FMNH 20635. 
Fimbrios klossi FMNH 71698. Geophis semidoliatus FMNH 98561. Gloydins saxatalis FMNH 11484: $G$. strauchi FMNH 15134. Gongylophis colubrinus FMNH 223196: G. colubrimus colubrimus FMNH 75214. Gonyosoma frenatum FMNH 22345. Grayia smythii FMNH 20820, 51701, 214761, 214763, 214770. Hapsidophrys lineatus FMNH 4021; H. smaragdina FMNH 4023. Helicops angulatus FMNH 5691, FMNH 217108; $H$. carinicaudus FMNH 11500. Heterodon nasicus FMNH 15993, 15994, 22455, 25418, 251144; H. platirhinos $\mathrm{FMNH}$ 3387, 4136, 22259, 22270, 22314, 22315, 22324, 22332, 22447-22449, 31306, 210651, 210652, 251261, 257008; $H$. simus FMNH 4765, 25964. Homalopsis buccata FMNH 1929. 117860, 252680-252685, 252689, 252690. Homoroselaps lactens FMNH 187420, 187421, 204893, 206416. Hoplocephalus bitorquatus FMNH 97311. Hydrodynastes bicinctus FMNH 131629; H. gigas FMNH 31318, 31356, 229936. Hydrophis belcheri FMNH 13612, 22994; $H$. brooki FMNH 178861, 178866, 178868; H. coggeri FMNH 13611; H. cyanocinctus FMNH 23421, 171752 , 171753, 213154-213158, 215840, 231639-231644, 231712, $231713,231716,231717,232747,232748,232757,232763$ $232766,232770,233205,234182,234200-234217,234219$, $234220,234222-234224,242169,245525-245539,245540-$ 245551, 249396, 249397, 249400, 249401, 249406, 249408249410; H. elegans: FMNH 216270; H. fasciatus $\mathrm{FMNH}$ 141143, 249348-249351, 249353-249357, 249468$249473, \quad 249475-249477, \quad 249547, \quad 249549, \quad 249618$ 249628; H. klossi FMNH 165003, 165006; H. lapemoides FMNH 73996, 242175, 242176, 242220-242224, 249187 249191, 249440, 249446-249448, 249450-249453; H. melanosoma FMNH 171754, 201114, 201116, 201118, 201120, 201121, 201124, 202169, 202170, 206714, 206716: $H$ ornatus FMNH 201132, 202926, 234172, 249311-249316, 249318-249344; H. spiralis FMNH 242172, 242173 , 242180-242184, 242226, 248799, 249306-249310, 249454, $249551-249553,249615-249617,249654 ; H$. torquatus FMNH 201133, 201168; $H$. sp. FMNH 231708, 234185, 248826. Hypmale hypnale FMNH 122513; $H$. nepa FMNH 121450. Imantodes cenchoa FMNH 22223 , 31035, 221400; I. temissimus FMNH 20612. Kerilia jerdlonii FMNH 133059, 178775, 242188, 249655. Lachesis muta FMNH 31748, 31749, 98753. Lampropeltis alterna FMNH 257010; L. getula californiae FMNH 22313, 22321, 22483, 23234; L. getula lollbrooki FMNH 22445, 31280, 31296, 212393; L. getula splendita FMNH 31310; L. triangulum elapsoides FMNH 19312; L. triangulum hondurensis FMNH 250685; L. triangulum polyzona FMNH 4200; $L$. triangultm triangulum FMNH 22269, 98566, 207626, 252408; Lamprophis fuliginosus. FMNH 214776. 214777; L. lineatus FMNH 9916, 17698, 17702, 51684, 51697. 81103, 81105; L. olivacens FMNH 19473. Lapemis curtus FMNH 122529, 141158, 141159, 141161, 142063, 198402, 198410, 198442, 198443, 198466, 198918, 210065 $210070,210090,210165,213159,213160,213162-213164$, $213168,213169,213171,213173,213175-213179,213229$, $215262,215264,215276,230014,230019,230021,230022$, 230028, 230032, 230051-230058, 231376, 231731-231748.
$234118,234121,234128,234169,234228-234232,235469$, $235474,235476-235478,235480-235483,235490,235493$, 235496-235504, 235506-235509, 235511-235515, 242126, 242128, 242146, 249192. Laticauda colubrina FMNH 13820. 210061-210064. 234147-234166, 235388-235395, 235398$235425,236238,236245,236251,236279,236285-236292$, 236294 236301, 236303-236314, 236318, 236320, 236322 $236325,236327-236329,236341,236345,236347-236349$. 236354, 236357-236374, 236523, 244183-244202, 248797, 248798; L. laticandata FMNH 154782, 202812, 202813, 242185; L. semifasciala FMNH 106060, 120644, 120650, 120651. Leiopython albertisi FMNH 218609. Leptodeira maculata FMNH 98622; L. septentrionahs polysticta FMNH 4815, 4816, 8934, 31343, Leptomicrurus narduecii FMNH 5700, 62127. Leptophis alactulla FMNH 5292, 5294. 54974; L. mexicamus FMNH 193, 22257. Lepturophis borneensis FMNH 148896. Lichamura trivirgata roseofusca FMNH 8043, 31365. Limmopliis bicolor FMNH 18523. Lioheterodon madagascariensis FMNH 75591. Liophis epinephelus FMNH 232562, 232563 ; L. miliaris FMNH 15420; L. poecilogyrus FMNH 35699. Liopholidophis lateralis FMNH 75615. Lycodon anlicus FMNH 15060; L. striatus FMNH 121510. Lycophidion capense remiculatmm FMNH 81086. Lystrophis dorbignyi FMNH 9508, 10199; $L$. semicinctus FMNH 10863. Lytorhynchus diadema FMNH 164704; L. maynardi FMNH 167666. Macrocalamus lateralis FMNH 109943. Macropisthodon rudis FMNH 24952. Macrovipera lebetina FMNH 19601, 65218. Malpolon moilensis FMNH 72083; M. monspessulamis FMNH 19615. Masticoplis flagellum FMNH 22344, 22461, 98568, 257101, 258769; M. flagellum flagellum FMNH 21922, 22229. 22377; M. flavigularis flavigularis FMNH 213416; M. schotti FMNH 6801: M. sp. FMNH 98567. Mastigodryas bifossatus FMNH 9243, 51669; M. healhii FMNH 232583. Mehelya capensis FMNH 13129; M. poensis FMNH 19467. Microcephalophis gracilis FMNH 171755, 249464. Micruroides euryxanthus FMNH 41952. Micrurus fulvius FMNH 6804, 39479, 229600; M. fulvius fulvins FMNH 34982; M. nigrocinctus FMNH 16119, 31101, 31104, 31109, 210092-210094; M. spixii princeps FMNH 22592; M. sp. FMNH 200569. Montatheris lindii FMNH 154720. Morelia amethistina FMNH 212271, 218599, 232744, 257051; $M$. spilota FMNH 21714, 22234, 22380, 22420, 218598; $\boldsymbol{M}$. viridis FMNH 21733, 207854, 211850, 213403. Naja atra FMNH 6635; N. kaouthia FMNH 15823; N. naja FMNH 22044, 22408, 22421, 31361, 212312, 212313, 212333-212335, 212398-212400, 212526, 212527, 212529-212532, 212581212583,212585-212587; N. nigricollis FMNH 222374: $N$. nivea FMNH 17656, 31359; N. sp. FMNH 98920. Natrix natrix FMNH 51620; $N$. tessellata FMNH 19604. Nerodia cyclopion FMNH 22274, 95326: $\mathrm{N}$. erytlrogaster FMNH 22309, 22310; N. erythrogaster transversa FMNH 98574-98576; N. fasciata FMNH 22390, 217640; N. fasciata pictiventris FMNH 211920; N. floridana FMNH 95329; N. rhombifer FMNH 2664 , 22306-22308, 22319, 98955; N. sipedon FMNH 22047. 
22262, 22284, 98569-98572, 216226: N. sipedon sipedon FMNH 98573; $N$. taxispilota FMNH 8220. 31295; $N$. sp. FMNH 250849. Neusterophis variegatus FMNH 179356. Ninia sebae FMNH 20359. Notechis scutatus FMNH 11123, 11127, 20770. Oligodon albocincius FMNH 11795: O. cyclurus FMNH 14434: O. fasciolatus FMNH 169437: O. formosanus FMNH 6691, 24961: O. octolincatus FMNH 100901. 129423: O. taeniatus FMNH 119662: $O$. violaceus FMNH 6700, 6703. Opheodrys aestivus FMNH 8603. 21259. 21260. 211917; O. vernalis FMNH 16149. 22227. 22304, 98578-98581, 217395. Ophiophagus hamah FMNH 22275, 22276, 22409, 22482, 98765. Ophryacus undulatus FMNH 38505. Opisthotropis latonchi FMNH 24865. Orophis monticola FMNH 18760, 25187: O. okinavensis FMNH 45074. Oxybelis acneus FMNH 10998, 22231. 22355, 31037. 98913: $O$. argentens FMNH 16789; $O$. fulgidus FMNH 4207. 5301. 5302, 22369, 22376, 25250. Oxyrhabdium modestum FMNH 96532. 98858. Oxyrhopus petola digitalis FMNH 11193; O. petola sebae FMNH 20094. Pareas margaritophorus FMNH 6661. Pelanis platurus FMNH 51637-51639. 154882, 171581, 171613, 171628, 171632, 171644, 171652, 171671, 171680, 171690, 171701, 216510, 216517, 216518. 216519. 216538-216542. 217156-217158, 217397. 218435. 218439. Philodryas chanissonis FMNH 6401. 209130, 210381, 210382, 210386; P. elegans FMNH 34281, 34313, 39372; $P$. elegants rufidorsatus FMNH 41595: $P$. patagoniensis FMNH 19395. 51667; $P$. simonsii FMNH 232579. Philothammus irregularis FMNH 12967. Phimophis guianensis FMNH 22579. Phyllorhynchus decurtatus FMNH 22419, 31284; P. decurtatus perkinsi FMNH 18419. Pituophis catenifer FMNH 3417, 22221, 22487, 98582-98584. 191778 , 191779, 196100, 229894, 250590, 251141, 251142. 251260, 256997: P. deppei FMNH 1497: P. melanoleucus FMNH 22342. 22356, 211907, 212394. 217641. 258730. Plagiopholis styani FMNH 24873. Polemon collaris FMNH 58999. Porthidium dunni FMNH 104676; P. yucatanicum FMNH 36181. Protobothrops jerdonii FMNH 28199; $P$. mucrosquamatus FMNH 16255, FMNH 140101. Psanmodynastes pictus FMNH 148905, 148907; P. pulverulentus FMNH 24997, 53485. 53501. Psammophis phillipsi FMNH 12976; P. schokari FMNH 129758, 129760, 129762; P. sibilans sibilans FMNH 72044, 72050, 72070; P. subtaeniatus sudanensis FMNH 51687. Psendaspis cana FMNH 16044, 51628, 51696. Pseudechis australis FMNH 166929: Pseudechis porphyriacus FMNH 11119, 11120, 20797, 22318. Pseudocerastes persicus FMNH 207656. Pseudoeryx plicatilis FMNH 26638. Pseudonaja textilis FMNH 11122, 169700. Pseudorabdion collaris FMNH 120377; P. longiceps FMNH 71596. Pseudoxenodon macrops sinensis FMNH 7757. Pseustes poecilonotus FMNH 16755, 98771, 217107: $P$. sulfurens sulfurens FMNH 22327. Ptyas dhummades FMNH 22340; $P$. fuscus FMNH 145833: $P$. korros FMNH 24851: $P$. mucosus FMNH 22045, 24857, 31026, 31029: $P$. nigromarginatus FMNH 18728. Python curtus FMNH 22472, 212308.
222372; P. molurus FM1NH 207647, 218576; P. molurus bivitiatus FMNH 223198; $P$. regius FMNH 31033. 223195: $P$. reticulatus FMNH 15678. 31281. 31324. 211852: $P$. sebae FMNH 8545, 11162, 11170, 13121. 22366. 196592: $P$. sp. FMNH 218979. Pythonodipsas carinata FMNH 170024. Regina septemvittata FMNH 16132. Rhabdophis tigrinus FMNH 16839. Rhammophis aethiopissa FMNH 19476. 19477. Rhamphiophis oxyrhynchus rostratus FMNH 16143, 51686. Rhinobothryum bovallii FMNH 55883. Rhinocheilus lecontei FMNH 22418, 22488. Salvadora grahamiae FMNH 98585. 98586: S. grahamiae grahamiae FMNH 22370: $S$. grahamiac lineata FMNH 41688. Sanzinia madagascariensis FMNH 109899. Scaphiophis albopunctatus FMNH 27350: S. albopunctatus albopunctatus FMNH 51685. Sibynomorphus ventrimaculatus FMNH 9259. Sibynophis bivillatus FMNH 53368; S. geminatus FMNH 131202: $S$ sagittarius FMNH 131411. Simoselaps bertholdi FMNH 152149: S. semifasciatus FMNH 152144. Sinomicrurus japonicus FMNH 48797. Sinonatrix aequifasciata FMNH 24762: S. anmularis FMNH 24766; S. percarinata FMNH 18751; S. trianguligerus FMNH 98942. 128409. 210104. Siphlophis cervinus FMNH 31196. Sistrurus catenatus FMNH 432. 11034. 22230, 22273. 22311. 22346. 216239: $S$. miliarius FMNH 21761. 22388. 98899. 98900. 98930: S. miliarius barbouri FMNH 484553; S. ravus FMNH 113016. Sonora semianmulata FMNH 46496, 98587. Spalerosophis diadema FMNH 22777, 63128, 75241, 153046; $S$. diadena schiraziana FMNH 20894. Spilotes pullatus FMNH 51668, 218436, 257007: S. pullatus mexicanus FMNH 4205. 5291. Stenorrhina degenhardiii FMNH 232576: S. fremimillei FMNH 36018. Stilosoma extenuatum FMNH 48441. Storeria dekayi FMNH 22235. 98588-98590: S. occipitoniaculata FMNH 98591-98594. 207632. 207633. Symphimus mayae FMNH 36385. 36387. Tantilla gracilis FMNH 18597, 30048, 30123. 30135, 98595, 98596. 98746. Telescopus fallax iberius FMNH 19499; T. semianmulatus semiannulatus FMNH 57656. Thalassephina viperina FMNH 198480, 215559. 215561. Thammophis butleri FMNH 15562, 21567; $T$. eques FMNH 2037. 98598; T. marcianus FMNH 565, 98602-98604: $T$. proximus FMNH 23693, 98605, 98606; T. radix FMNH 22050-22052, 98599-98601, 217214; $T$. sirtalis FMNH 22357, 22358, 217155, 217396, 217639, 258770: T. sirtalis parietalis FMNH 98607, 98608, 98618, 196148; T. sirtalis sirtalis FMNH 98609-98617, 207627. 207628: T. valida FMNH 98577. Thelotornis capensis capensis FMNH 17676; T. kirtlandii FMNH 98748. Thrasops flavigularis FMNH 19470. Toluca lineata FMNH 98856, 98857; $T$. lineata varians FMNH 98544, 98545. Tomodon degener FMNH 9370, 12358. Tretanorhinus mocquardi FMNH 16752. Trimeresurus albolabris FMNH 6710, 6713: T. flavomaculatus FMNH 53562; T. popeiorum FMNH 67273; T. puniceus FMNH 131847; T. stejnegeri FMNH 14430, 25195, 127229, 127233. 127238; T. sumatranus FMNH 71644, 216567. Trimorphodon bisculatus FMNH 223666, 223667: $T$. biscutatus lambda FMNH 98621. Tripanurgos compres- 
sus FMNH 221399. Tropidoclonimm lineatum FMNH 98619. 98620. Tropidodipsas fischeri fischeri FMNH 20257. Tropidolaenms wagleri FMNH 71640, 129468. Tropidophis pardalis FMNH 233. Typhlops punctatusl lineolatus FMNH 31371. Uronacer cateshyi FMNH 18357: U. oxyrhynchus FMNH 5986. Uropeltis melanogaster FMNH 167048. I'rmicella ammilata FMNH 24103, 97926. Vipera ammodytes FMNH 21762, 98912, 142997; $V$. aspis FMNH 23438; V' berus FMNH 166671, 167120; I. palaestinae FMNH 48522;
V. renardi FMNH 134381. Virginia striatula FMNH 98562-98564; I. valeriae elegans FMNH 11050. 98565. IIaglerophis merremii FMNH 51665, 51666. Walterinnesia aegyptia FMNH 69240. Xenelaphis hexagonotus FMNH 128269. Xenochrophis piscator FMNH 7060. Xenodermus javanicus FMNH 67427. Xenodon merremi FMNH 195870, 195884, 195896; $X$. rabdocephalus FMNH 21775: $X$. rabdocephalus mexicamus FMNH 49349; X. severns FMNH 11198. Xenopeltis unicolor FMNH 122000, 138682, 148900, 178975, 246193. 

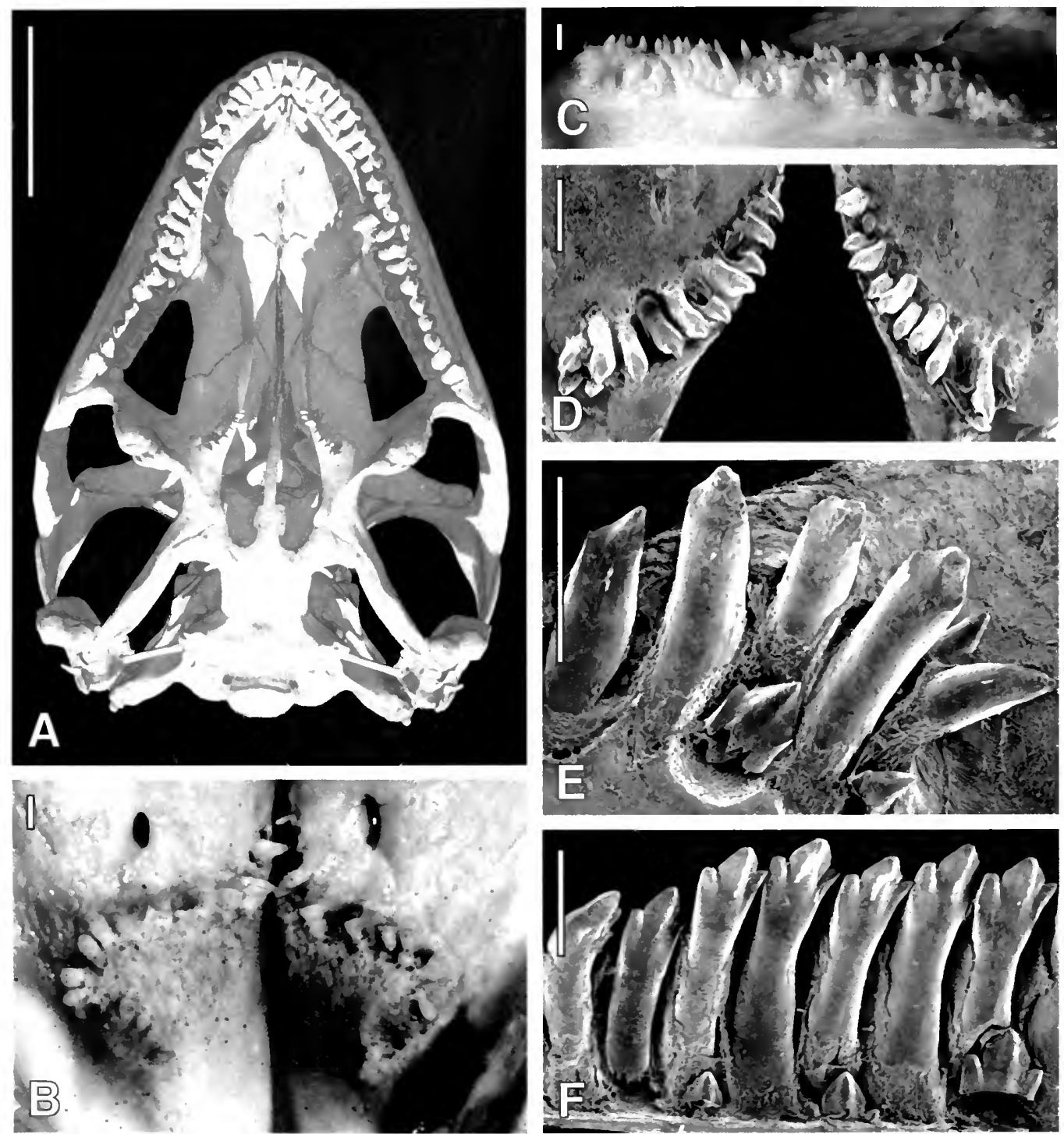

Fig. 1. (A) CT scan showing ventral view of the skull in Brachylophus fasciatus (FMNH 210158). (B) Ventral view of pterygoids of Ctenosmura sp. (FMNH 6175). (C) Ventrolingual view of right pterygoid tooth row of Iguana iguana (FMNH 51679). (D) SEM micrograph showing ventral view of pterygoids of Ctenosania sp. (FMNH 98370). (E) SEM micrograph showing ventrolabial view of right pterygoid teeth of $C$. similis (FMNH 211849). (F) SEM micrograph showing lingual view of left maxillary teeth of $C$. similis (FMNH 211849), for comparison to $\mathbf{E}$. Anterior toward top in $\mathbf{A}-\mathbf{B}$ and $\mathbf{D}$. Anterior to right in $\mathbf{C}$. Anterior to left in $\mathbf{E}-\mathbf{F}$. Scale bar equals $1 \mathrm{~cm}$ in $\mathbf{A}$, $1 \mathrm{~mm}$ in B F. 

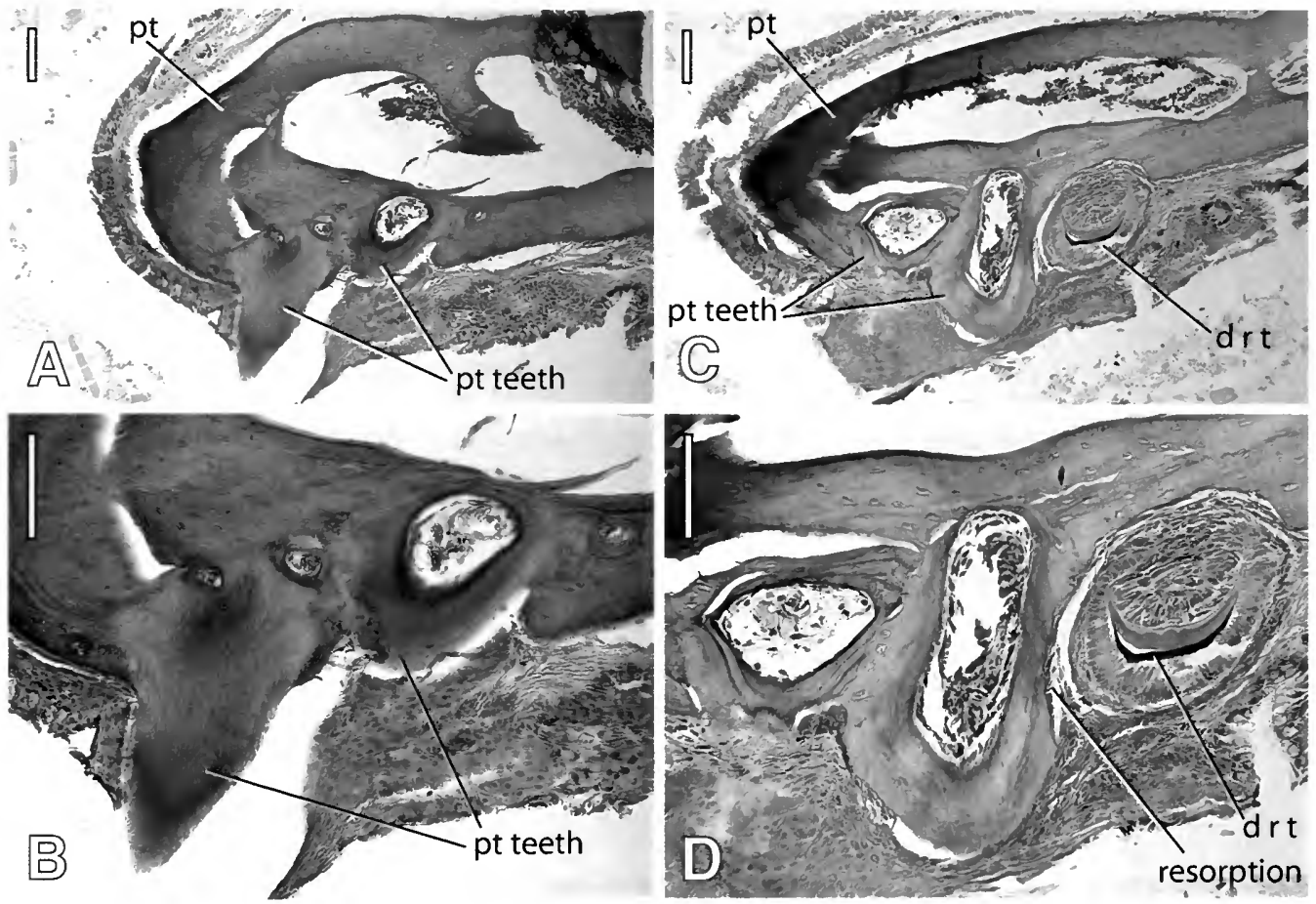

FIG. 2. (A, B) Transverse sections through right pterygoid of Crotaphytus collaris (FMNH 210169), seen in posterior aspect. (C, D) Transverse sections through right pterygoid of $C$. collaris (FMNH 210169). seen in posterior aspect, showing tooth replacement. Medial to left in all. Scale bar equals $0.1 \mathrm{~mm}$ in all. 

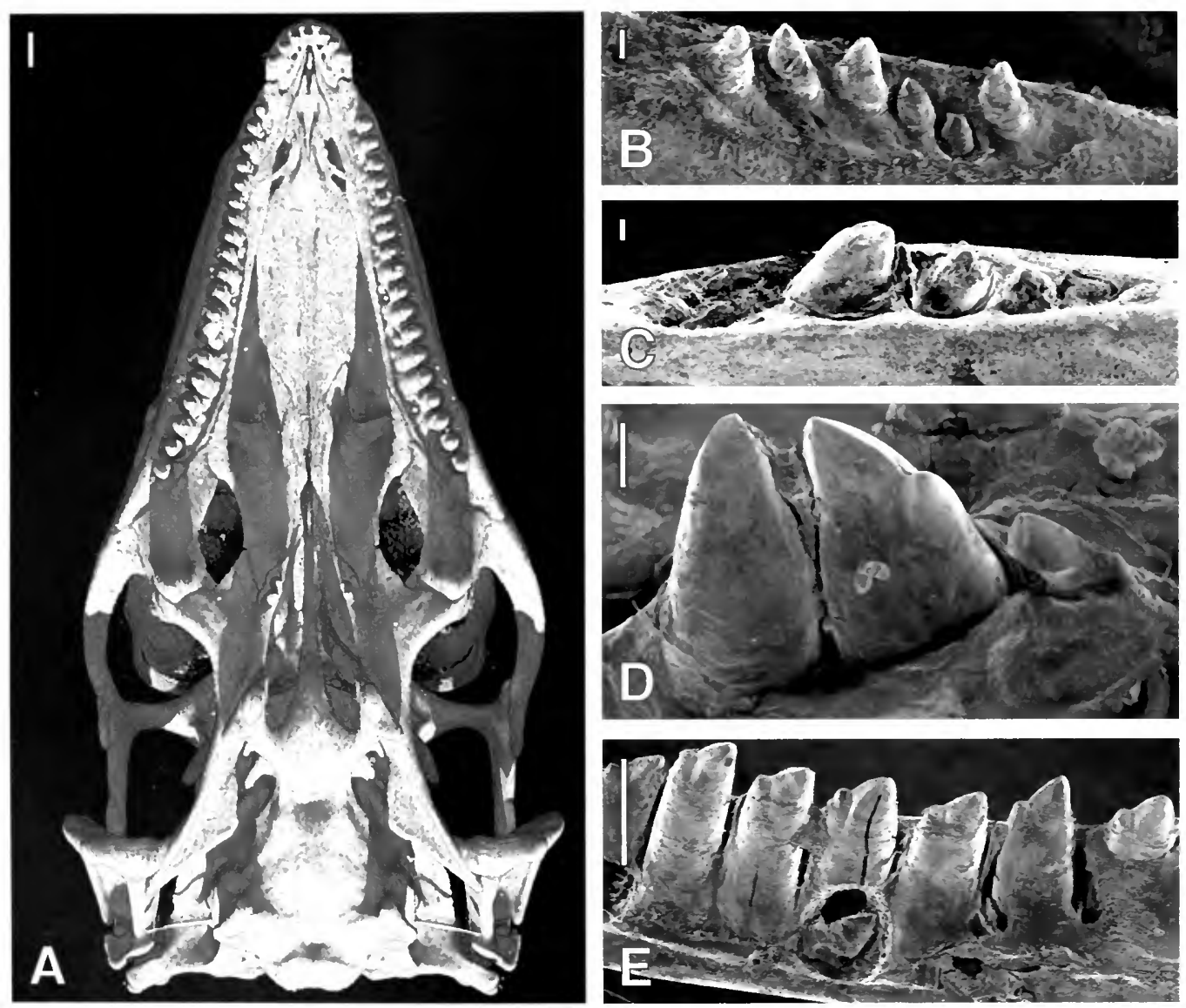

Fig. 3. (A) CT scan showing ventral view of the skull in Aspidoscelis tigris (FMNH 161622). (B) SEM micrograph showing ventrolabial view of left pterygoid teeth in A. deppei (FMNH 98492). Anterior to right. (C) SEM micrograph showing labial view of right pterygoid teeth in Kentropix calcarata (FMNH 31352). Anterior to left. (D) SEM micrograph depicting ventrolabial view of right pterygoid teeth in Aspidoscelis sp. (FMNH 98470). showing cusps. Anterior to left. (E) SEM micrograph depicting lingual view of left maxillary teeth in Aspidoscelis sp. (FMNH 98470), for comparison to D. Anterior to left. Scale bar equals $1 \mathrm{~mm}$ in A. $0.1 \mathrm{~mm}$ in B D. $1 \mathrm{~mm}$ in E. 

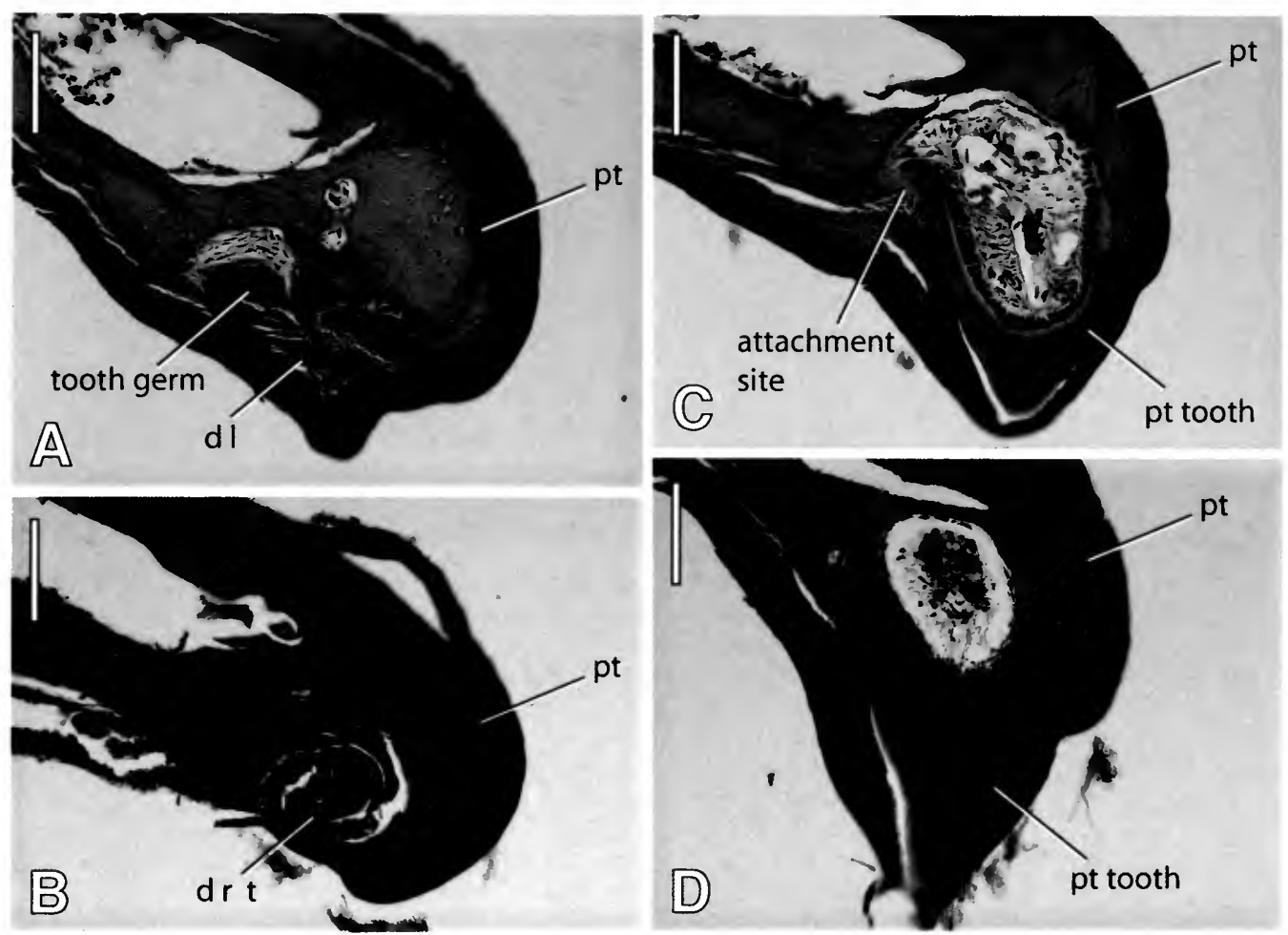

Fig. 4. (A) Transverse section through left pterygoid of Aspidoscelis tigris (FMNH 115480), seen in posterior aspect, showing early tooth germ formation in pterygoid cavity. (B) Transverse section through left pterygoid of $A$. tigris (FMNH 115480), seen in posterior aspect, showing developing tooth germ in pterygoid cavity. (C) Transverse section through left pterygoid of $A$. tigris (FMNH 115480), seen in posterior aspect, showing developing tooth attachment. (D) Transverse section through left pterygoid of A. tigris (FMNH 115480), seen in posterior aspect, showing a fully ankylosed tooth. Medial to right in all. Scale bar equals $0.1 \mathrm{~mm}$ in all. 

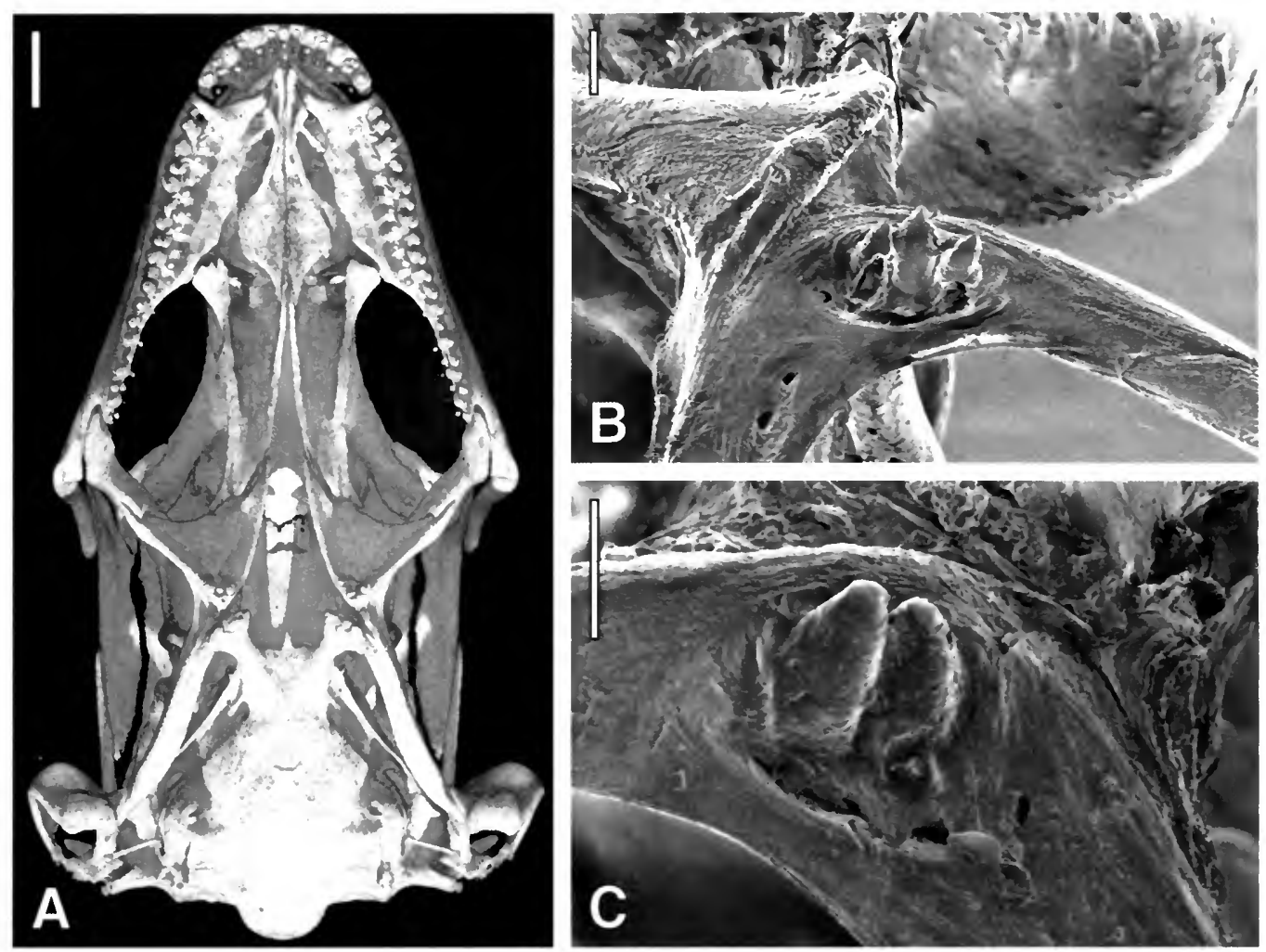

FIG. 5. (A) CT scan showing ventral view of the skull in Colobosama modesta (USNM 341978). (B) SEM micrograph showing anteroventral view of right pterygoid teeth in G. speciosis (FMNH 165771). (C) SEM micrograph showing mesiolabial view of left pterygoid teeth of $G$. speciosus (FMNH 165771). Anterior toward top in $\mathbf{A}$ and toward bottom in $\mathbf{B}, \mathbf{C}$. Scale bar equals $1 \mathrm{~mm}$ in $\mathbf{A}, 0.1 \mathrm{~mm}$ in $\mathbf{B} \mathbf{C}$.
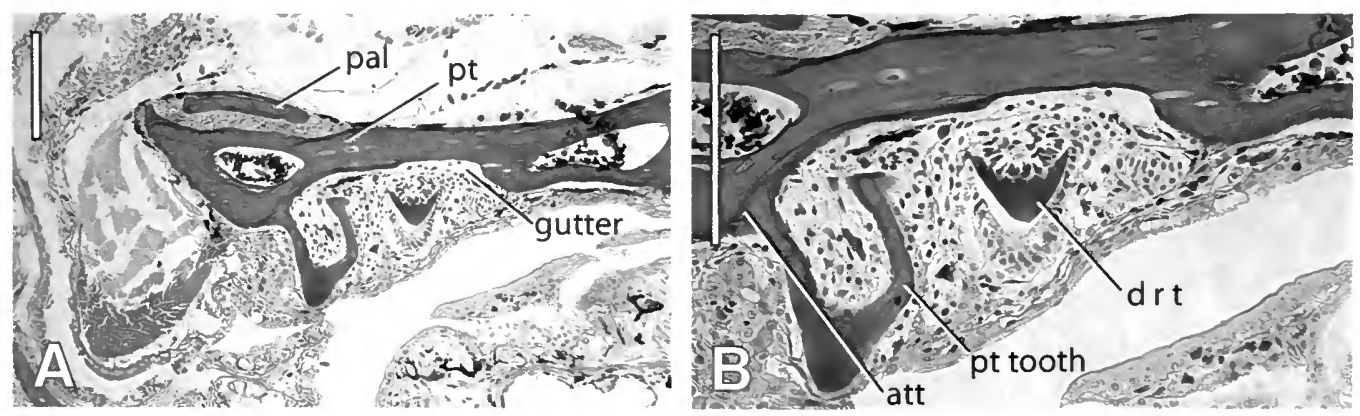

FIG. 6. (A, B) Transverse section through right pterygoid of Gimmophthalmus speciosus (FMNH 176990), seen from posterior aspect, showing developing tooth germ. Medial to left in both. Scale bar equals $0.1 \mathrm{~mm}$ in both. Medial to left in both. 

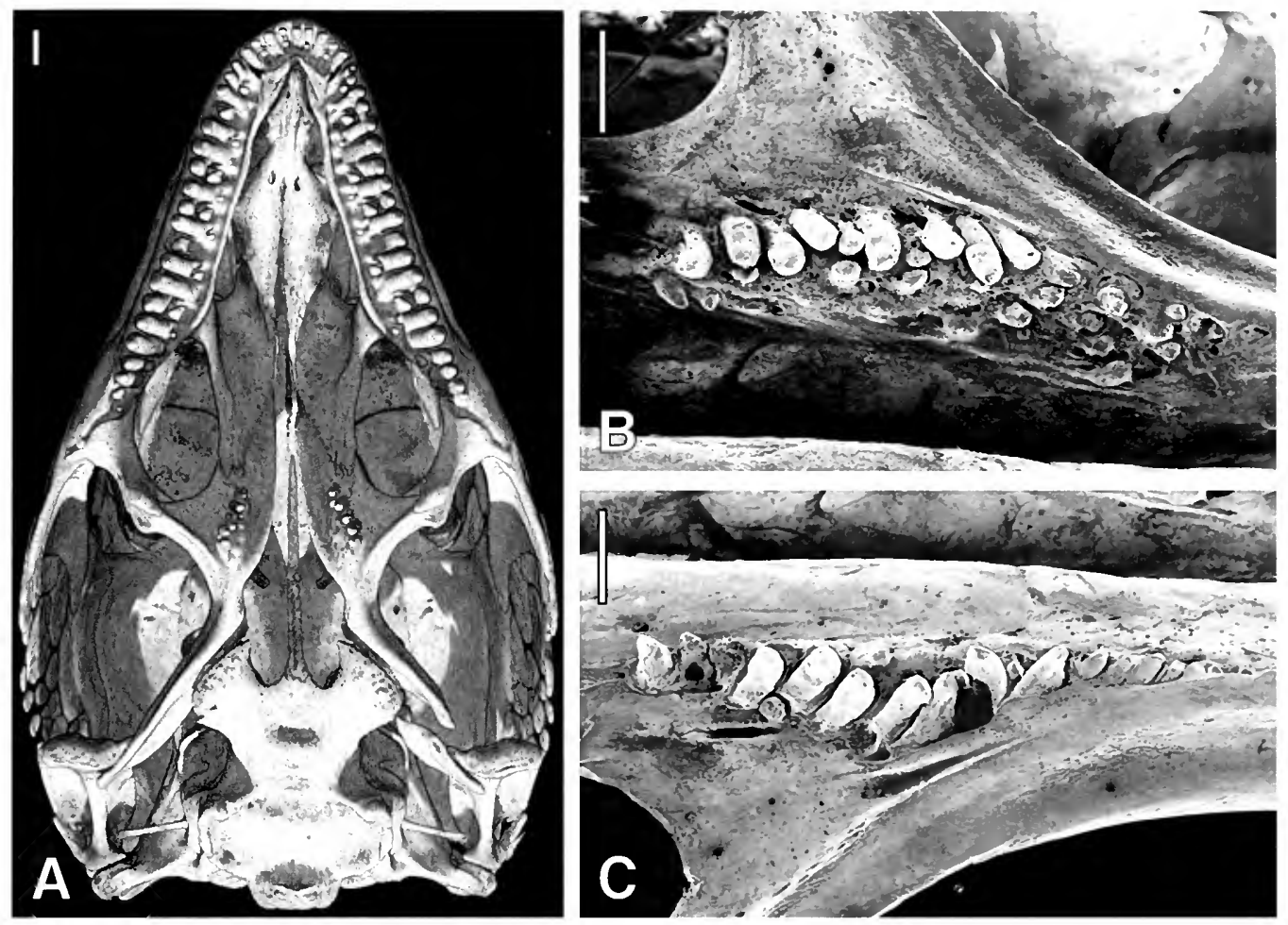

FIG. 7. (A) CT sean showing ventral view of the skull in Lacerta viridis (YPM 12858). (B) SEM mierograph depicting vent ral view of left pterygoid teeth in $L$. lepida (FMNH 22098). showing older. more worn teeth medial to actively replacing teeth. Anterior toward left. (C) SEM mierograph depicting ventrolabial view of right pterygoid teeth in L. lepida (FMNH 22098). showing active replacement. Anterior toward left. Scale bar equals $1 \mathrm{~mm}$ in all.
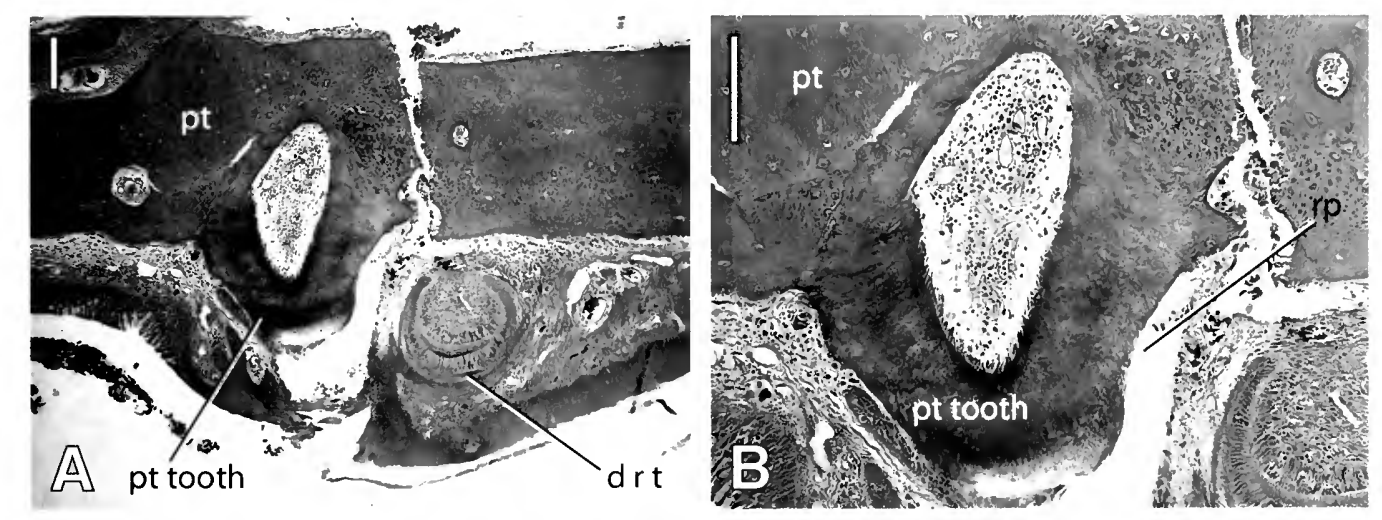

Fig. 8. (A, B) Transverse section of right pterygoid of Lacerta lepida (FMNH 83665), seen in posterior aspect. showing developing replatement tooth labial to ankylosed tooth. Medial to left in all. Scale bar equils $0.1 \mathrm{~mm}$ in all. 

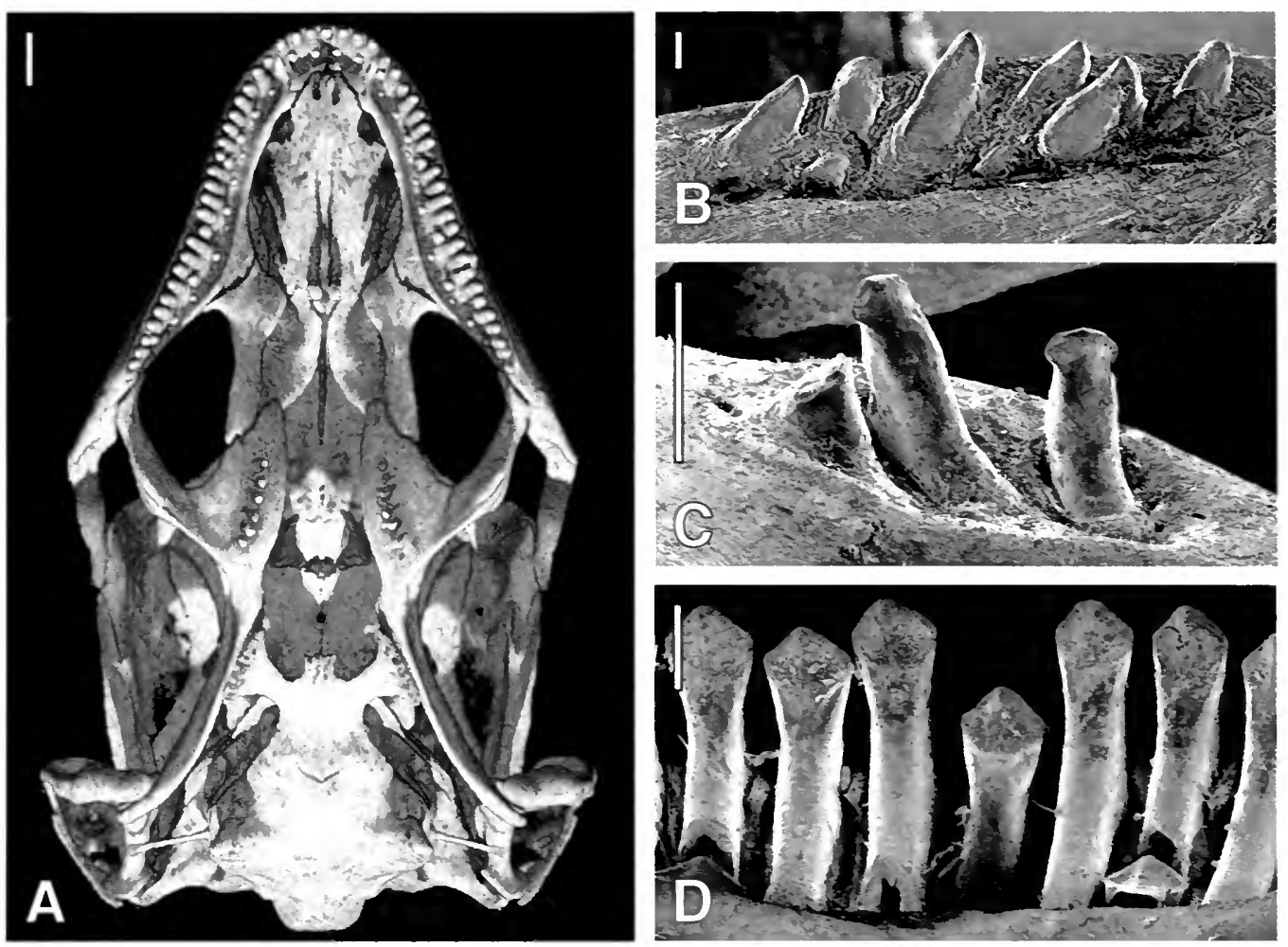

FlG. 9. (A) CT scan depicting ventral view of the skull in Eumeces fasciatus (YPM 12689). (B) SEM1 micrograph showing labial view of right pterygoid teeth of E. fasciatus (FMNH 98513). Anterior to left. (C) SEM micrograph depicting mesiolabial view of left pterygoid teeth in Corucia zebrata (FMNH 257163), showing crown form. Anterior to right. (D) SEM micrograph depicting lingual view of right maxillary teeth in $C$. zebrata (FMNH 257163). for comparison to C. Anterior to right. Scale bar equals $1 \mathrm{~mm}$ in A, $0.1 \mathrm{~mm}$ in B. $1 \mathrm{~mm}$ in C-D.
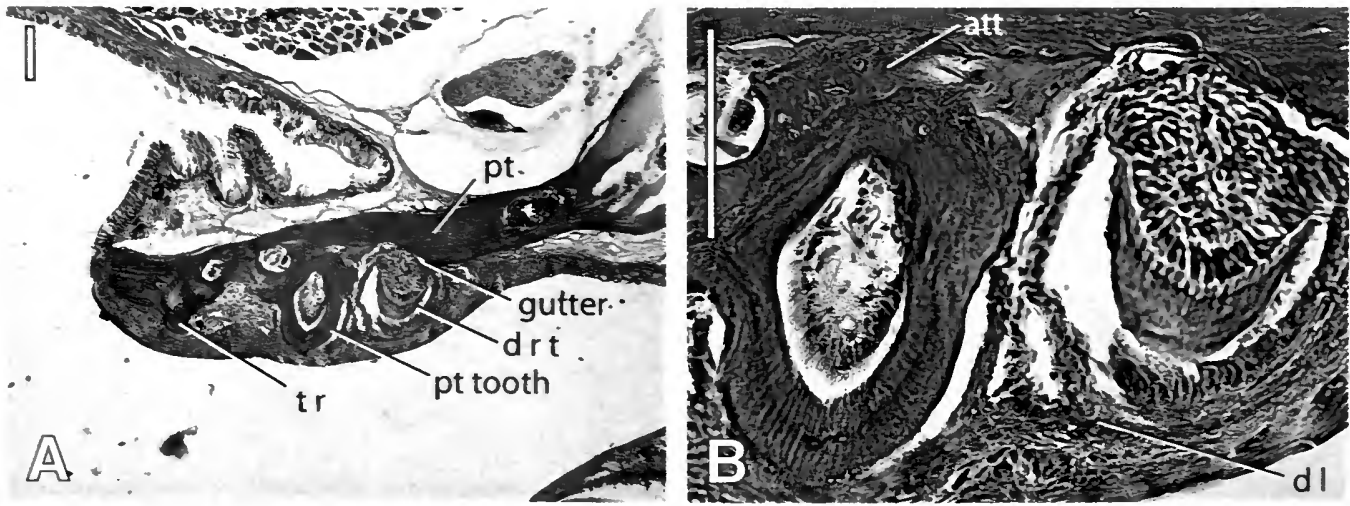

Fig. 10. (A) Transverse section through right ptervgoid of Eumeces fasciatus (FMNH 118853). seen from posterior aspect. (B) Transverse section through right pterygoid of $E$. fasciatus (FMNH 118853 ). seen from posterior aspect, showing detail of tooth undergoing labial replacement. Medial to left in both. Scale bar equals $0.1 \mathrm{~mm}$ in both. 

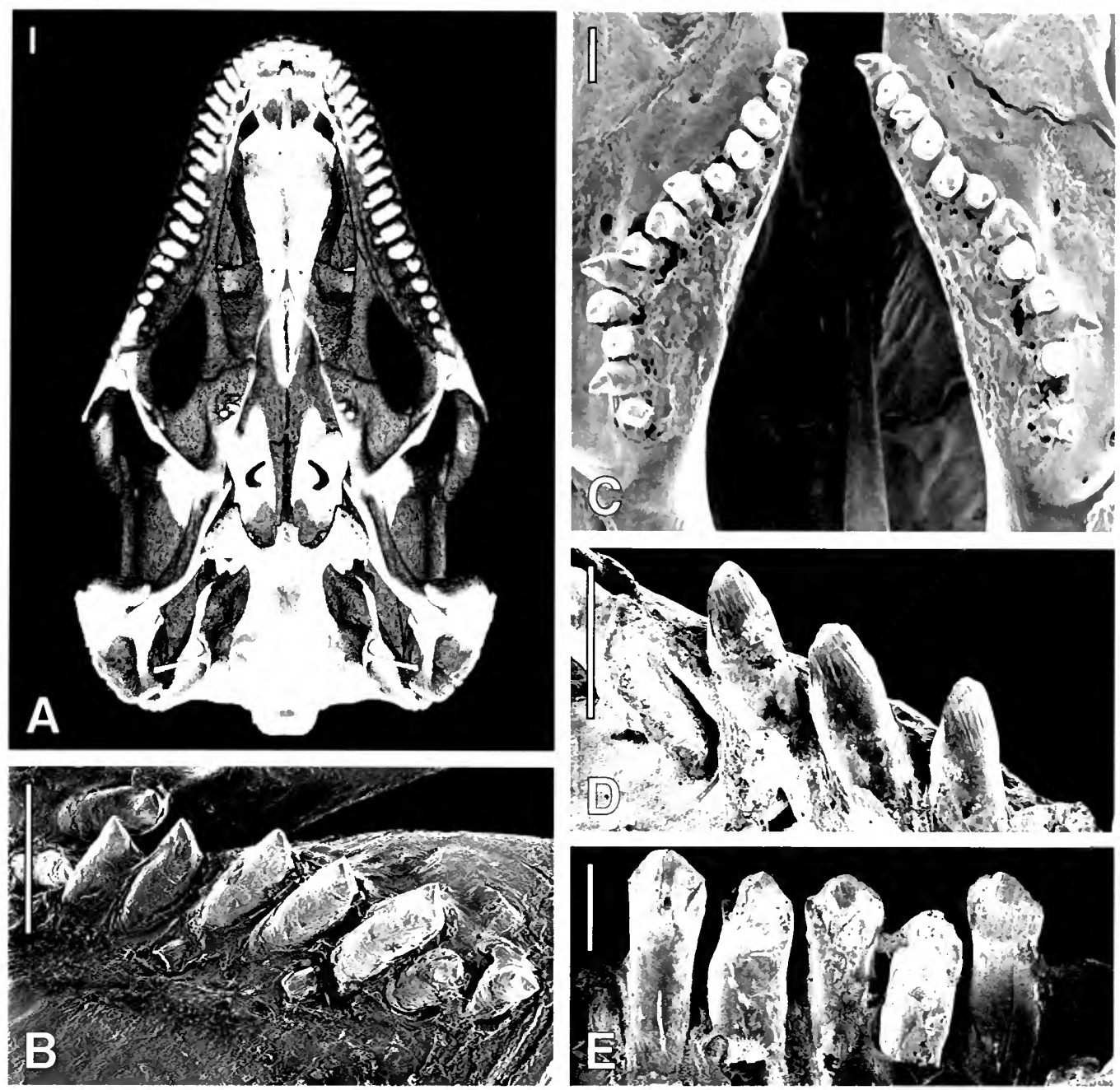

Fk. 11. (A) CT sean showing ventral view of the skull in Zonosamus ormatus (YPM1 12671). (B) SEM micrograph showing ventrolabial view of right pterygoid of Gorhoscumus nigmolineotus (FMNH 15375 ). demonstrating replacement. Anterior 10 left. (C) SEM micrograph showing ventral view of pterygoid tooth rows in G. validus (FMNH 2i5858). Anterior toward top. (D) SEM micrograph showing mesiolabial view of left pterygoid teeth in $G$. validus (FMNII 22293). Anterior to right. (E) SEM mierograph show ing lingual view of right maxillary teeth in $G$. validus (FMNH 22293). Anterior to right. Seale bars ecpual $1 \mathrm{~mm}$.
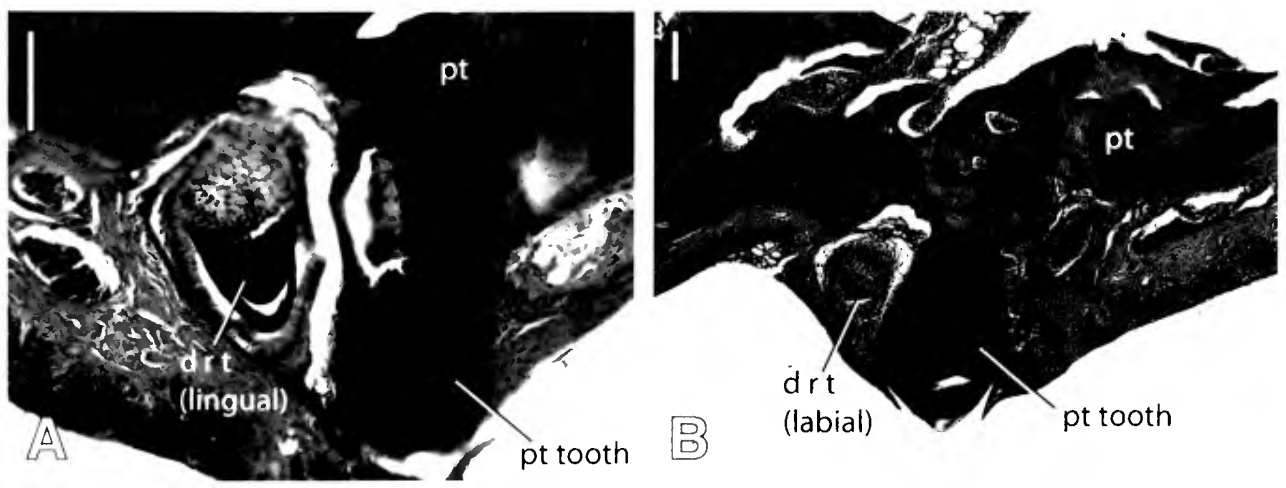

Fig. 12. (A) Transterse section through right pterygoid of Gerrhosamms nigrolinutus (FMNH 15373). seen from posterior aspect, showing tooth undergoing lingual replacement. Medial to left. (B) Transverse section through left pterygoid of G. migrolineatus (FMNHI 15373), seen from posterior aspect, showing tooth undergoing labial replacement. Medial to right. Scale bar equals $0.1 \mathrm{~mm}$ in both. 

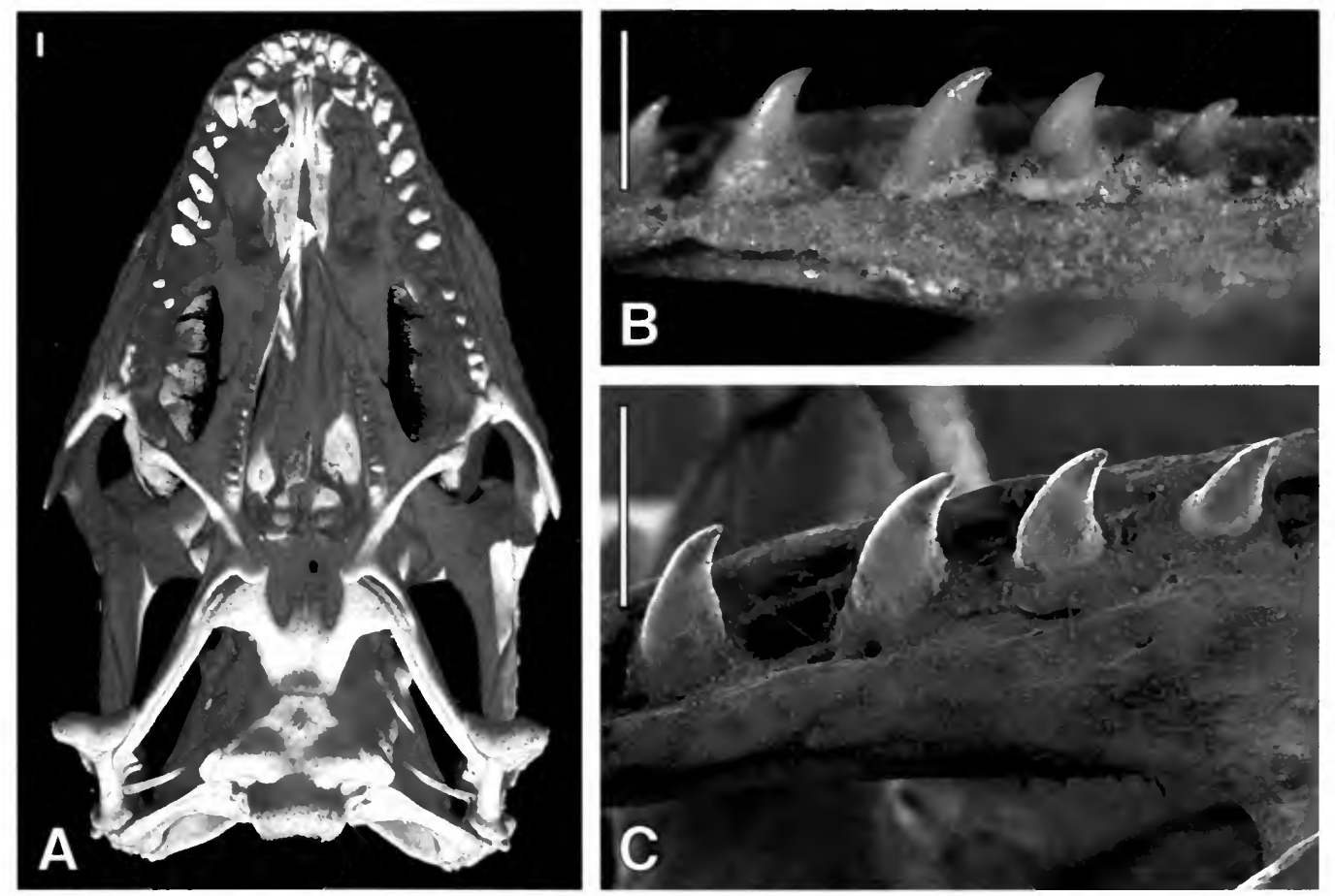

Fig. 13. (A) CT scan showing ventral view of the skull in Shinisaurus crocodilurus (FMNH 215541). (B) Labial view of right pterygoid tooth row in $S$. crocodilurus (UF 62536), showing tooth bases surrounded by attachment tissue. Anterior to left. (C) SEM micrograph depicting ventrolabial view of right pterygoid teeth in $S$. crocodilurus (UF 62536), showing implantation within a longitudinal gutter in the pterygoid. Anterior to left. Scale bar equals $1 \mathrm{~mm}$ in all. 
This page was intentionally left blank. 

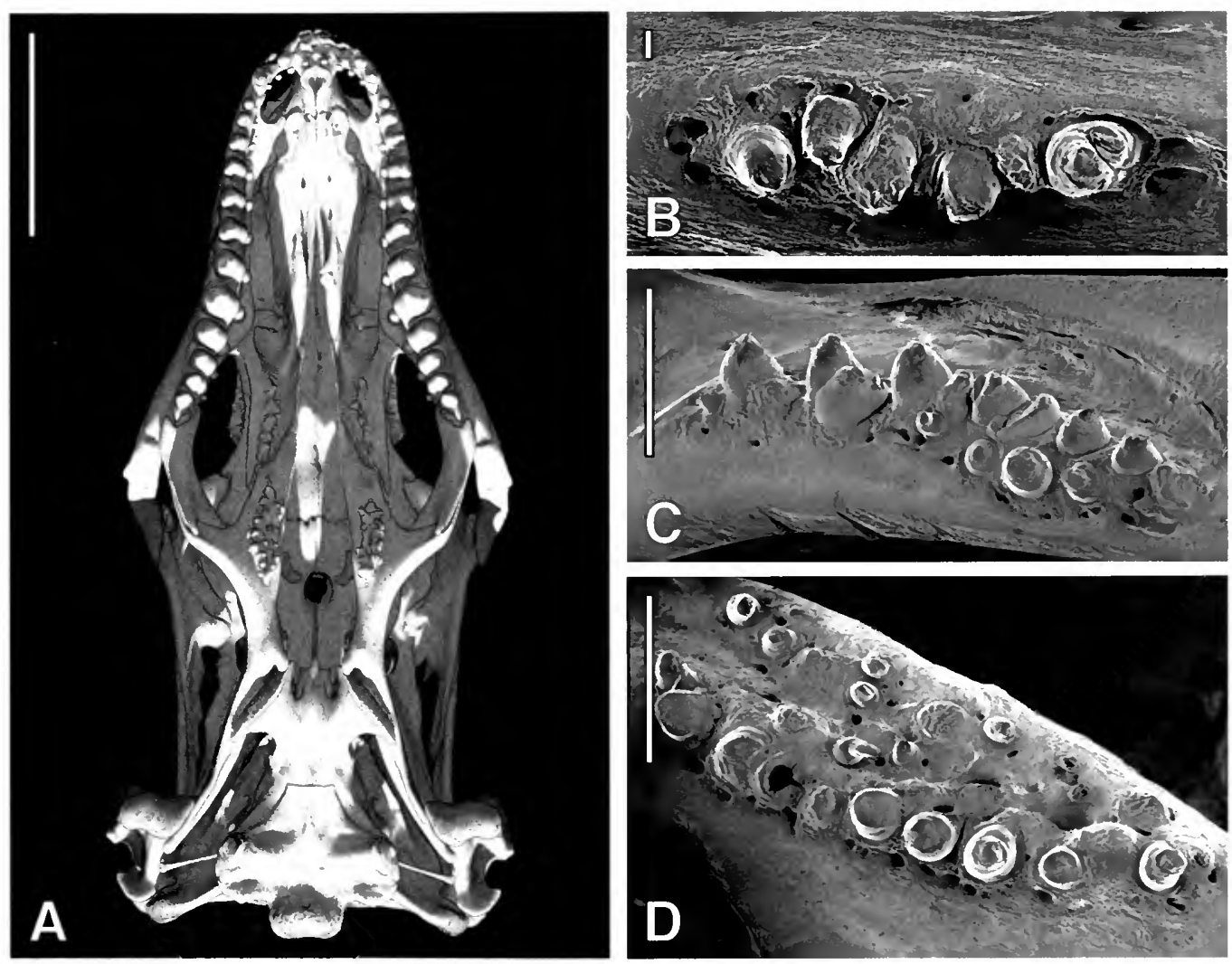

FIG. 14. (A) CT scan showing ventral view of the skull in Ophisaurus apodus (YPM 12870). (B) SEM micrograph showing ventral view of the left vomer in O. apodus (FMNH 22359). (C) SEM micrograph showing ventrolabial view of the right palatine in $O$. apodus (FMNH 22359). (D) SEM micrograph showing ventral view of the right pterygoid in $O$. apodus (FMNH 22359). Anterior toward top in A. Anterior to left in B-D. Scale bar equals $1 \mathrm{~cm}$ in $\mathbf{A}, 0.1 \mathrm{~mm}$ in $\mathbf{B}, 1 \mathrm{~mm}$ in $\mathbf{C}-\mathbf{D}$. 

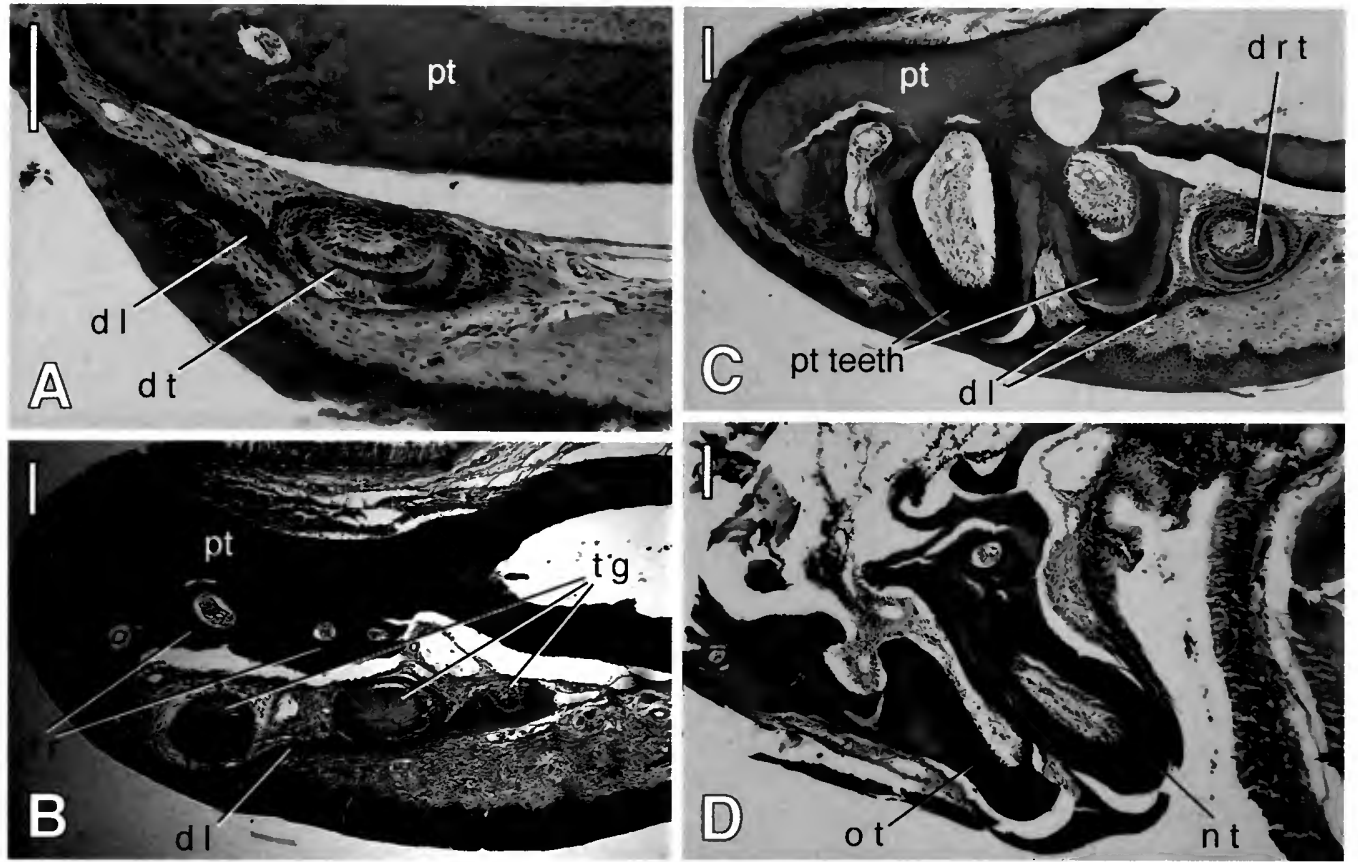

F1G. 15. (A) Transverse section of right pterygoid of Ophisaurus apodus (FMNH 161 121), seen in posterior aspect, showing replacement tooth germ in fold of dental lamina. (B) Transverse section of right pterygoid of $O$. apodus (FMNH 161121), seen in posterior aspect, showing several tooth germs developing within a single fold of dental lamina; note the incompletely resorbed pterygoid tooth bases dorsal to the developing teeth. (C) Transverse section of right pterygoid of $O$. apodus (FMNH 161121), showing two ankylosed teeth (left) and one developing tooth bud (right). (D) Transverse section of right pterygoid of $O$. apodus (FMNH 161121), seen in posterior aspect, showing a functional tooth ankylosed adjacent a partially resorbed, more medial tooth. Medial to left in all. Scale bar equals $0.1 \mathrm{~mm}$ in all. 

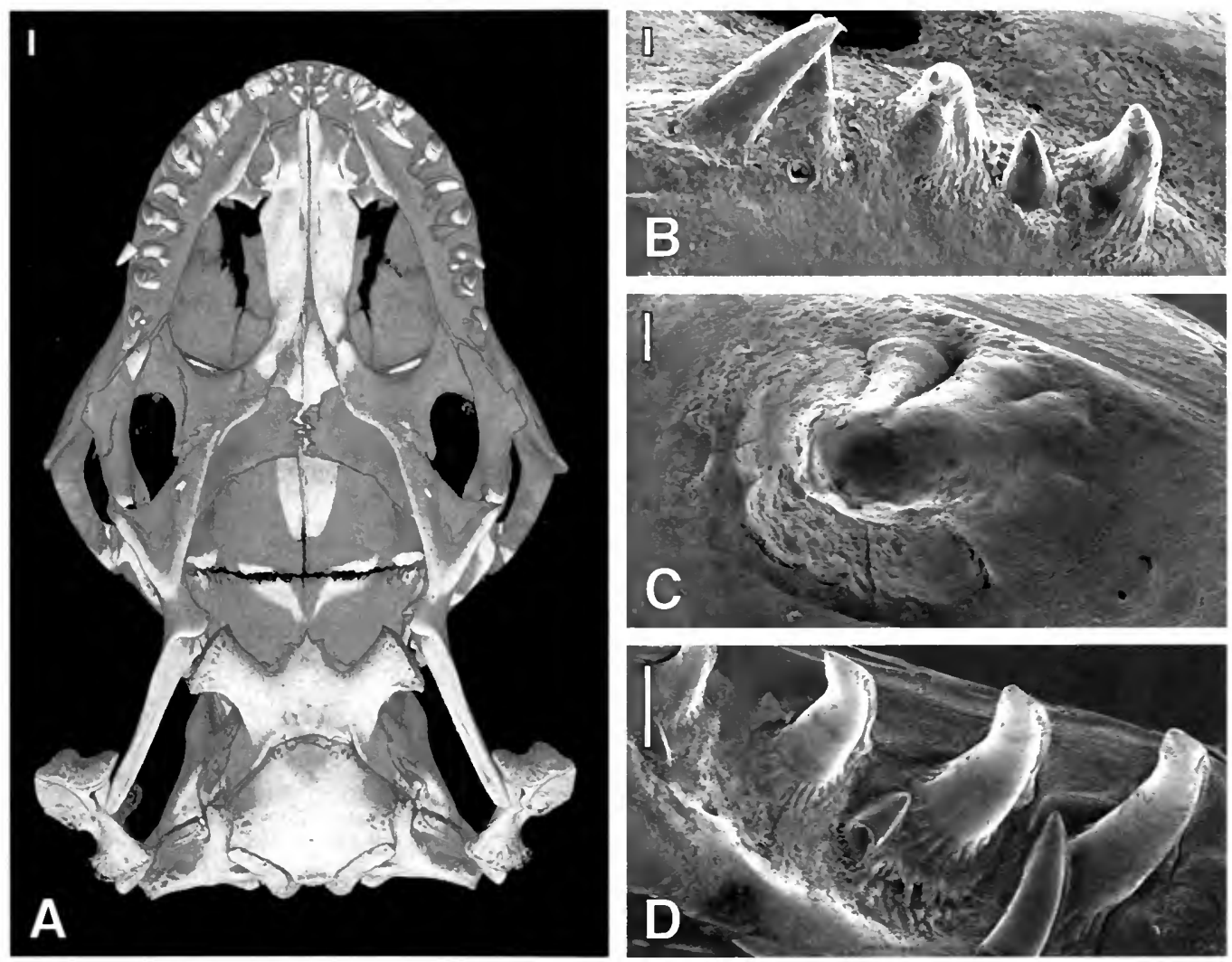

FIG. 16. (A) CT scan showing ventral view of the skutl of a juvenile Heloderma suspectum (TNHC 62767). (B) SEM micrograph showing mesiolingual view of right pterygoid tooth row in $H$. suspectum (FMNH 98469). Anterior toward right. (C) SEM micrograph depicting ventral view of right pterygoid tooth in $H$. suspectum (FMNH 218077). showing plicidentine at tooth base. Anterior toward left. (D) SEM micrograph depicting distolingual view of right maxillary teeth in $H$. suspectum (FMNH 98469). Anterior toward right. Scale bar equals $1 \mathrm{~mm}$ in $\mathbf{A} .0 .1 \mathrm{~mm}$ in B-C. $1 \mathrm{~mm}$ in $\mathbf{D}$. 
This page was intentionally left blank. 

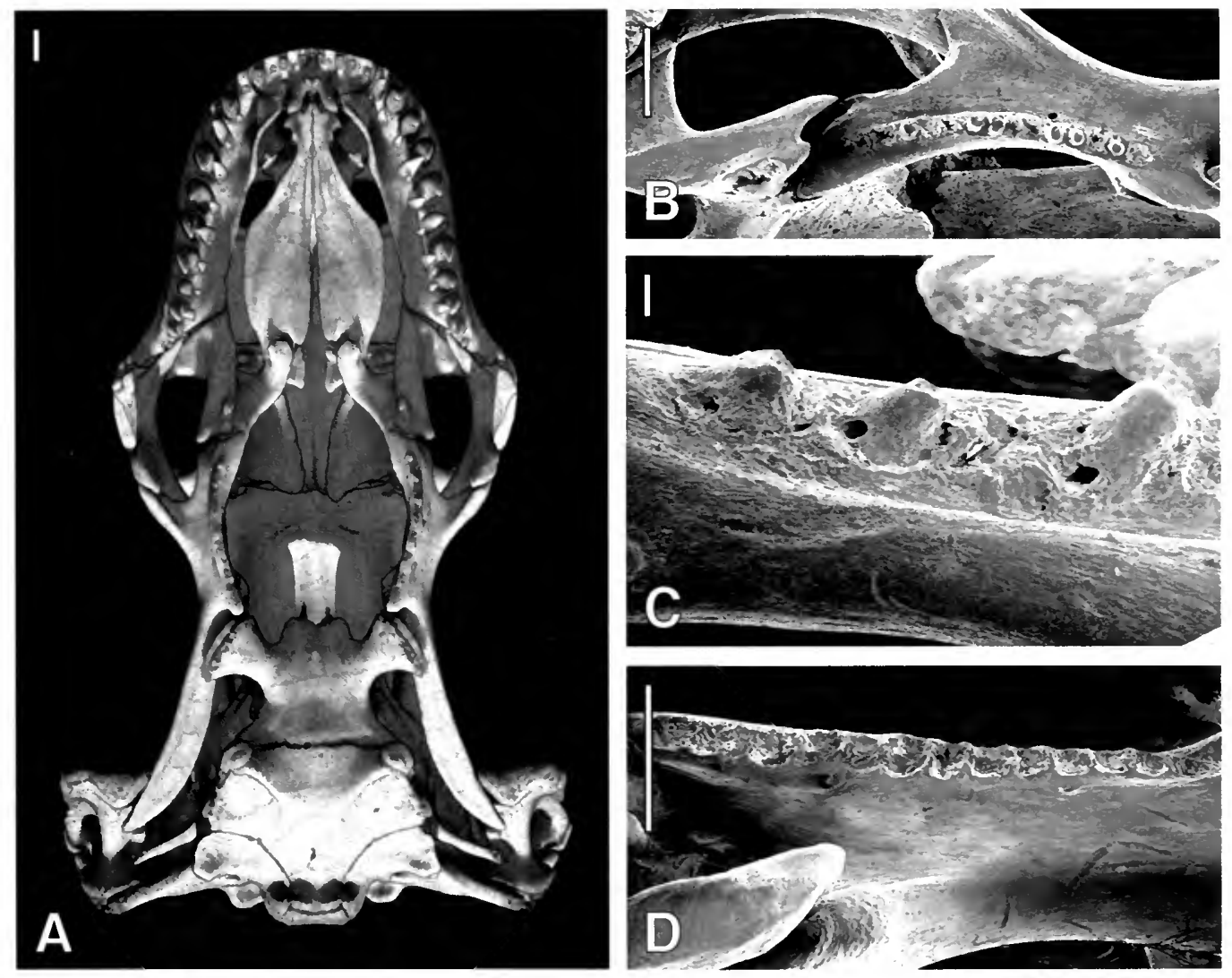

Fig. 17. (A) CT scan showing ventral view of the skull of Lanthanotus borneensis (FMNH 148589). (B) SEM micrograph showing ventral view of left pterygoid and palatine in L. borneensis (MCZ 8305). Anterior toward left. (C) SEM micrograph showing ventrolingual view of left pterygoid tooth bases in L. borneensis (MCZ 8305). Anterior toward left. (D) SEM micrograph showing ventrolabial view of right pterygoid in $L$. borneensis (FMNH 134711), depicting empty tooth row with "sockets" formed by interdental ridges. Anterior toward left. Scale bar equals $1 \mathrm{~mm}$ in $\mathbf{A}-\mathbf{B}, 0.1 \mathrm{~mm}$ in $\mathbf{C}, 1 \mathrm{~mm}$ in $\mathbf{D}$. 

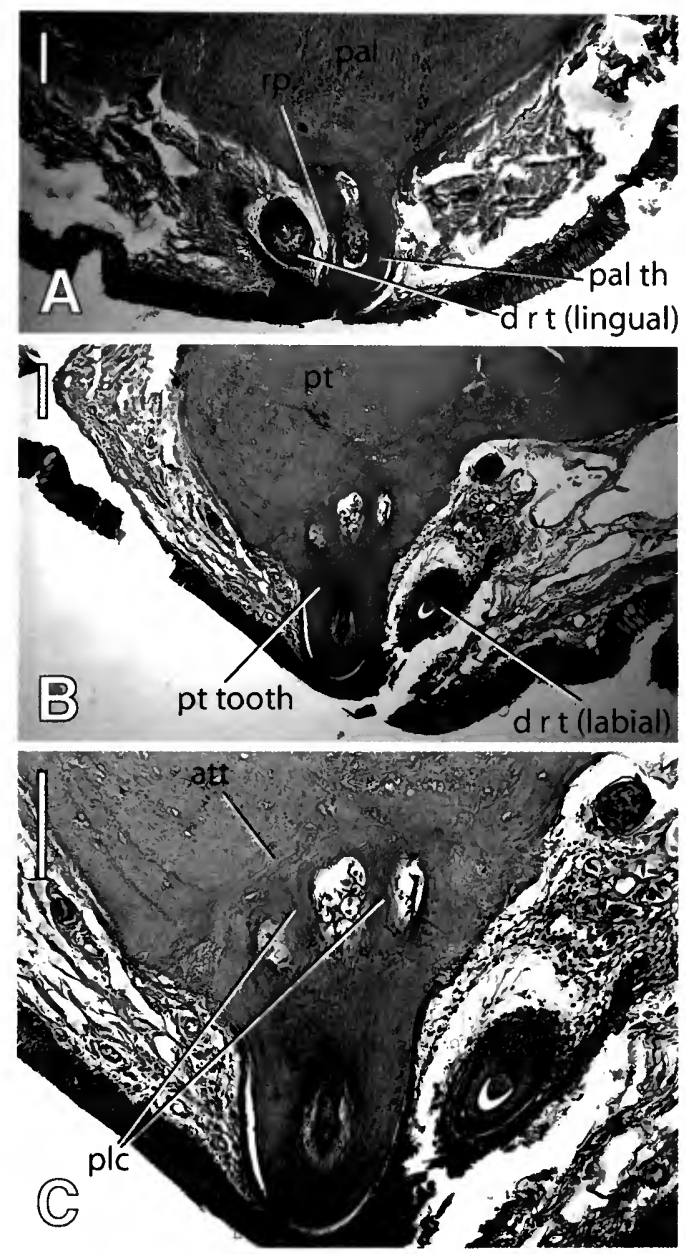

Fig. 18. (A) Transverse section of right palatine of Lanthanotus borneensis (FMNH 151714), seen in posterior aspect, showing developing replacement tooth medial to functional tooth. (B, C) Transverse section of right pterygoid of $L$. borneensis (FMNH 151714), seen in posterior aspect, showing detail of tooth attachment and developing plicidentine at tooth base. Medial to left in all. Scale bar equals $0.1 \mathrm{~mm}$ in all. 

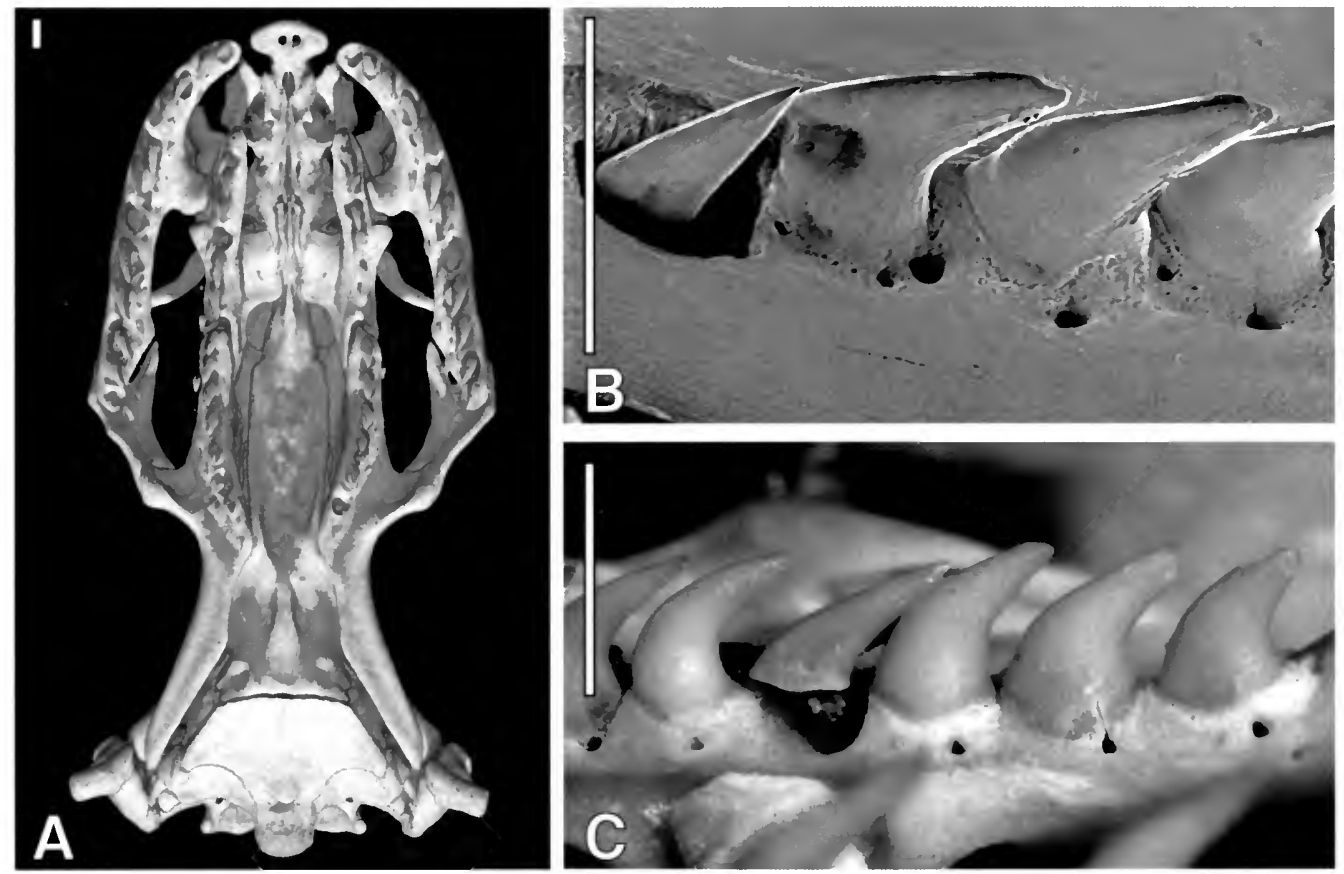

Fig. 19. (A) CT scan showing ventral view of the skull in Cylindrophis ruffus (FMNH 60958). (B) SEM micrograph depicting ventrolabial view of right pterygoid teeth in C. ruffus (FMNH 179033). Anterior to left. (C) Photograph depicting labial view of right palatine teeth in C. ruffus (FMNH 179033). Anterior to left. Scale bar equals $1 \mathrm{~mm}$ in all. 

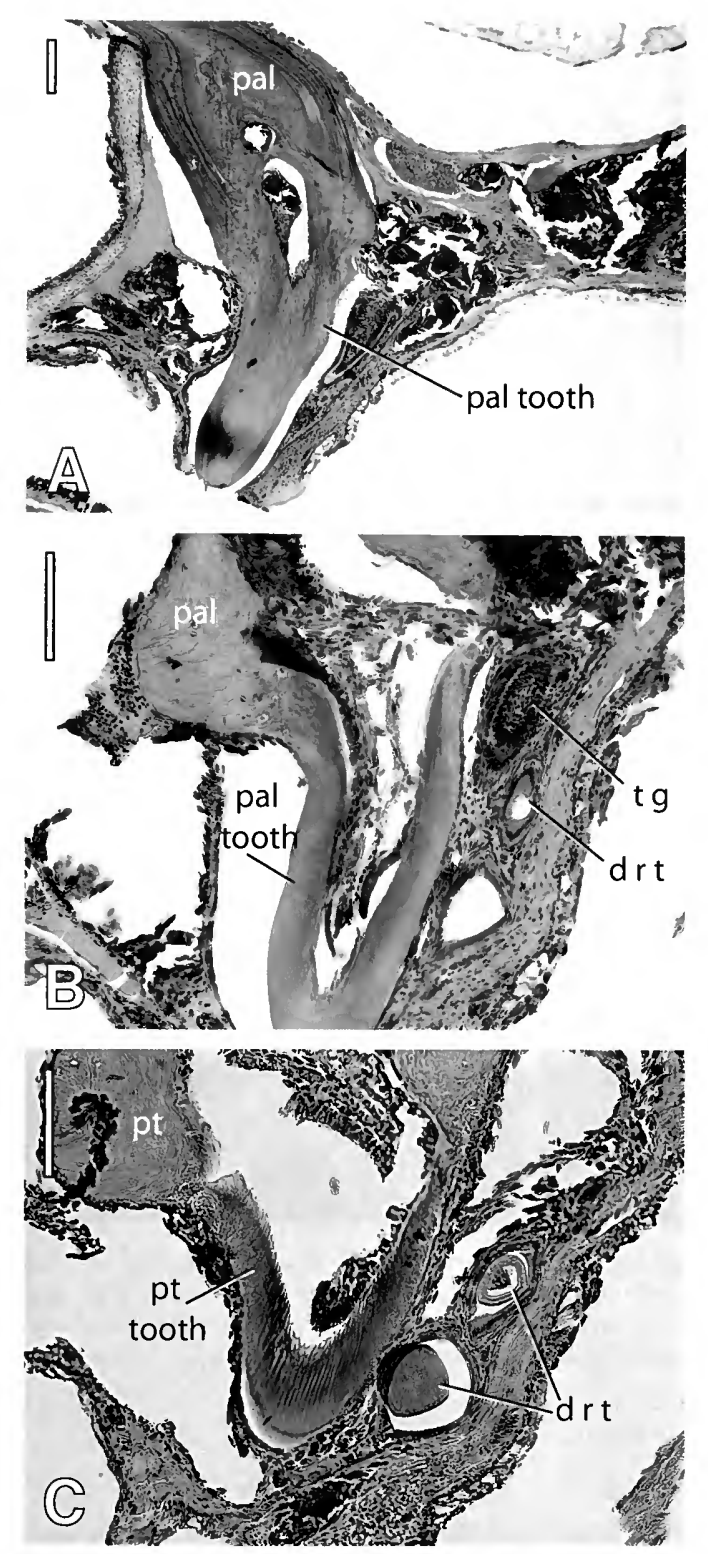

Fig. 20. (A) Transverse section of right palatine of Cylindrophis ruffus (FMNH 131778), seen in posterior aspect. (B) Transverse section of right palatine of C. ruffuis (FMNH 131778), seen in posterior aspect, showing recumbent replacement teeth on labial side of affixed tooth. (C) Transverse section of right pterygoid of $C$. ruffus (FMNH 131778), seen in posterior aspect, showing recumbent replacement teeth on labial side of affixed tooth. Medial to left in all. Scale bar equals $0.1 \mathrm{~mm}$ in all. 

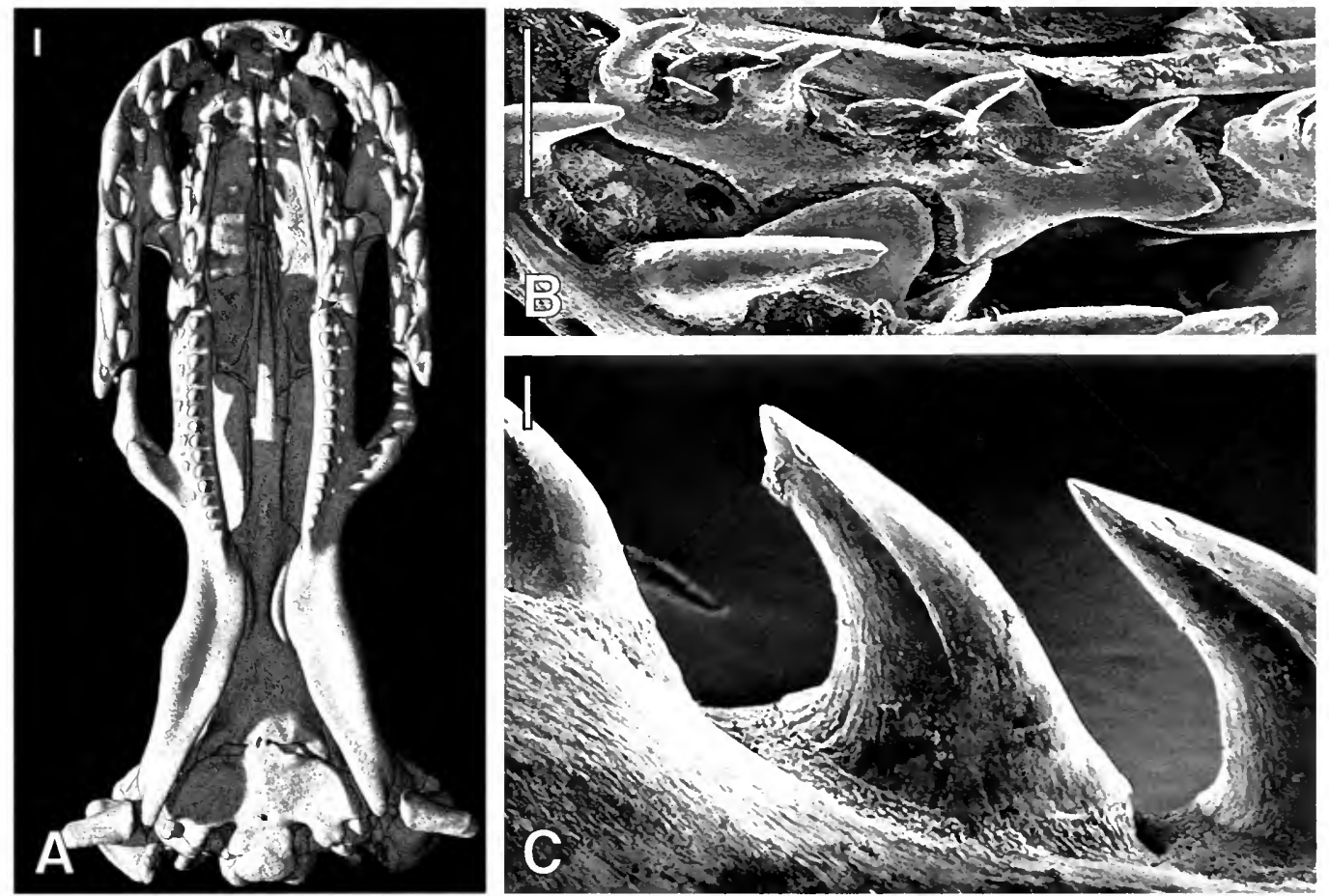

F1G. 21. (A) CT scan showing ventral view of the skull of Anilits scytale (USNM 204078). (B) SEM micrograph depicting ventrolabial view of the right palatine tooth row of $A$. scytale (FMNH 35688). Anterior toward left. (C) SEM micrograph depicting lingual view of a right palatine tooth in A. scytale (FMNH 35683), showing tooth base and attachment tissues. Anterior to right. Scale bar equals $1 \mathrm{~mm}$ in A-B, $0.1 \mathrm{~mm}$ in $\mathbf{C}$. 

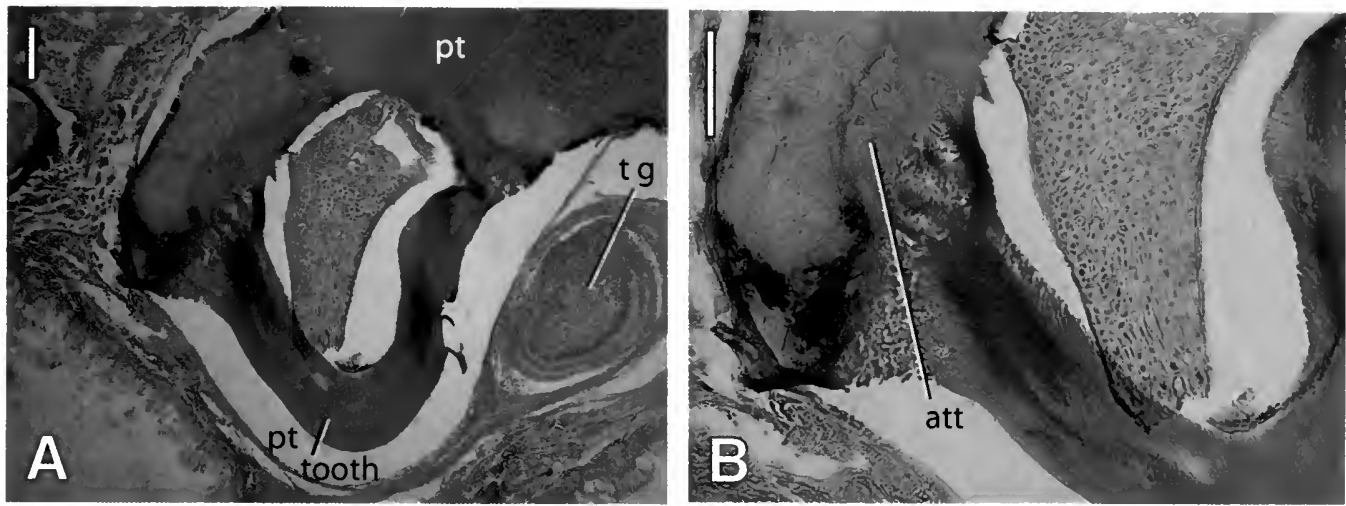

Fig. 22. (A, B) Transverse section of right pterygoid of Anilius scytale (FMNH 35687), seen in posterior aspect, showing a replacement tooth developing labial to a functional tooth. Medial to left in both. Scale bar equals $0.1 \mathrm{~mm}$ in both. 

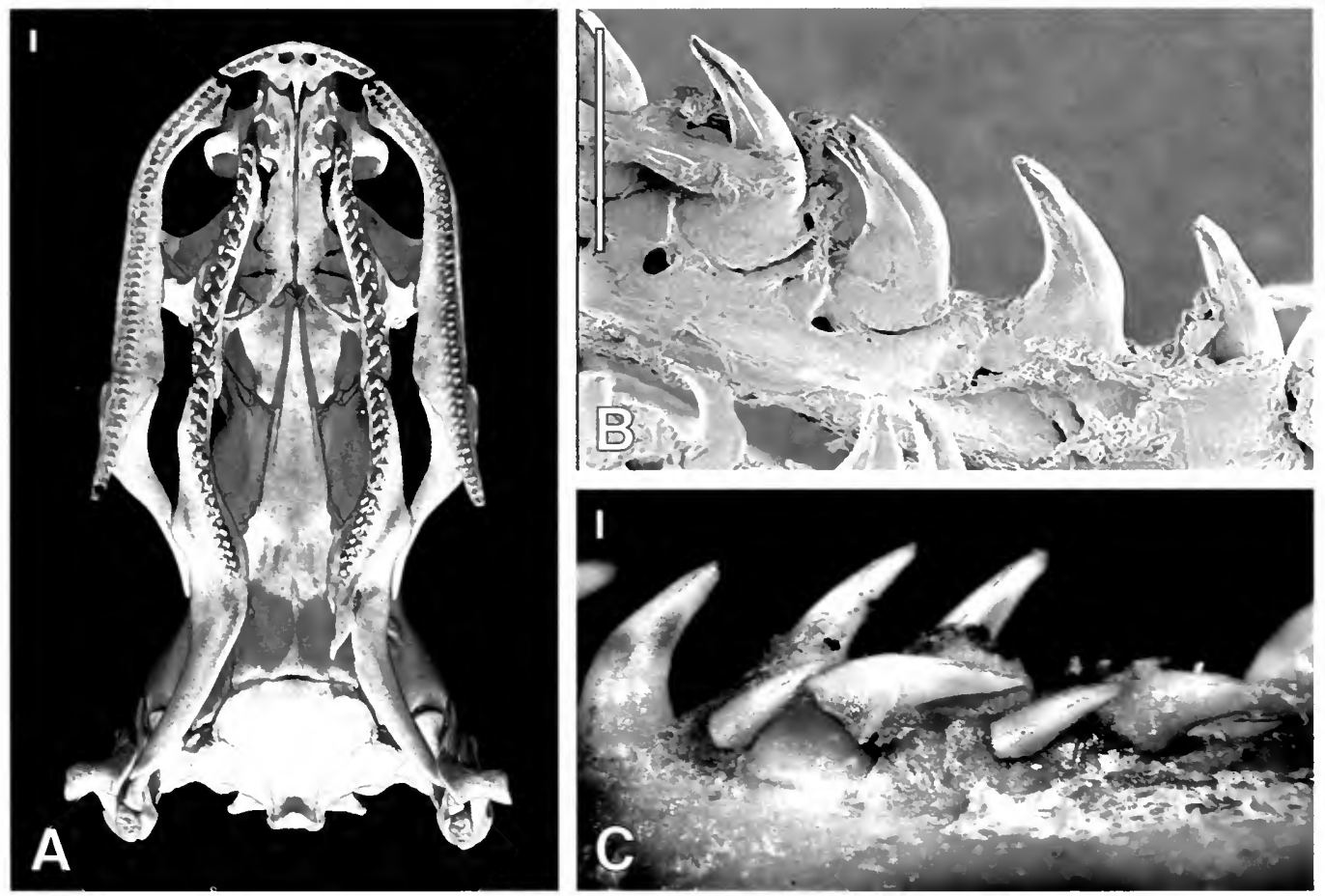

Fig. 23. (A) CT scan showing ventral view of the skull in Xenopeltis unicolor (FMNH 148900). (B) SEM micrograph showing labial view of left pterygoid teeth of $X$. unicolor (FMNH 178975). Anterior to right. (C) Photograph depicting labial view of right pterygoid teeth of X. unicolor (FMNH 178975), showing recumbent replacement teeth. Anterior to left. Scale bar equals $1 \mathrm{~mm}$ in A-B. $0.1 \mathrm{~mm}$ in C. 

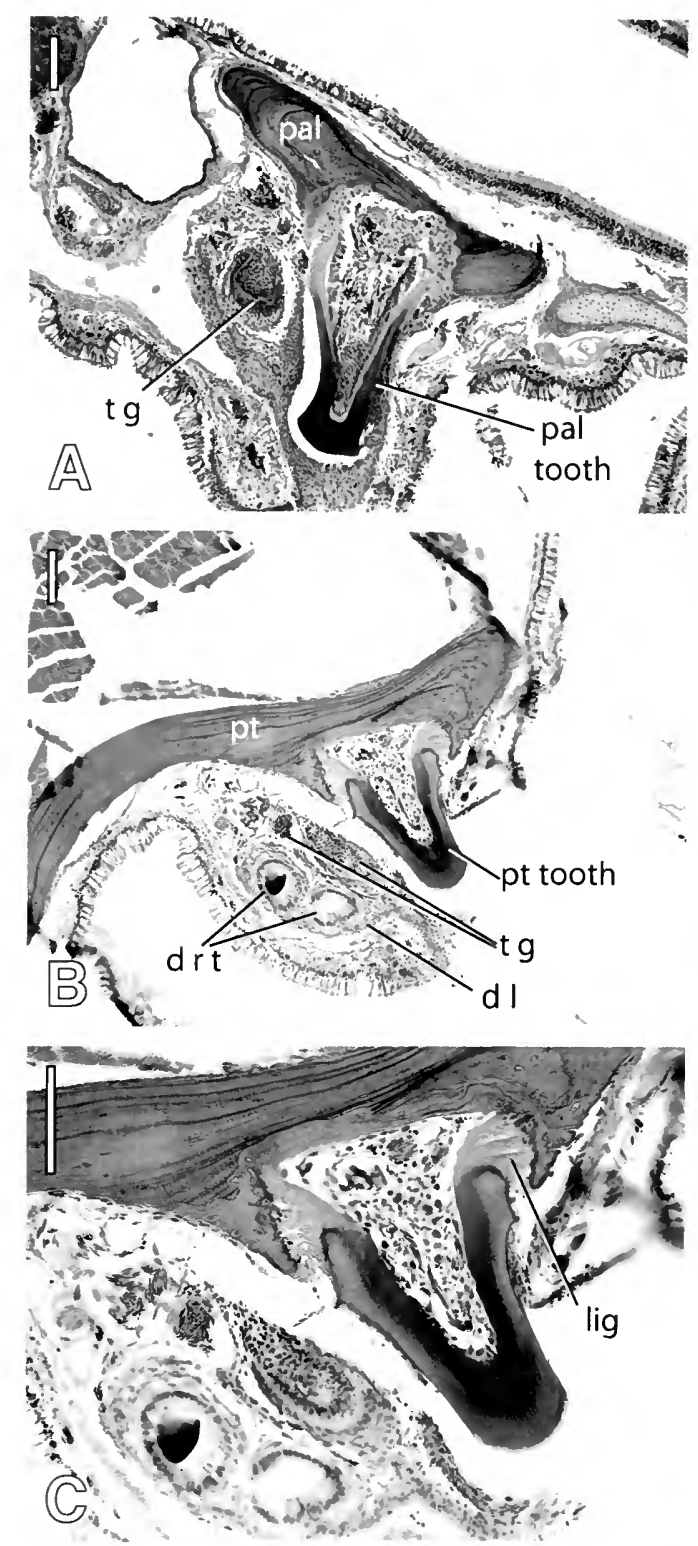

FIG. 24. (A) Transverse section of left palatine of Xenopeltis unicolor (FMNH 246193), seen in posterior aspect. (B, C) Transverse section of left pterygoid of $X$. minicolor (FMNH 246193). seen in posterior aspect, showing ligamentous attachment of pterygoid tooth. Medial to right in all. Scalc bar equals $0.1 \mathrm{~mm}$ in all. 

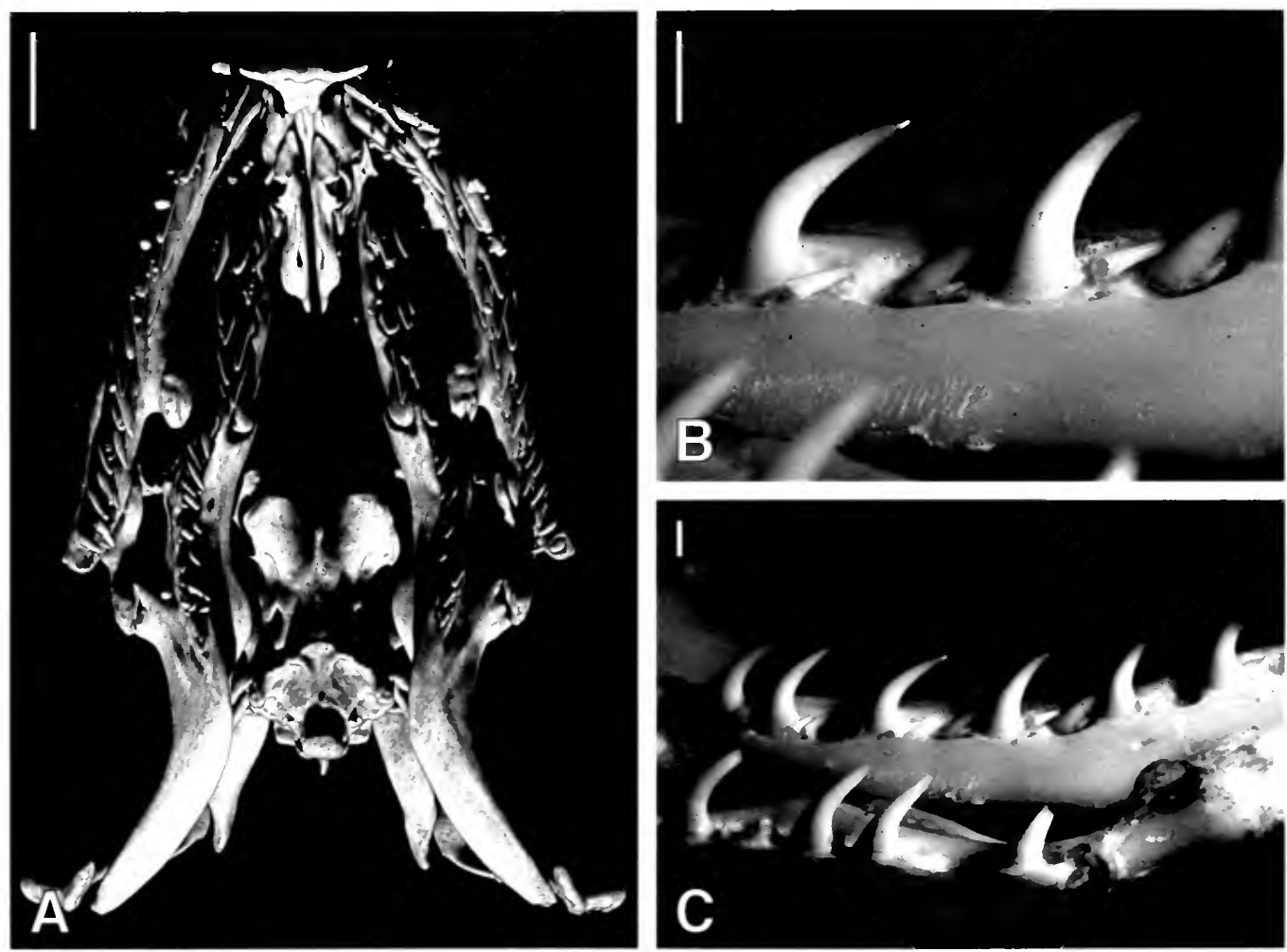

Fig. 25. (A) CT scan showing ventral view of the skull of Boa constrictor (FMNH 31182). (B) Labial view of right pterygoid teeth in B. constrictor (FMNH 22438), showing replacement teeth. Anterior to left. (C) Photograph depicting labial view of right pterygoid tooth row in B. constrictor (FMNH 22438), showing replacement teeth. Anterior to left. Scale bar equals $1 \mathrm{~cm}$ in A, $1 \mathrm{~mm}$ in B-C. 

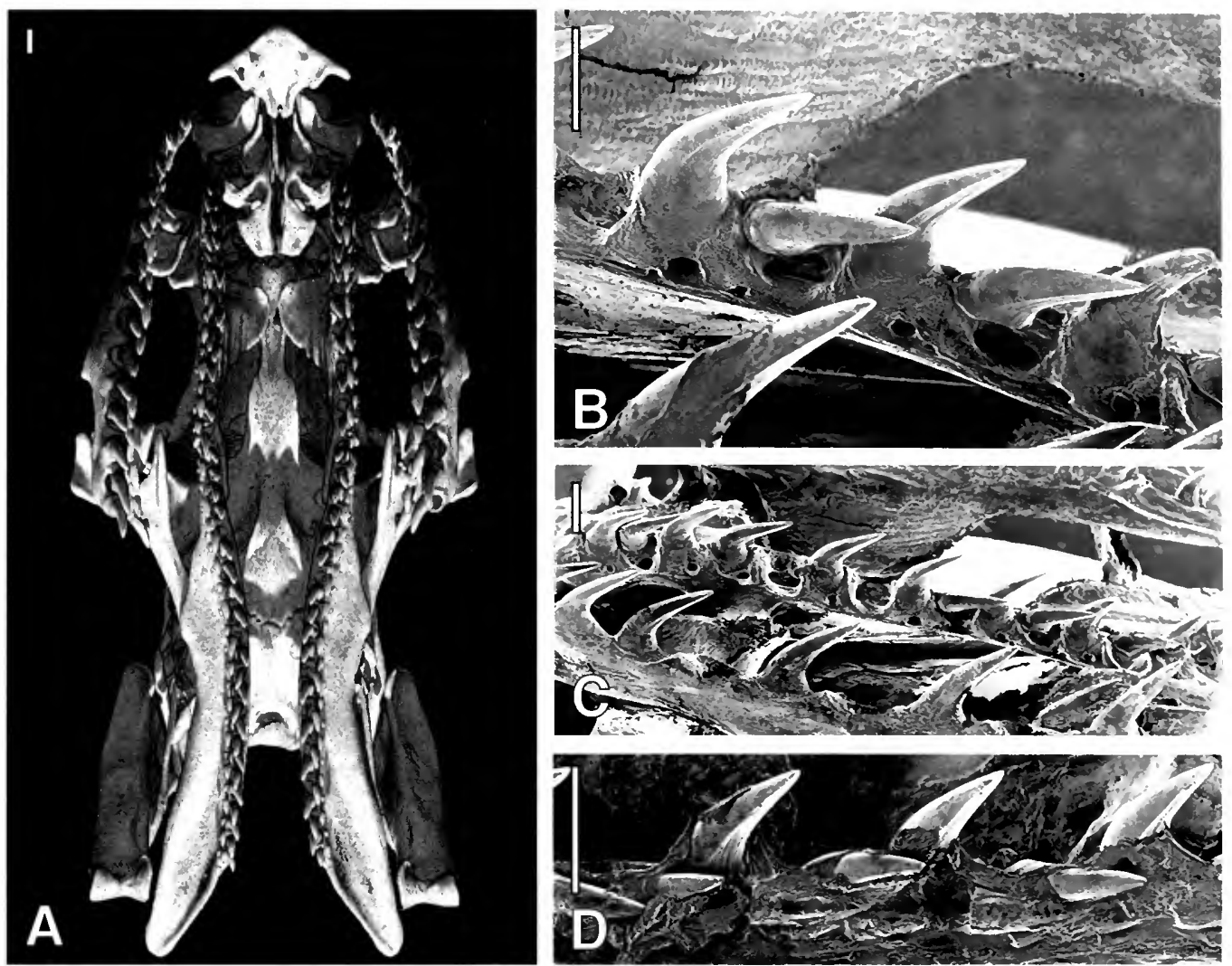

FIG. 26. (A) CT sean showing ventral view of the skull in Coluber constrictor (FMNH 135284). (B) SEM micrograph showing ventrolabial view of right palatine teeth in C. constrictor (FMNH 22347), demonstrating carinae and labial replacement. Anterior toward left. (C) SEM micrograph showing ventrolabial view of right palatine tooth row in $C$. constrictor (FMNH 22347). Anterior toward left. (D) SEM micrograph showing ventrolabial view of right pterygoid tooth row in C. constrictor (FMNH 22347), depicting recumbent replacement teeth within dental lamina at base of tooth row. Anterior toward left. Scale bar equals $1 \mathrm{~mm}$ in all.

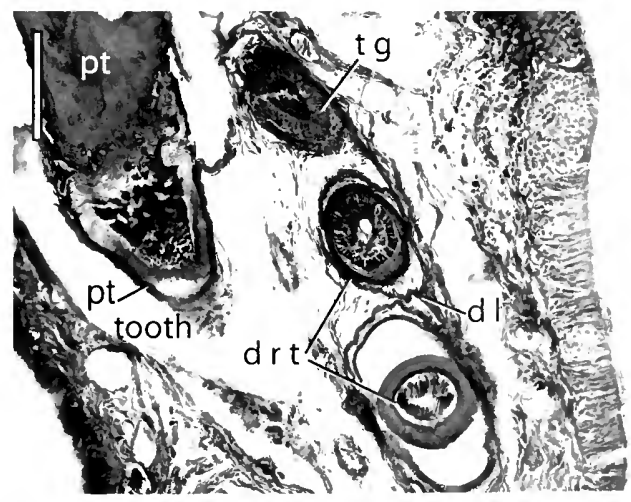

Fig. 27. Transverse section of right pterygoid of $C$. constrictom (personal collection of Carl Gans). seen in posterior aspect, showing affixed tooth and recumbent replacement teeth. Medial to left. Scale bar equals $0.1 \mathrm{~mm}$. 

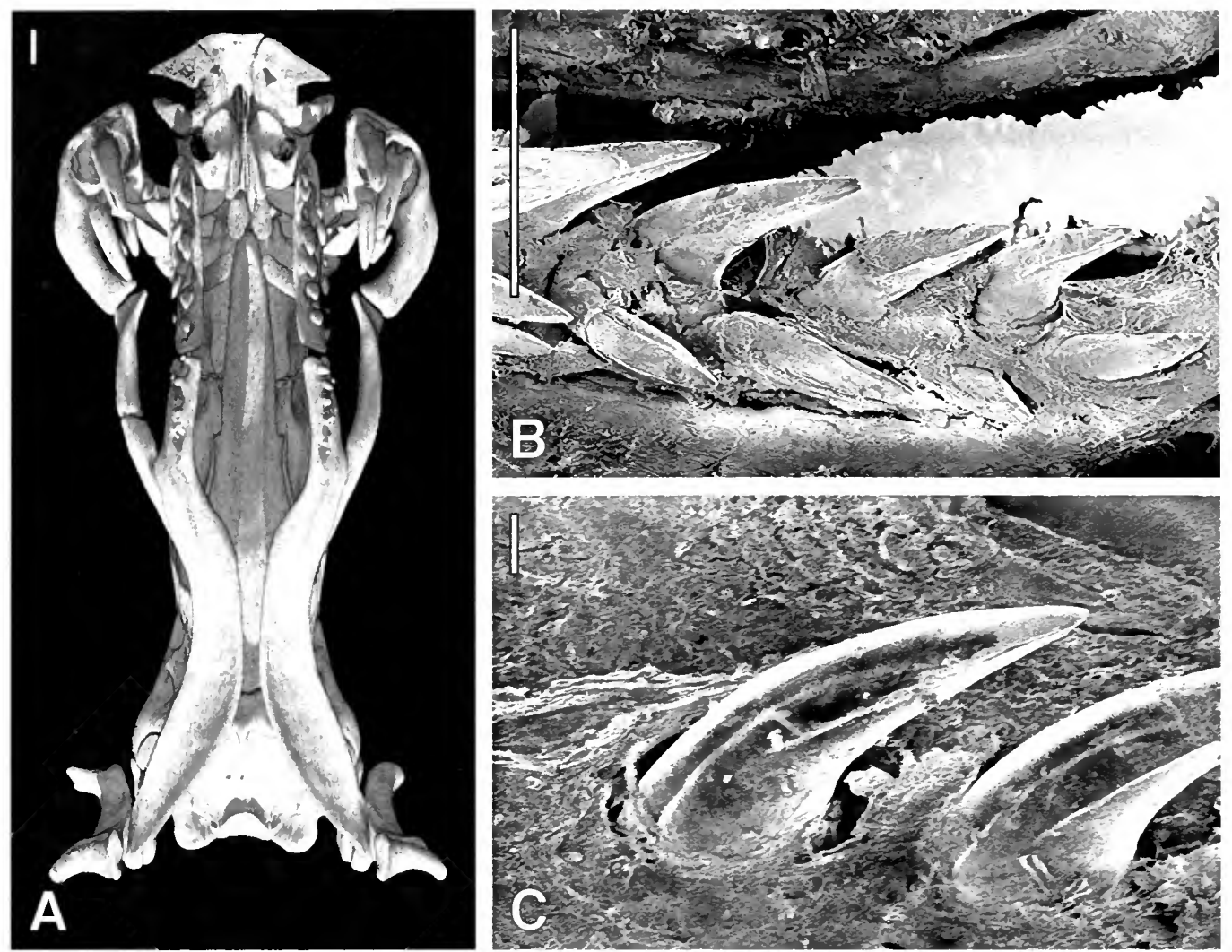

FIG. 28. (A) CT scan showing ventral view of the skull in Micturls fulvius (FMNH 39479). (B) SEM micrograph showing ventrolabial view of right palatine tooth row of 1 . nigrocinctus (FMNH 31109), demonstrating recumbent replacement teeth. Anterior toward left. (C) SEM micrograph showing ventrolingual view of left palatine teeth of M. migrocinctus (FMNH 31101), depicting mesiolingual grooves. Anterior toward left. Scale bar equals $1 \mathrm{~mm}$ in $\mathbf{A}$ B, $0.1 \mathrm{~mm}$ in $\mathbf{C}$.
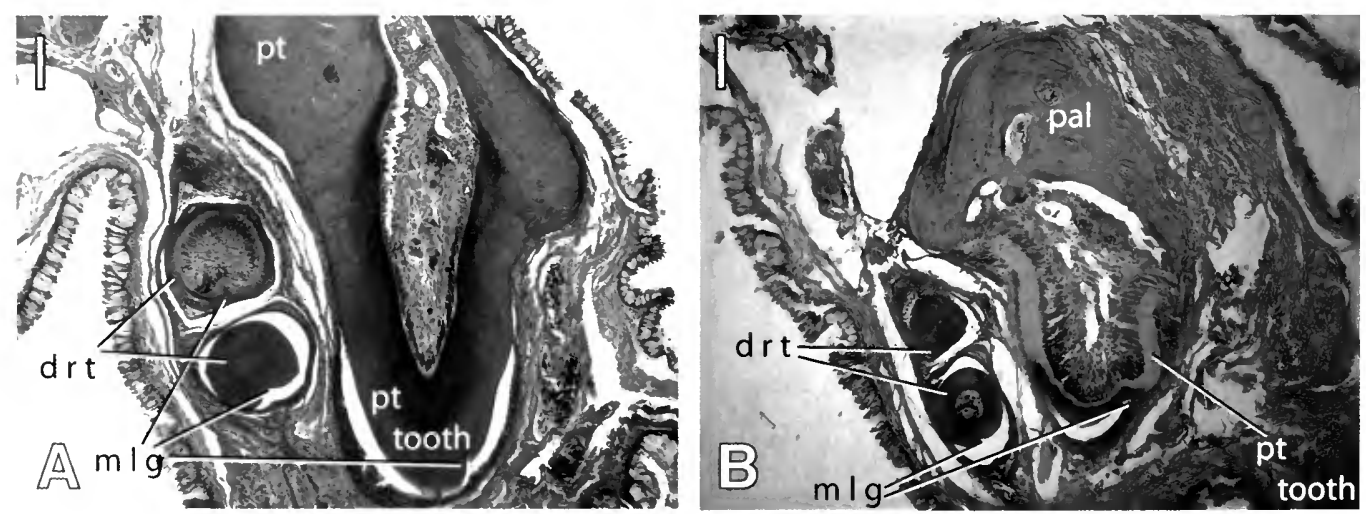

FIG. 29. (A) Transwerse section of left pterygoid of Micrutus nigrocinctus (FMNH 31104), seen in posterior aspect: note mesiolingual groove evident in recumbent replacement tooth. (B) Cross section of left palatine of $M$. nigrocinctus (FMNH 31104), seen in posterior aspect, showing tooth undergoing ankylosis. Medial to right in both. Scale bar equals $0.1 \mathrm{~mm}$ in both. 

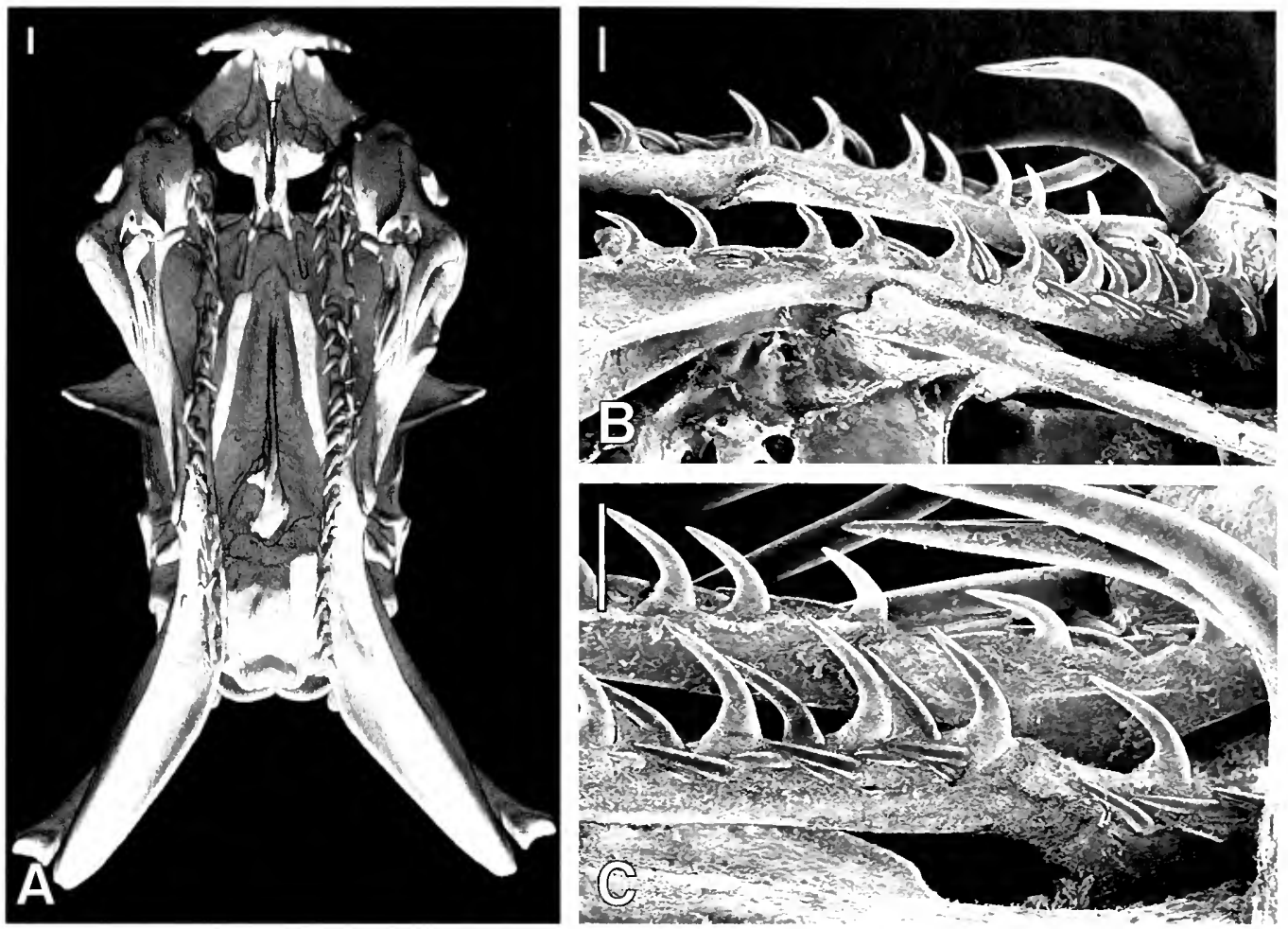

FIG. 30. (A) CT scan showing ventral view of the skull in Agkistrodon contortrix (FMNH 166644). (B) SEM micrograph showing labial view of left palatine and pterygoid tooth rows in A. contortrix (FMNH 98623). Anterior toward right. (C) SEM micrograph showing ventrolabial view of left palatine tooth row in A. contortrix (liMNII 98623). Anterior toward right. Scale bar equals $1 \mathrm{~mm}$ in all.
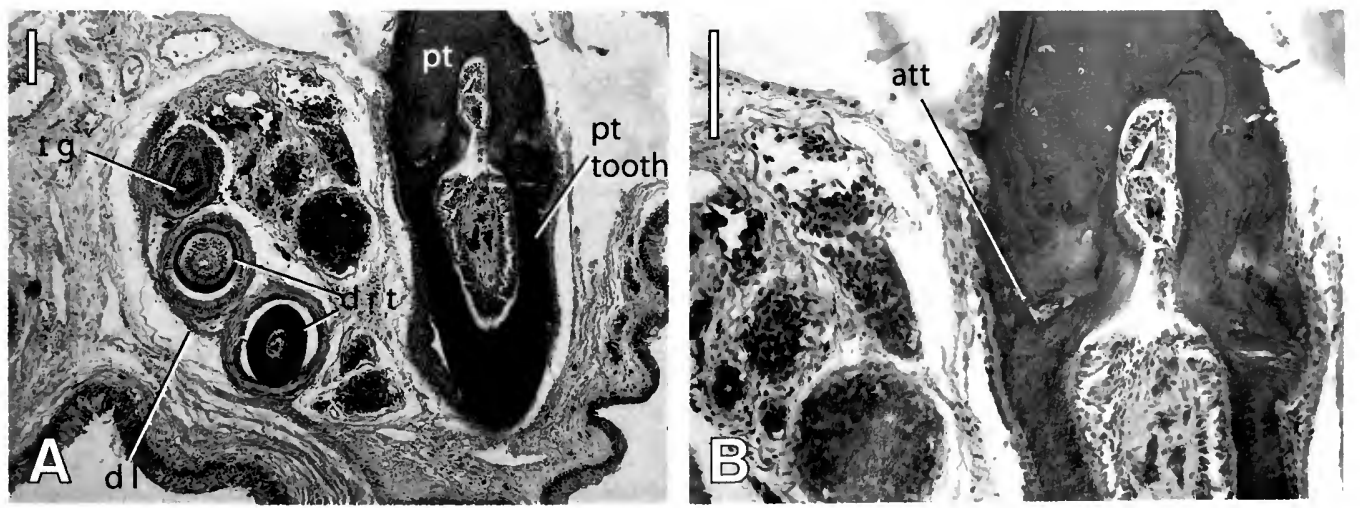

FIG. 31. (A) Transverse section of left palatine tooth of Agkistroton contortrix (1.MNI1 62059), seen in posterior aspect, showing replacement teeth in dental lamina on labial side of tooth. (B) Transverse section of led palatine tooth of $A$. contortrix (FMNH 62059), seen in posterior aspect. showing attachment. Medial to right in both. Scale bar equals $0.1 \mathrm{~mm}$ in both. 




UNIVERSITY OF ILLINOIS-URBANA 